\title{
CARACTERIZAÇÃO ESPACIAL DE RISCOS NA AGRICULTURA E IMPLICAÇÕES PARA O DESENVOLVIMENTO DE INSTRUMENTOS PARA SEU GERENCIAMENTO
}

\author{
MARCELO NeRY BURgo
}

\begin{abstract}
Dissertação apresentada à Escola Superior de Agricultura “Luiz de Queiroz”, Universidade de São Paulo, para obtenção do título de Mestre em Ciências, Área de Concentração: Economia Aplicada.
\end{abstract}

P I R A C I C A B A

Estado de São Paulo - Brasil

Fevereiro - 2005 


\title{
CARACTERIZAÇÃO ESPACIAL DE RISCOS NA AGRICULTURA E IMPLICAÇÕES PARA O DESENVOLVIMENTO DE INSTRUMENTOS PARA SEU GERENCIAMENTO
}

\author{
MARCELO NERY BURGO \\ Bacharel em Ciências Econômicas
}

Orientador: Prof. Dr. RICARDO SHIROTA

\begin{abstract}
Dissertação apresentada à Escola Superior de Agricultura “Luiz de Queiroz”, Universidade de São Paulo, para obtenção do título de Mestre em Ciências, Área de Concentração: Economia Aplicada.
\end{abstract}

P I R A C I C A B A

Estado de São Paulo - Brasil

Fevereiro - 2005 


\section{Dados Internacionais de Catalogação na Publicação (CIP) DIVISÃO DE BIBLIOTECA E DOCUMENTAÇÃO - ESALQ/USP}

\section{Burgo, Marcelo Nery}

Caracterização espacial de riscos na agricultura e implicações para o desenvolvimento de instrumentos para seu gerenciamento / Marcelo Nery Burgo. - - Piracicaba, 2005.

103 p. : il.

Dissertação (Mestrado) - - Escola Superior de Agricultura Luiz de Queiroz, 2005.

Bibliografia.

1. Administração agrícola 2. Análise de risco 3. Perdas agrícolas (Aspecto econômico) 4. Produção agrícola 5. Seguro agrícola I. Título

CDD 631.11 
A meus pais e irmãos 


\section{AGRADECIMENTOS}

Agradeço à minha família, a meus amigos, aos colegas de mestrado, a todos os professores do Departamento de Economia, Administração e Sociologia da ESALQ, em especial aos professores Ricardo Shirota, Evaristo Marzabal Neves, Márcia Azanha Ferraz Diaz de Moraes, Alexandre Lahóz Mendonça de Barros, aos funcionários do Departamento de Economia, Administração e Sociologia da ESALQ, especialmete à Maria Aparecida Maielli Travalini e ao Conselho Nacional de Desenvolvimento Científico e Tecnológico (CNPq) pelo apoio financeiro ao longo do mestrado. 


\section{SUMÁRIO}

Página

LISTA DE FIGURAS.......................................................................... vi

LISTA DE TABELAS............................................................................ viii

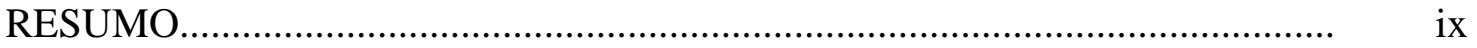

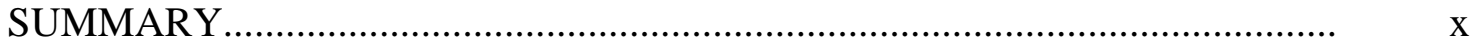

1 INTRODUÇÃO

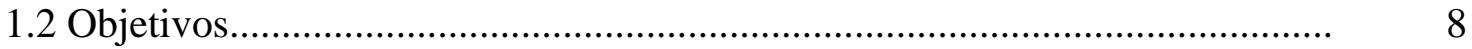

2 REVISÃO DE LITERATURA................................................................ 10

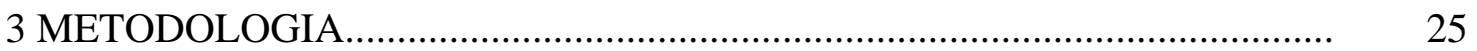

3.1 Referencial metodológico......................................................................... 25

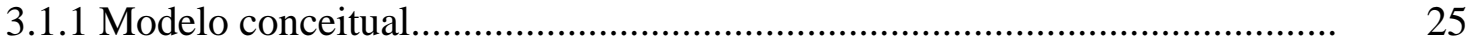

3.1.2 Modelo conceitual para definição de prêmios de seguros........................... 30

3.1.3 Procedimentos estatísticos utilizados...................................................... 32

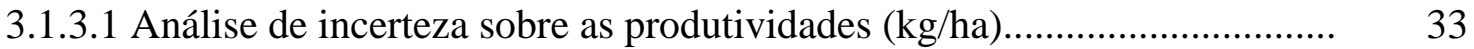

3.1.4 Medidas de risco consideradas (desvio-padrão e coeficiente de variação)... 47

3.1.5 Coeficiente de correlação..................................................................... 48

3.1.6 Correlação de produtividade X distância.................................................... 48

3.2 Fonte de dados..................................................................................... 50

3.3 Preparação dos dados............................................................................ 51

3.4 Ferramental computacional utilizado......................................................... 51

4 RESULTADOS E DISCUSSÃO..................................................................

4.1 caracterização geral da produtividade e medida de risco............................... 53

4.2 Impactos da distância na correlação espacial............................................... 60

4.3 Estimativa dos prêmios de seguro baseado em índices de produtividade........ 62 
4.4 Estimativa dos prêmios de seguro utilizando diversificação espacial.............. 77

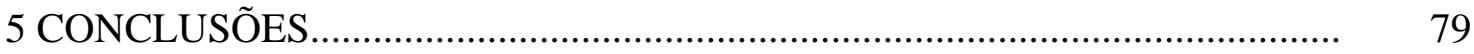

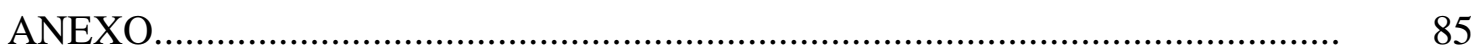

REFERÊNCIAS BIBLIOGRÁFICAS.......................................................... 101 


\section{LISTA DE FIGURAS}

Página

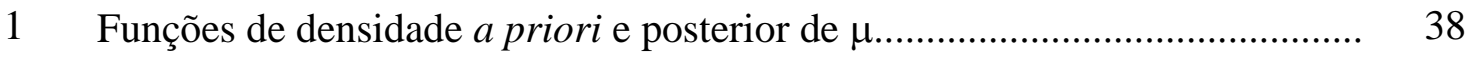

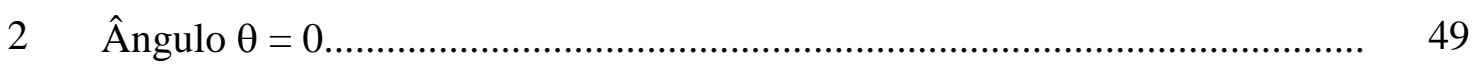

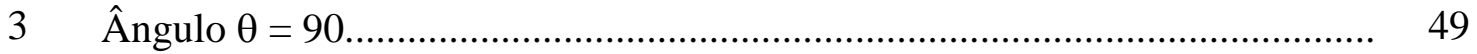

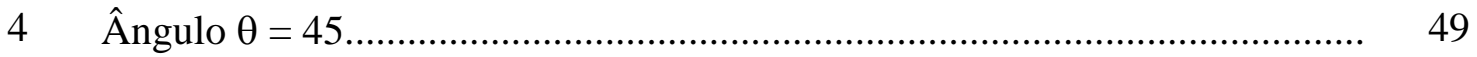

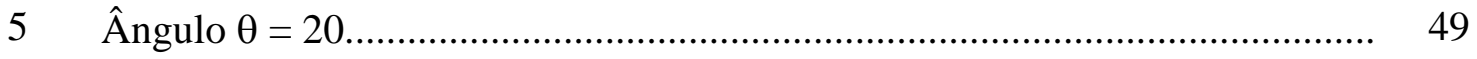

$6 \quad$ Produtividade esperada de soja em quilos por hectare até $1999 \ldots \ldots \ldots \ldots \ldots \ldots \ldots . . . . . . . . . .54$

$7 \quad$ Produtividade esperada de soja em quilos por hectare até $2003 \ldots \ldots \ldots \ldots \ldots \ldots \ldots . . . . . . .55$

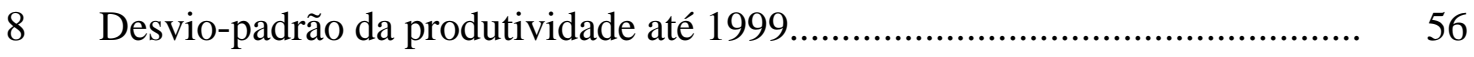

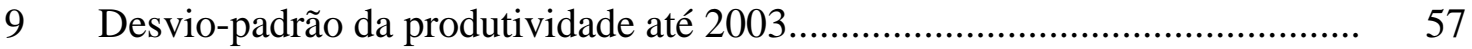

10 Coeficiente de variação da produtividade média da soja até 1999 ................. 58

11 Coeficiente de variação da produtividade média da soja até 2003 ............... 59

12 Correlação entre a precipitação pluviométrica e a distância.......................... 60

13 MT: Relação espacial da produtividade segundo direções diferentes ............ 61

14 RS: Relação espacial da produtividade segundo direções diferentes............. 62

15 Taxas de prêmios líquidos de seguros a partir do modelo A ........................ 64

16 Taxas de prêmios líquidos de seguros a partir do modelo B......................... 65

17 Taxas de prêmios líquidos de seguros a partir do modelo A para o milho ..... 67

18 Taxas de prêmios líquidos de seguros a partir do modelo B para o milho..... 68

19 Histograma da distribuição dos prêmios do seguro para os municípios



20 Histograma da distribuição dos prêmios do seguro para MS......................... 70

21 Histograma da distribuição dos prêmios do seguro para MT.......................... 71

22 Histograma da distribuição dos prêmios do seguro para GO........................ 71 
23 Histograma da distribuição dos prêmios do seguro para PR.......................... 72

24 Histograma da distribuição dos prêmios do seguro para SP......................... 73

25 Histograma da distribuição dos prêmios do seguro para MG........................ 73

26 Histograma da distribuição dos prêmios do seguro para RS.......................... 74

27 Histograma da distribuição dos prêmios do seguro para SC......................... 75

28 Histograma da distribuição dos prêmios do seguro para BA.......................... 76

29 Histograma da distribuição dos prêmios do seguro para TO.......................... 76

30 Espaço tridimensional de um ponto na superfície da terra............................ 88

31 Triângulo retângulo (a).................................................................... 89

32 Dois pontos (A e B) situados na superfície da terra e a distância linear $\mathrm{C}_{\mathrm{L}}$ entre

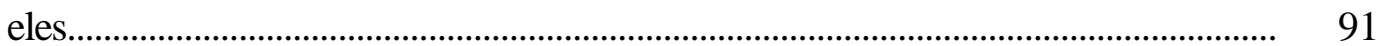

33 Triângulo retângulo (b)................................................................... 93

34 Apresentação da planilha para cálculo da distância linear entre municípios... 94

35 Formato da planilha na implementação do cálculo em software .................... 100 


\section{LISTA DE TABELAS}

Página

1 Taxas de prêmios de seguro com e sem diversificação espacial da

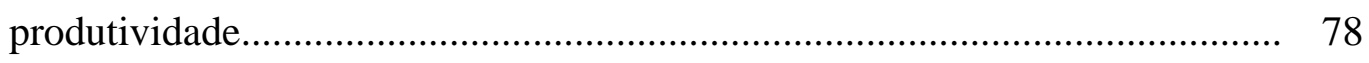

$2 \quad$ Latitude e longitude das cidades................................................................. 95

$3 \quad$ Latitude e longitude das cidades em radianos.................................................. 96

4 Distância $Z_{A}$ de cada uma das cidades........................................................... 96

$5 \quad$ Distância $d_{x}$ das cidades............................................................................. 96

$6 \quad$ Valores de $\mathrm{Y}_{\mathrm{A}}$ e $\mathrm{X}_{\mathrm{A}}$ para cada um das cidades............................................... 97

$7 \quad$ Distâncias $\mathrm{X}_{\mathrm{C}}, \mathrm{Y}_{\mathrm{C}} \mathrm{e} \mathrm{Z}_{\mathrm{C}}$ das cidades............................................................... 97

8 Distância linear entre as cidades.................................................................. 98

9 Ângulo entre os vetores que representam a distância entre cada cidade......... 98

10 Distâncias curvilínea, linear e calculada com ferramenta especializada.......... 99 


\title{
CARACTERIZAÇÃO ESPACIAL DE RISCOS NA AGRICULTURA E IMPLICAÇÕES PARA O DESENVOLVIMENTO DE INSTRUMENTOS PARA SEU GERENCIAMENTO
}

\author{
Autor: MARCELO NERY BURGO \\ Orientador: Prof. Dr. RICARDO SHIROTA
}

\section{RESUMO}

O risco de produtividade afeta diretamente a renda do produtor rural, mas existem diversas ferramentas de administração que visam diminuir esses riscos. $\mathrm{O}$ trabalho apresenta, a partir de uma revisão abrangente da literatura, os possíveis ganhos e perdas que a diversificação espacial como controle de risco oferecem ao produtor rural. Através de mapas que apresentam medidas estatísticas de dispersão e evidenciam o efeito da distância e da direção geográfica na correlação da produtividade da soja entre regiões, pode-se mostrar como a diversificação espacial pode beneficiar o produtor rural. Com a utilização de dados do IBGE e de métodos estatísticos bayesianos foram estimados prêmios líquidos de seguro para a soja e estudado o efeito da diversificação espacial no cálculo desses prêmios de seguro. Os resultados obtidos ao longo do trabalho permitem concluir que as produtividades variam espacialmente com mais intensidade no sentido da latitude (leste-oeste) do que no sentido da longitude (norte-sul). Ainda, foi possível verificar que o cálculo da taxa de prêmio líquido de seguro a partir da regressão das produtividades anteriores retorna valores mais baixos do que quando calculada pela média desses dados e que a diversificação espacial reduz o prêmio médio do seguro em comparação a quando o seguro é calculado para cada município individualmente. 


\title{
SPACE CHARACTERIZATION OF RISKS IN THE AGRICULTURE AND IMPLICATIONS FOR THE DEVELOPMENT OF INSTRUMENTS FOR HIS/HER ADMINISTRATION
}

\author{
Author: MARCELO NERY BURGO \\ Adviser: Prof. Dr. RICARDO SHIROTA
}

\section{SUMMARY}

The productivity risk affects the income of the rural producer directly but several administration tools that seek to reduce those risks exist. The work presents, starting from an including revision of the literature, the possible earnings and losses that the space diversification as risk control offers to the rural producer. Through maps that present statistical measures of dispersion and they evidence the effect of the distance and of the geographical direction in the correlation of the productivity of the soy among areas, it can be shown as the space diversification can benefit the rural producer. With the use of data of IBGE and of statitical bayesian methods they were dear liquid prizes of insurance for the soy and studied the effect of the space diversification in the calculation of those prizes of safe. The results obtained along the work allow to conclude that the productivities vary espacialmente with more intensity in the latitudinal direction (east-west) than in the longitudinal direction (north-south). Still, it was possible to verify that the calculation of the tax of liquid prize of insurance starting from the regression of the previous productivities returns lower values than when made calculations by the average of those data and that the space diversification reduces the medium prize of the 
insurance in comparison with when the insurance is calculated for each municipal district individually. 


\section{INTRODUÇÃO}

Este trabalho tem como objetivo geral caracterizar e analisar certos aspectos do risco na agricultura associados à diversificação espacial, assim como os possíveis impactos da diversificação na precificação adequada de contratos de seguro agrícola. $\mathrm{O}$ trabalho estima prêmios líquidos de um seguro para a soja baseado em índices de produtividade (tais como os utilizados nos EUA e Brasil) sob diferentes condições de diversificação e regionalização. A cultura da soja foi escolhida para foco da análise tendo em vista sua importância e distribuição espacial abrangente, cobrindo grande parte do território nacional, e por ser uma das principais culturas plantadas hoje no país.

A importância da soja pode ser expressa em números. O Brasil em pouco mais de 30 anos, passou de uma produção de um milhão de toneladas de soja em 1970 para 51 milhões de toneladas em 2003. O primeiro levantamento de intenção de plantio para a safra de verão 2004/05 realizado pela CONAB aponta um aumento médio na área da ordem de 4,7\% comparativamente à safra anterior. Em termos nacionais, a produção aumentará em média 21\%, devendo atingir um volume de 60,1 milhões de toneladas, enquanto o aumento na produtividade está previsto em 22,2\%. Considerando os preços de exportação, o "complexo soja" nacional (grão, farelo e óleo) vendeu um valor aproximado de US\$ 7 bilhões na safra 2003/2004, ou seja, cerca de 10\% de todas as nossas exportações anuais, e que somou no acumulado de janeiro a agosto de 2004 um total de US\$ 7,5 bilhões exportados, segundo dados do Ministério do Desenvolvimento, Indústria e Comércio Exterior e do Ministério da Agricultura. 
Em relação ao consumo mundial da soja, estima-se que deve manter o mesmo ritmo de expansão acelerado dos últimos anos, estimulado especialmente pelas compra realizadas pelos países que devem assumir a liderança em termos do consumo mundial do produto e seus derivados. Levando-se em consideração que os atuais concorrentes (Estados Unidos e China) do Brasil no mercado internacional da soja apresentam posição de desvantagem para manter a estratégia de consecutivos aumentos de produção e exportação nos próximos anos, o país surge nas perfeitas condições para atender esse crescimento da demanda mundial, aumentando ainda mais a importância da commodity brasileira no cenário nacional e internacional, apesar dos problemas enfrentados atualmente como a "ferrugem asiática" que tende a limitar o crescimento e expansão da safra atual de soja.

Os próximos parágrafos apresentam uma visão geral sobre alguns conceitos de risco relevantes para atividades agrícolas, assim como das principais ferramentas para gerência desses riscos visando uma amenização de seus efeitos.

A agricultura, ou mais precisamente o processo produtivo da agricultura apresenta características muito específicas se comparada a outros setores produtivos de uma economia. Umas das características mais marcantes é a magnitude e natureza dos riscos aos quais está sujeita, riscos estes que não ocorrem comumente na produção industrial por exemplo. Alguns riscos mais significativos são: risco associado às variações não antecipadas na produtividade em função de fatores climáticos e/ou biológicos; risco associado às variações não antecipadas de preço (riscos de mercado) e ainda, risco associado a ferimentos e problemas de saúde dos trabalhadores rurais, que estão mais propícios a ferimentos por animais, contaminação por agrotóxicos, entre outros.

Para um melhor entendimento dos conceitos usados no trabalho, algumas discussões a respeito das noções de risco são apresentadas e explicadas a seguir. As 
várias perspectivas revelam a dificuldade existente de se ter uma única definição que encontre aceitação geral dentro da literatura.

O risco pode ser definido, segundo Harwood et al. (1999) como uma incerteza que afeta o bem-estar dos indivíduos, e está associado freqüentemente com a idéia de adversidade e perda.

Para Bernstein (1997), a palavra risco é derivada do italiano antigo risicare, que significa ousar, arriscar. Assim, o risco pode ser entendido como uma opção e não como um destino.

De acordo com a definição existente em dicionário popular, risco pode ser entendido como sendo uma situação em que há probabilidade mais ou menos previsível de perda ou ganho, ou seja, o risco é um evento incerto, mas previsível.

É importante destacar que certos autores sugerem diferenças entre risco e incerteza. Esta última, de acordo com o dicionário Aurélio é definida como sendo uma falta de certeza, ou ainda, aquilo que apresenta um resultado ou futuro incerto e indeterminado a priori. Dentro da literatura econômica várias definições são populares como no caso a de que a incerteza indica situações envolvendo probabilidades não mensuráveis, ao contrário do risco que indica o fato de se existirem probabilidades mensuráveis, ou seja, que é possível de se prever. Mais recentemente essas noções vêm se tornando obsoletas com as noções de probabilidade subjetiva e de incerteza de segunda ordem, presentes dentro do método Bayesiano.

De acordo com Silva (2001), incertezas imprimem, geram e implicam em riscos associados à possibilidade da ocorrência de resultados indesejáveis ou adversos para determinados eventos e fenômenos. Desta forma, os processos de tomada de decisão podem ser influenciados por incertezas. 
Assim, a administração de riscos preocupa-se com a análise e seleção de alternativas para reduzir os efeitos que podem ser ocasionados pelos tipos de riscos existentes. Requer a administração de riscos, tipicamente, a avaliação e entendimento dos riscos a serem gerenciados, dos retornos esperados, e outras variáveis.

Para um produtor individual, a administração do risco pode envolver a definição de combinação de atividades com retornos incertos. Pode-se dizer que a gerência (administração) de risco envolve escolher entre alternativas para reduzir os efeitos do risco na atividade de um produtor, e assim, melhorar seu bem-estar.

Algumas estratégias da administração de risco (tais como a diversificação) reduzem alguns riscos internos da atividade, outros (tal como os contratos de produção) diminuem riscos externos, e ainda outros (tal como manter recursos líquidos) fortalecem a capacidade dos produtores de se auto-proteger perante as adversidades decorrentes.

Os produtores têm muitas opções para gerenciar riscos na agricultura. Eles podem realizar um mix em sua atividade (diversificação de culturas ou de localização) ou então um mix na estrutura financeira da propriedade (alterando a relação entre passivo e ativo) entre alternativas. Além disso, dispõem de outras ferramentas, como o seguro agrícola e o hedging de preços.

Mesmo em situações similares, cada produtor tem um entendimento diferente frente ao risco, o que faz com que uma regra única não possa ser utilizada para administrá-lo. O entendimento individual do risco varia muito de acordo com o conhecimento do produtor, com o tipo de produção, com o tamanho da propriedade, entre outras variáveis.

De fato, um produtor que possui maior aversão ao risco, pode preferir ter um rendimento médio mais baixo, em troca de um risco (medido como a probabilidade de um retorno negativo, por exemplo) mais baixo. Além disso, vale destacar ainda, que as 
ferramentas de administração de risco podem se complementar. Desta forma, cada um pode ter o seu jeito de desenvolver estratégias para reduzir os eventos incertos, de acordo com o que for melhor e mais eficaz para a sua propriedade.

São apresentados a seguir alguns tipos de ações que um produtor pode realizar para melhor administrar o risco de suas atividades:

- Seguro Agrícola: protege o produtor de uma eventual redução na produtividade de sua produção, ou seja, caso o rendimento de sua produção esteja abaixo de um nível definido (de acordo com o contrato) ele será indenizado. Porém vale destacar que muitas vezes o prêmio pago pelo seguro é percebido como elevado motivando-o a optar por fazer seguro apenas de uma parcela de sua atividade, ou mesmo não utilizá-lo.

- Contratos de Produção: contratos de produção dão geralmente ao contratante (comprador da commodity), um maior controle sobre o processo de produção. Esses contratos, na maioria das vezes, especificam os insumos a serem usados (geralmente cedidos pelo contratante), a quantidade e a qualidade da commodity que será entregue e o preço que será pago ao produtor. Com isso o contratante tem um maior controle sobre os métodos de produção, o que pode ser eficiente também quando o produto em questão apresenta uma certa especificidade. Para o produtor, os contratos de produção podem eliminar principalmente os riscos de preços, tanto dos insumos a serem comprados para a produção, assim como na sua produção final que será ofertada ao mercado. Hoje bastante comuns são os contratos de produção entre grandes empresas (exportadoras, indústrias) e os produtores, que servem como garantia de renda para o produtor e garantia de insumos (matéria-prima) para essas empresas.

- Mecanismos de fixação antecipada de preços: o produtor, a partir da análise de seus custos de produção pode saber antes mesmo de sua produção estar colhida, 
qual o preço que deverá comercializar seus produtos no futuro para que esses cubram os seus custos de produção e também o assegurem uma certa margem de lucro. Porém, o produtor sabe que os preços sofrem muitas oscilações e este pode não ser o ideal para atender as condições acima quando ele estiver com o produto pronto e quiser vendê-lo no mercado. Com o hedging em mercado futuro, o produtor pode afixar um preço que considera "justo" para a sua produção em uma Bolsa de Futuros (no caso do Brasil a BM\&F) e assim se proteger das oscilações de preços que ocorrerão no mercado até a venda de sua produção final. Deve ficar claro, que quando o preço da mercadoria subir, ele deverá pagar a diferença e quando o preço cair ele receberá a diferença, pois irá garantir o preço que foi negociado a futuro, independente de este ter aumentado ou diminuído no mercado físico. Outros mecanismos de fixação antecipada de preços são os contratos a termo, assim como as CPRs. Uma outra estratégia que o produtor tem para se proteger do risco de preços é aquela denominada de contratos de opções no mercado futuro. Uma opção é um título no qual o comprador (geralmente o produtor rural) tem o direito, mas não a obrigação de exercê-la se conveniente o for. Uma opção de compra, por exemplo, é um contrato no qual o emissor se compromete a comprar uma determinada commodity a um determinado preço. Assim, se o preço da commodity estipulado na opção for maior que o preço da mesma no mercado, o produtor exerce a opção e recebe o valor da diferença entre o preço do mercado fixo e o do estipulado no contrato. Se na opção, a commodity tiver um preço menor que no mercado, o produtor vende a sua mercadoria no mercado físico, e não exerce a opção, fazendo com que esta, como diz a linguagem específica, simplesmente "vire pó".

Além das ferramentas apresentadas acima, há também a diversificação espacial que será examinada com maior profundidade neste trabalho. A diversificação empresarial ou espacial é uma forma comum e relativamente fácil de se administrar o risco de produtividade. Ocorre quando o produtor divide a sua produção em duas ou mais áreas distintas, separadas por uma certa distância. Por exemplo, se o produtor 
deseja plantar 1000 hectares de milho, ele pode produzir 500 hectares em uma propriedade e 500 hectares em uma outra, de forma a se beneficiar de uma correlação entre rendimentos de produção favorável, reduzindo com isso o risco existente. Exemplos clássicos ocorrem na China, onde pequenos produtores raramente possuem uma única área para sua produção, e nos Estados Unidos onde os produtores dificilmente plantam a sua produção em uma única área. Importante destacar ainda, que esses produtores americanos nem sempre são donos de toda a área onde plantam, utilizando-se em grande maioria de arrendamentos de terra para efetivarem sua produção, o que facilita o deslocamento entre áreas, e assim o processo da diversificação.

No Brasil, dois exemplos também podem ser citados. O primeiro é o de um grupo de produtores de algodão, que diversificam a sua produção total em três diferentes estados: São Paulo, Mato Grosso e Goiás, e distribuem plantação e colheita dessas áreas em diferentes períodos. O segundo exemplo é o caso de produtores de maçã de São Joaquim e Fraiburgo em Santa Catarina ${ }^{1}$, cujo principal risco de produtividade é afetada pela ocorrência de chuvas de granizo. Nesta região, a diversificação espacial é bastante utilizada por dois motivos: o primeiro é o fato de a chuva de granizo cair na maioria das vezes em áreas concentradas, e com a diversificação espacial se tem uma pulverização do risco; o segundo motivo está relacionado com a relação custo-benefício, pois o custo de implantação da diversificação espacial é semelhante ao custo de implantação de outras ferramentas de gerenciamento de riscos (telas de proteção), porém o retorno de produção, em média, é maior uma vez que se produz em uma área mais ampla a custos similares.

Há, contudo o custo de se administrar uma área dupla, o que deve ser sempre considerado nas análises. O produtor pode, além da diversificação espacial, realizar uma diversificação de produto, como exemplo, ele pode produzir em uma propriedade a cultura do milho, e na outra a cultura da soja, caso essas apresentem uma baixa correlação de rendimento de produção.

\footnotetext{
${ }^{1}$ Yuri (2003)
} 


\subsection{Objetivos}

Os objetivos a serem buscados no trabalho são:

a) Realizar uma revisão bibliográfica sobre a utilização da diversificação espacial da produção agropecuária na redução do risco associado a essa atividade.

b) Apresentar um modelo baseado em fatos estilizados que possa mostrar, do ponto de vista teórico, como a diversificação espacial pode beneficiar ou não um produtor rural.

c) Estimar medidas estatísticas de dispersão e correlação espacial da produtividade de soja, utilizando dados municipais do IBGE, durante o período 1990 a 2003, para os estados: Rio Grande do Sul, Santa Catarina, Paraná, São Paulo, Mato Grosso do Sul, Goiás, Mato Grosso, Bahia, Maranhão e Tocantins. O objetivo dessa mensuração é a construção de mapas que possam evidenciar o efeito da distância e da direção geográfica na correlação entre as produtividades de soja plantadas entre dois pontos distintos.

d) Estimar, utilizando dados do IBGE e métodos estatísticos Bayesianos, prêmios líquidos de um seguro para a soja baseados em índices de produtividade (tais como os utilizados nos EUA e Brasil) para o nível municipal.

e) Avaliar o efeito da diversificação espacial no cálculo de prêmios de seguro, utilizando os resultados do item anterior.

O que se pretende examinar é se a utilização da diversificação espacial como ferramenta de administração de riscos pode reduzir o valor dos prêmios dos seguros, 
fazendo com que estes tornem mais acessíveis aos produtores agrícolas. Na elaboração deste modelo, o estudo irá se concentrar no caso específico da cultura da soja, considerando as principais regiões produtoras do território nacional.

Resumidamente, o trabalho visa contribuir para um melhor entendimento da caracterização da precificação dos seguros agrícolas quando se realizam alternativas que visam diminuir o risco de produtividade aos quais estão sujeitos os produtores agrícolas. A caracterização estatística do risco associado à produtividade de soja, decorrente de efeitos espaciais, acaba sendo um elemento importante para generalizações sobre o impacto da diversificação (e mesmo tamanho de propriedades) sobre o precificação do seguro.

Para o desenvolvimento destes objetivos, muito importante será a análise de dados históricos de produtividades de diferentes regiões, assim como a utilização de ferramentas econométricas, fundamentadas em métodos bayesianos, que facilitarão o desenvolvimento e caracterização do trabalho. 


\section{REVISÃO DE LITERATURA}

Para familiarizar o leitor a respeito do tema principal do trabalho, será apresentada a seguir uma revisão de trabalhos que caracterizam riscos na agricultura, assim como publicações relacionadas à ferramenta de gerência ou administração de risco que envolvem a dimensão espacial, ou seja, além das abordagens que envolvem a agricultura e os riscos que são freqüentes nesta, procurar-se-á verificar a ocorrência da diversificação espacial como medida de redução desse risco, não apenas no Brasil como também nas diversas partes do mundo. Também procurar-se-á apresentar um levantamento sobre os estudos referentes à metodologia que será utilizada no trabalho, que envolvam métodos estatísticos Bayesianos.

Para Barros (1999) o cenário político-econômico - nacional e internacional - que se espera para o futuro deverá continuar contando com a globalização, a liberalização econômica e escassez de recursos públicos. Estas três características acabam por produzir efeitos de grande importância sobre o agronegócio no Brasil. O agronegócio, assim como outros setores da economia, depende de três condicionantes para o bom desempenho de suas funções: rentabilidade, gerenciamento de riscos e financiamento. Considerando-se que o setor público está cada vez mais afastado das decisões de mercado no que se refere a recursos financeiros, uma estratégia ótima de crescimento dependerá do desenvolvimento de novos instrumentos (públicos e privados) que focarão as questões associadas à rentabilidade, gerenciamento de riscos e financiamento.

Desta forma, como o autor coloca, o setor privado já vem tomando iniciativa, e reagindo ativamente a essas novas necessidades, criando mecanismos de gerenciamento de riscos 
(contratos a termo e de futuros, troca de insumos por produtos, etc.) e de financiamento, principalmente através de recursos externos. Com isso, o setor privado assume menor dependência do setor público, ao desenvolver essas iniciativas criativas de gerenciamento de riscos e financiamento de suas atividades. Porém o governo não ficou para trás. Este vem criando alternativas de sustentação de preços e gerenciamento de riscos agrícolas que se enquadram nos reduzidos orçamentos e que com isso, impliquem em um menor envolvimento operacional de sua parte.

Em Harwood et al. (1999) é apresentada uma detalhada explicação sobre grande parte das ferramentas utilizadas para a administração de riscos referentes à produção agrícola. Os autores se preocupam em apresentar primeiramente quais são essas ferramentas e de que forma elas podem ser mais bem utilizadas para ajudarem os produtores a controlar os riscos existentes. São apresentadas ferramentas como: a diversificação espacial/empresarial, o seguro agrícola, os contratos de produção, os contratos em mercados futuros, as opções em mercados futuros entre outras. Conjuntamente, são apresentadas fórmulas de cálculos que ajudam os produtores a definir qual a melhor maneira de realizar a sua gerência de risco, levando se em conta o tipo de propriedade, o seu tamanho, a sua cultura, entre outras características.

Uma análise importante que os autores realizam é a da existência da renda offfarm, assim definida. Esta pode ser entendida como uma diversificação intersetorial, que ajuda o produtor a diminuir o seu risco e, por conseguinte, aumentar a sua receita líquida. Um exemplo para melhor entendimento seria aquele em que o produtor rural se dedica a atividade rural, enquanto algum membro de sua família (geralmente um filho, ou o próprio produtor) se dedica a uma atividade exterior à fazenda, como uma atividade/trabalho na cidade. Isto o ajuda a garantir uma receita líquida mínima, independente do rendimento de sua produção ou do preço que será pago pelo seu produto. 
Uma informação importante colocada pelos autores neste mesmo artigo é o fato de as propriedades que apresentam um rendimento anual menor que US\$50.000 procuram como forma de administrar riscos manter dinheiro em caixa para se auto financiar caso ocorra algum problema, optando pouco por outros instrumentos. Já as propriedades que apresentam um rendimento anual maior que US\$500.000 estão mais aptas a utilizar ferramentas de administração de riscos, principalmente os contratos e a diversificação empresarial, e mesmo a permanência de dinheiro em caixa para o auto-seguro que também é bastante comum.

Azevedo Filho (2001) apresenta uma discussão a respeito das principais fontes de gerenciamento e administração de riscos na agricultura. Entre outras considerações, o trabalho apresenta e define conceitos gerais que facilitam o entendimento de seguros e ferramentas existentes para este, analisa experiências de outros países que utilizam o seguro baseado em indicadores de produtividade e apresenta um estudo de caso envolvendo a cultura da soja, onde são analisadas diferentes ferramentas de administração e gerenciamento de riscos para esta atividade. Porém, o foco principal apresentado refere-se às perspectivas existentes no Brasil em relação ao desenvolvimento e crescimento da utilização de indicadores regionais correlacionados com a produtividade agrícola para a elaboração de contratos de seguros agrícolas, o que já ocorre em diversos países. Atualmente é utilizado como índice para a elaboração de seguros agrícolas a produtividade local, e esta na maioria das vezes está sob o controle do produtor. Assim, o desenvolvimento de indicadores de produtividade em nível regional pode eliminar problemas importantes como aqueles associados ao risco moral, à anti-seleção e aos altos custos operacionais na comercialização e monitoramento das operações.

O mesmo trabalho destaca que experiências no mundo com o seguro baseado em índices regionais de produtividade não têm obtido resultados sustentáveis, com exceção da Índia. Isso está baseado no fato de muitos países, como os Estados Unidos, 
subsidiarem em grande parte o seguro agrícola fundamentado em indicadores de produtividades locais, fazendo com que o produtor opte por este último, uma vez que é mais abrangente e pode ser obtido a custos baixos. Porém, com o intenso afastamento dos governos federais dos mercados, tais subsídios devem ser reconsiderados, e por virtude, diminuídos ou retirados, proporcionando aos seguros fundamentados em índices de produtividades regionais expectativas de um futuro e desenvolvimento promissores.

Segundo Azevedo Filho (2001) ainda, a utilização de seguros fundamentada em indicadores de produtividades regional não está limitada apenas aos produtores rurais, mas também a outros agentes econômicos que estejam expostos a prejuízos decorrentes de variações desfavoráveis na produtividade e/ou renda agrícola (ex: transportadores, comerciantes, entre outros).

De acordo com Babcook, Hart e Hayes (2002), o seguro agrícola é a ferramenta de administração de riscos mais usada pelos produtores agrícolas nos Estados Unidos. Porém, o aumento dos subsídios ao seguro agrícola nesse país tem incentivado a demanda por seguros com níveis de cobertura maior do que os tradicionais $65 \%$. Os autores descobriram que mais de 50\% dos seguros agrícolas americanos tem taxa de prêmio para milho, soja e trigo que não são consistentes com as leis da probabilidade, principalmente para aqueles com níveis de cobertura acima dos 75\%. Desta forma, taxas cobradas pelos prêmios atualmente estão longe das taxas consideradas pelos autores como sendo uma taxa justa pelo prêmio do seguro agrícola. Isto faz com que os produtores que apresentam riscos de produtividade mais altos estejam aumentando os níveis de coberturas de suas áreas, e os produtores de baixo risco não estão, o que acaba sendo prejudicial para o seguro como um todo, uma vez que a tendência a perdas e indenizações é bem maior, o que faz com que as taxas dos prêmios dos seguros sejam mais altas. Por fim, os autores colocam que uma taxa justa seria aquela que fosse baseada de acordo com a cultura e também de acordo com a região, ou seja, obedeceria a índices diferentes de acordo com a cultura e a região, o que não ocorre atualmente. Tal 
fato faria com que todos os produtores apresentassem um melhor retorno da administração de riscos em cada dólar investido no seguro.

Yuri (2003) demonstra que a diversificação espacial já vem sendo utilizada por alguns produtores de maçã, principalmente nas cidades de São Joaquim e Fraiburgo (SC), como medida de gerenciamento e redução de risco. Segundo o autor, as chuvas de granizo (principal risco de produção para a maçã) ocorrem apenas em áreas isoladas, ou seja, em áreas focalizadas. Dificilmente uma chuva de granizo atinge uma grande extensão territorial. Com a diversificação espacial então, um produtor que possui duas áreas produtoras de maçã, pode se assegurar de que, caso em uma dessas áreas tenha tido a ocorrência de granizo, dificilmente esta mesma ocorrência atingirá uma segunda área de produção geograficamente mais distante da primeira, o que lhe garante um determinado nível de produção devido à pulverização do seu risco local. Verifica-se também, que a diversificação espacial apresenta um custo de implantação equivalente a outros mecanismos de proteção contra a chuva de granizo, como as telas de proteção, por exemplo.

Caffagni e Marques (1999) caracterizam os principais agentes atuantes no seguro agrícola do Brasil. Primeiramente é apresentada a organização do mercado segurador brasileiro, que está dividido em: corretores de seguros, sociedades de seguro mútuo, sociedades cooperativas de seguros, companhias comerciais de seguro e resseguradoras. Posteriormente, é apresentada a divisão do sistema segurador brasileiro em privado e público. Os seguros privados são constituídos pelos corretores de seguros, companhias de seguros, sociedades mútuas, pela resseguradora nacional, e por instituições normativas, fiscalizadoras e reguladoras. Já o seguro público é constituído pelo Programa de Garantia da Atividade Agropecuária (PROAGRO).

Entre as instituições apresentadas neste artigo, destaca-se a Companhia de Seguros do Estado de São Paulo (COSESP) que é a única empresa brasileira que vinha atuando com volumes significativos no setor agropecuário, porém com pouca 
importância segurada uma vez que só atende aos Estados de São Paulo e do Paraná; as sociedades de seguro mútuo, dando destaques para a Cooperativa Agropecuária Batavo Ltda e a Cooperativa Agrária Mista Entre Rios Ltda e Associação dos Fumicultores do Brasil (Afubra), que são três exemplos de sucesso desse tipo de associação; o Fundo de Estabilidade do Seguro Rural (FESR); o Instituto de Resseguros do Brasil (IRB); as instituições normativas, fiscalizadoras e reguladoras do seguro privado nacional, representadas pelo Conselho Nacional de Seguros Privados (CNSP) e pela Superintendência de Seguros Privados (SUSEP); e por último o exemplo do PROAGRO, que é o seguro público do Brasil, e que em quase toda a sua existência apresentou resultados insatisfatórios, tanto do ponto de vista de administração quanto em relação à finalidade de seguro. Importante destacar que essas definições são válidas ainda para hoje.

Como conclusão, tal artigo coloca que a utilização de seguro agrícola no Brasil ainda é bem pequena. Isso porque para o demandante do seguro agrícola (produtor rural) ainda existem poucas alternativas no mercado, devido à pequena oferta, uma vez que o interesse das empresas (seguradoras) privadas em atuarem no mercado ainda é baixo. Com isso, relaciona-se o fato de o prêmio pago para se obter o seguro ser bastante alto, e acima do verificado no mercado internacional. Já pelo lado da oferta, esta é baixa pelo fato de haver uma escassez de dados estatísticos e cadastrais e pelo alto custo de entrada de novas empresas, o que gera uma falta de interesse pelas companhias de seguro no ramo agropecuário, causando conseqüentemente uma falta de concorrência, refletindo-se novamente em um alto preço cobrado pelos prêmios do seguro.

Azevedo Filho (1999), apresenta um pequeno histórico do seguro agrícola no Brasil considerando os dois principais sistemas que oferecem estes seguros: o PROAGRO e a COSESP. Em relação ao PROAGRO, este é um programa público, que visa fornecer garantias aos agentes financeiros do crédito rural, mas que sempre apresentou desempenho desastroso. Uma explicação para isso é o fato de existirem limitadas utilizações de conhecimento atuariais para cálculo dos prêmios, definição não 
muito clara das coberturas nos contratos e a não preocupação com o monitoramento de operações que visam a diminuição de fraudes, talvez este o maior problema do PROAGRO. Já a COSESP, mesmo sendo uma instituição pública, é a única seguradora que opera em maior escala no seguro agrícola. Suas atividades são desenvolvidas de forma similar à que ocorre em seguradoras privadas, apresentando um desempenho histórico superior ao apresentado pelo PROAGRO.

No mesmo artigo, são apresentadas algumas alternativas para seguros agrícolas privados como o seguro de granizo, de animais, e para a propriedade rural como um todo (benfeitorias, máquinas, veículos rurais, produtos estocados, entre outros) uma vez que experiência pelo mundo afora mostra que são raras as situações em que seguradoras privadas oferecem seguros abrangentes de produção na agricultura sem o devido amparo do Estado.

Por fim, o autor do artigo destaca que os programas tradicionais de seguro são fundamentados na produtividade agrícola local do estabelecimento agrícola, para definição do processo de indenizações. Porém, este sistema está sob o controle do produtor, podendo existir assim eventuais problemas decorrentes de risco moral (fraude) e seleção adversa. Uma alternativa para eliminar estes problemas seria o uso de indicadores mais facilmente observáveis, e que não estivessem ao controle dos produtores, como indicadores de produtividade média do município, microrregião, estado ou país, e indicadores climáticos de fácil medição. Esses indicadores, para facilitar a correta formulação das indenizações, devem ser obtidos por processos de medida adequados e seguros, através de instituições idôneas.

Blarel et al. (1992) analisam a fragmentação da propriedade em Gana e Ruanda e puderam concluir que os benefícios de se fragmentar uma propriedade superam os custos de se realizar esta atividade. Essa característica da propriedade nesses dois países aponta que quanto maior a densidade populacional, maior a fragmentação e que da mesma forma, o crescimento da população conduz a maior fragmentação de 
propriedades. $\mathrm{O}$ autor também pode verificar que a fragmentação das propriedades serve como ferramenta de administração de riscos, pois ajuda a diminuir o risco de produtividade das áreas. No caso de Ruanda, as áreas para plantio são bastante extensivas e possuem uma diversidade climatológica muito grande, o que vem a confirmar com este exemplo o fato de a fragmentação ser uma ferramenta de administração de risco. Uma ressalva que o autor coloca ainda é que os administradores ou políticos desses países que realizam a diversificação deveriam lutar para que os produtores possam vencer os maiores problemas da fragmentação, que são: dificuldade de crédito rural, mão-de-obra não especializada e dificuldade de colocar seus produtos no mercado.

Ainda sobre o mesmo tema, Nartea e Barry (1994) afirmam que a diversificação espacial de uma produção agrícola gera benefícios. Porém, muitas vezes, como no caso de Illinois nos Estados Unidos, esses podem ser tão pequenos que o custo de se realizar a diversificação acabam por anular tais benefícios. Custos estes relacionados como o monitoramento e supervisão de duas ou mais áreas, o custo de transporte, o de combustível, o de capital não remunerado dos administradores entre outros. Por fim, os autores colocam ainda que uma dispersão ou diversificação excessiva pode criar situações de troca entre risco e retorno não favoráveis.

Schurle (1995) descreveu em um artigo a questão da economia do tamanho. Seguiu-se o enfoque de que quanto maior a área menor é a variabilidade do rendimento (economia de tamanho). Mostrou que na economia de tamanho o risco de negócio (business risk) ao produtor é menor quanto maior a área, mas esta relação não se verificava quando se levava em conta o risco financeiro (financial risk). $\mathrm{O}$ autor ainda realizou um comentário importante sobre a questão da diversificação espacial, afirmando que esta ajuda na administração do risco de produtividade pelos produtores. Nessa tendência, para ser plenamente eficiente, uma propriedade deve buscar apresentar as duas características colocadas acima. Deve ser grande o suficiente para gerar os ganhos da economia do tamanho, mas deve também ser diversificada (ferramenta de 
administração de riscos), ou seja, um tamanho ideal para a propriedade deve ser encontrado levando-se em conta estas duas informações levantadas e apresentadas pelo autor. Outro aspecto importante destacado pelo autor é a relação entre tamanho e a diversificação espacial da produção com o valor dos prêmios cobrados em seguro. A variabilidade menor decorrente de áreas maiores e/ou maior diversificação da produção pode motivar uma redução nos prêmios do seguro agrícola.

Schurle (1996) também descreve sobre a questão do impacto que o tamanho da propriedade tem na variabilidade do rendimento das produções. Utilizando análises estatísticas, este autor chegou à conclusão de que quanto maior a propriedade menor é a variabilidade do rendimento da produção, ou seja, esses dois fatores (tamanho da propriedade e variabilidade do rendimento) são inversamente proporcionais. Ainda no mesmo artigo, o autor refere-se à questão dos prêmios que devem ser cobrados àqueles que querem assegurar suas propriedades. Para aqueles que possuem uma área grande, o prêmio do seguro deve ser relativamente menor devido a menor probabilidade de prejuízo quando levada em conta a variabilidade do rendimento. Desta mesma forma, aqueles produtores que possuem uma área relativamente pequena, devem pagar um prêmio pelo seguro proporcionalmente maior do que aqueles detentores de grandes áreas. Em uma pesquisa recente Azevedo Filho e Rolim (2001) evidenciam certos aspectos estatísticos do clima em escala geográfica local (1000 ha) que condicionam a redução da variabilidade da produtividade com o aumento da escala de produção.

Cohen (1996) faz um comparativo entre as vantagens de uma propriedade grande com a de uma propriedade pequena para se realizar a atividade agrícola. As vantagens das grandes propriedades são apresentadas em duas situações: a primeira é que elas operam com vantagens em economias de mercado, pois têm a possibilidade de adquirir insumos em grande escala e por isso mesmo a preços menores, e a segunda são as economias técnicas, pois há uma operação mais econômica da propriedade, como no caso da divisão do trabalho, onde se têm trabalhadores especializados devido ao grande número desses na propriedade. Já as vantagens das pequenas propriedades estão no 
menor custo e maior eficiência na supervisão e administração da área e um menor número de trabalhadores necessários, o que faz com que muitas vezes o administrador tenha de assumir o papel de trabalhador e com isso ter uma função mais participativa e colaborativa. Um grande problema de pequenas propriedades é a dificuldade que essas possuem de obterem capital (empréstimos), fato que acaba condicionando-as a permanecerem como pequenas propriedades. O autor diz ainda que as vantagens de se operar em grande escala na agricultura são menores quando se comparam estas às vantagens obtidas na atividade industrial.

Nguyen et al. (1996) afirma que a fragmentação da propriedade, pelo menos em seu estudo realizado na China, envolve custos que podem ser maiores que os benefícios. Este custo varia ainda para cada tipo de produção. Na mesma linha, os autores colocam que, para se haver a consolidação das terras na China, não deve haver a intervenção governamental para alocar e fragmentar propriedades. O governo deve sim regularizar e estabelecer o direito de uso da terra e se preocupar em promover o crédito rural e a facilidade de acesso ao mercado aos produtores.

Coble et al. (1996) desenvolvem em seu trabalho um modelo teórico que sugere a inclusão de dados de retorno de mercado e de retorno de seguro para a definição do Multiple Peril Crop Insurance (MPCI) que é um modelo de seguro agrícola que não apresenta taxas fixas, mas sim variáveis de acordo com as características da produção agrícola específica. A partir de resultados empíricos, estes autores concluem que a inclusão desses dois tipos de dados é significante. Apenas para definir, o modelo MPCI é um contrato oferecido pela Federal Crop Insurance Corporation (FCIC) nos Estados Unidos, no qual as indenizações ocorrem quando há uma queda na produtividade agrícola abaixo do nível especificado no contrato de seguro. No trabalho é mostrado como é realizada a indenização e apresenta o modelo MPCI a partir de uma estimação empírica de um produtor de trigo de Kansas entre os anos de 1987 e 1990. Um fato interessante que os autores concluem com essa nova modelagem é que uma pequena 
variância da indenização é encontrada para produtores com uma grande probabilidade de uma pequena indenização, mas que estão também menos prováveis a grandes perdas.

Rosenberg e Young (1999) desenvolvem o uso do modelo Bayesiano para analisar dados de séries temporais. A aproximação Bayesiana é utilizada para analisar neste artigo as taxas de desemprego nos Estados Unidos, que é uma série de dados temporais macroeconômicas. Os autores colocam que o entendimento de variáveis das séries de dados temporais macroeconômicas pode ajudar a área atuarial a precificar os seus produtos. Ou seja, o propósito da técnica de modelagem de séries de dados temporais é que a ciência atuarial pode usá-las na precificação de produtos de seguros. É desenvolvido no artigo também um ajuste para modelos de medidas que podem ser usados na escolha de modelos alternativos. No artigo é mostrado então como a aproximação Bayesiana na série de dados temporais pode proporcionar mais informações do que a aproximação clássica. O modelo Bayesiano incorpora uma maneira de predizer as mudanças na variância em cada parte do processo. Assim, no artigo é mostrada uma maneira de determinar os deslocamentos da variância e também a quantidade total de deslocamentos.

A aproximação Bayesiana para série de dados temporais, ainda segundo Rosenberg e Young (1999) apresenta uma mais completa forma de analisar os dados e incorporar tais informações no modelo. Este desenvolve uma combinação de dados com informações a priori sob uma estrutura sistemática. Os modelos Bayesianos assumem que os parâmetros do modelo variam de acordo com as distribuições pré-definidas. A distribuição a priori dos parâmetros desconhecidos pode ser baseada em opiniões de experts. Quando os dados indicam que as pressuposições adjacentes do modelo têm mudado, a aproximação Bayesiana pode ser adaptada. Alguns modelos Bayesianos podem ainda medir a mudança no nível da variância do processo.

Ker e Goodwin (2000) apresentam uma nova metodologia para estimar produtividades futuras e assim derivar também as taxas de seguro. Nesta aplicação, é 
utilizado um estimador, denominado kernel não paramétrico, para estimar as probabilidades condicionais baseado no estimador Bayes kernel não paramétrico. Os autores afirmam que essas inovações metodológicas podem melhorar o problema enfrentado com dados. Um dos problemas verificados na análise com os estimadores kernel é que as produtividades estimadas nem sempre apresentam momentos igual aos momentos dos dados iniciais. Porém, de acordo com o tamanho da amostra, existem técnicas que conseguem corrigir essas falhas. Desta forma, a partir de simulações empíricas apresentadas no artigo, este estimador pode proporcionar significantes ganhos de eficiência na estimação de produtividades. Por fim, os autores sugerem que estes estimadores podem e devem ser usados para estimar produtividades de diversas culturas, e não apenas do milho, que é o caso específico desta análise.

Herzog (2002) discute a aplicação da estatística Bayesiana em conjunto com métodos Monte Carlo para problemas práticos. Este artigo apresenta duas aplicações do paradigma Bayesiano na área de seguros. $\mathrm{Na}$ primeira, é apresentado como realizar a predição da apreciação de valores individuais de moradia e um segundo modelo apresenta como realizar a predição da taxa anual de mortalidade de indivíduos assegurados. Segundo o autor, uma das propriedades dos seguros que garantem a saúde do seguro, é o fato de a ciência atuarial estar sempre preocupada em como predizer o total de perdas do seguro durante um próximo período de observações. Assim, esta ciência freqüentemente tem de realizar tais previsões a partir de períodos anteriores, e pode se basear nos modelos bayesianos para resolver estes problemas. Mostra ainda este autor como usar números pseudo-aleatórios ou quase-aleatórios para simular perdas totais usando distribuições preditivas para a freqüência das reivindicações de seguro.

Goodwin (2000) afirma que o governo norte-americano continua fortemente adepto a sua política de oferecer subsídio aos produtores agrícolas, quer por meio de seguros de produção quer por meio de seguro de renda. Apesar de o governo demonstrar que pretende diminuir aos poucos esta participação, os baixos preços das commodities e as secas localizadas tem feito suas intervenções serem cada vez maiores. Segundo o 
autor, a agricultura possui características especiais (desastres naturais, pestes, alta volatilidade dos preços) que favorecem e justificam essa interferência do governo com a finalidade de proteger a renda do produtor. O Estado argumenta ainda que a intervenção na agricultura é necessária para garantir os alimentos que a população necessita, mas é de conhecimento geral que o apoio à agricultura é um eficiente meio de eleger representantes políticos nessas regiões.

Sobre o seguro, o autor argumenta que existem cinco tipos de produtos que garantem a renda do produtor agrícola, todos com forte influência do governo. Mas um novo tipo de seguro, o Group Risk Plan (GRP), apareceu com o intuito de afastar um pouco o governo na área de seguro agrícola e favorecer a entrada de instituições privadas. O GRP é um seguro baseado na produtividade de uma grande área como indicador para a definição do seguro, ou seja, a produtividade de toda uma área anteriormente definida é o limite que define se um produtor será indenizado ou não. Justamente por representar uma área mais extensa, esta modalidade de seguro reduz em grande parte os problemas associados ao risco moral tão freqüente na área atuarial. Apesar de o governo norte-americano ter se mostrado favorável à sua retirada do mercado de seguros agrícolas, novas estratégias de intervenção estão sendo introduzidas sinalizando que a agricultura norte-americana continuará sendo fortemente protegida.

Ker e Coble (2003) realizam uma comparação entre modelos paramétricos, não paramétricos e semiparamétricos, para calcular taxas de prêmios de seguros, que são derivadas a partir de estimativas de produtividades agrícolas. Dado o aumento do interesse em seguros agrícolas, risco agrícola, e a importância da identificação das funções de produção vêm ocorrendo uma grande preocupação com a melhoria dos métodos de caracterização das distribuições de produtividade. Infelizmente, nem sempre os dados disponíveis são suficientes para se realizar estimativas a partir de modelos paramétricos. Mas isso não deve ser visto como um obstáculo para se realizar análises econométricas. 
Desta forma, é proposto pelos autores o uso de um modelo de estimação semiparamétrico que, com custos diminutivos, mescla os benefícios dos modelos paramétricos e não paramétricos e ainda exclui a desvantagens destes. Ou seja, o propósito do modelo semiparamétrico é que ele comporta-se como um estimador paramétrico, se o modelo paramétrico está correto, se não, comporta-se como um modelo não paramétrico. Assim, empiricamente, é mostrado que para pequenas quantidades de dados (no caso um número menor que 15), um estimador de probabilidade máxima normal (paramétrico) tenderá a ser preferido dados seus pequenos erros de estimação e por ser mais fácil de usar. Já para conjunto de dados entre 15 e 50 amostras, o estimador semiparamétrico tenderá a ser preferido a outros estimadores. Portanto, é importante lembrar segundo os autores, que o estimador semiparamétrico, devido a suas propriedades teóricas e os resultados na simulação, permite um procedimento empírico com maior grau de confiança para prever produtividades futuras.

Com um tema relacionado ao apresentado acima, Ramirez et al. (2003) apresenta uma comparação entre métodos paramétricos e não paramétricos. Para esses autores, os métodos não paramétricos são modelos livres, e tem a vantagem de apresentarem uma livre forma funcional e também pressuposições de distribuição. Estes modelos podem proporcionar um resultado mais exato e modelos robustos, porém, a aproximação paramétrica pode ser problemática quando analisa variáveis múltiplas a partir de pequenas amostras de dados. Os métodos paramétricos requerem uma forma funcional e pressuposições de distribuição e são, conseqüentemente, suscetíveis a especificação de erros e suas conseqüências estatísticas. Os métodos paramétricos são, portanto, mais vantajosos quando não se possui uma amostra muito grande de dados. Os autores apresentam assim, exemplos empíricos no artigo que ajudam a corroborar as afirmações anteriores.

Segundo Scandizzo (2002), o seguro por área (AI - Area Insurance) ou por grupo (GI - Group Insurance) é um programa de seguro que paga uma indenização proporcional a um indicador da receita média de um dado grupo de produtores que 
apresentam uma mesma característica. Este modelo de seguro apresenta a vantagem de que nenhum produtor é grande o suficiente para afetar a receita média da área, ficando o seguro livre do risco moral e aumentando assim a eficiência da ferramenta de administração do risco. O modelo GI foi introduzido como um programa modelo nos Estados Unidos em 1993 como um seguro-piloto para a produção de soja. Apesar deste modelo não ter sido considerado popular pelo tamanho da área assegurada em comparação a outras formas de seguro, conseguiu alcançar o objetivo de diminuir a assimetria de informação comumente existente, que é um dos primeiros passos mais importantes para as empresas privadas assumirem o lugar no governo na área de administração do risco agrícola.

Assim, o seguro por grupo (GI) deve ser considerado como uma forma geral de seguridade, no qual os pagamentos dependem das estatísticas fornecidas por uma determinada população (amostra). Tais estatísticas seriam os valores das médias da renda, da receita ou da produtividade de todas as propriedades que compõem a área do grupo. Desta forma, aqueles que apresentassem uma renda acima da renda média pagariam um prêmio, enquanto aqueles que estivessem renda abaixo da média da área receberiam um pagamento que cobrissem seus prejuízos. O equilíbrio para o seguro de uma determinada área seria encontrado então, quando o total de prêmios recebidos fosse igual ao total de "indenizações" pagas somadas aos custos administrativos da operação. 


\section{METODOLOGIA}

\subsection{Referencial metodológico}

Parte importante do trabalho envolve uma caracterização de estatísticas descritivas e sua geo-referenciação, de forma a permitir uma visualização adequada de parâmetros associados à magnitude: (a) da produtividade esperada de soja em quilos por hectare; (b) medidas de risco (desvio-padrão e coeficiente de variação); e, (c) de medidas de correlação entre produtividades obtidas em duas regiões e o efeito da distância/orientação geográfica na definição desta correlação.

Inicialmente, será apresentado um modelo conceitual fundamentado na teoria de decisão em condição de risco que motiva e dá consistência teórica ao esforço na direção da caracterização estatística geo-referenciada formulada no parágrafo anterior. Em seguida, nos próximos parágrafos serão descritos procedimentos específicos utilizados para obtenção destas medidas estatísticas.

\subsubsection{Modelo conceitual}

A caracterização estatística envolvendo geo-referenciação de parâmetros associados à produtividade e renda, que constituem parte importante deste trabalho, pode ser justificada através de um modelo conceitual que identifica objetivamente a utilização desses parâmetros estimados dentro de um processo de otimização visando o 
estabelecimento do nível ideal de diversificação espacial da produção de soja, assim como na definição de taxas de prêmios de seguro de produtores que tenham sua produção de soja em áreas distintas.

Considera-se inicialmente um produtor que possui duas áreas (A e B) onde pode alocar a sua produção. Ele pode alocar a sua produção totalmente na área A, totalmente na área B, ou realizar uma diversificação, alocando parte da produção para a área $\mathrm{A}$ e parte na área B. A alocação em cada área será representada pelo parâmetro $\underline{\alpha}$ que indica quanto alocar na área $\mathrm{A}[(1-\alpha)$ indica quanto alocará em $\mathrm{B}]$. O cálculo da receita líquida será representado da seguinte maneira:

$$
\begin{aligned}
& R L=\alpha R L_{A}+(1-\alpha) R L_{B} \\
& R L=\alpha\left(\bar{P} Y_{A}-C_{A}\right)+(1-\alpha)\left(\bar{P} Y_{B}-C_{B}\right)
\end{aligned}
$$

Onde:

$\mathrm{RL}=$ Receita Líquida;

$\alpha=$ coeficiente de produção (quanto do total de produção será produzido em A);

$\bar{P}=$ preço do produto (assumido como fixo);

$\mathrm{Y}_{\mathrm{n}}=$ produção do bem na área $\mathrm{n}$ (aleatório);

$\mathrm{C}_{\mathrm{n}}=$ custo de produção na área $\mathrm{n}$ (assumido como fixo).

Depois de apresentada a fórmula para se calcular a receita líquida de um produtor, caminha-se ao passo seguinte que é o de estimar parâmetros, derivados do modelo conceitual e que possibilitem a caracterização estatística da produção no espaço. Melhor dizendo, precisamos encontrar um valor de $\underline{\alpha}$ que maximize a esperança da utilidade da receita líquida (no modelo média-variância ${ }^{2}$ ).

\footnotetext{
${ }^{2}$ ver Azevedo Filho (2000)
} 
Ou seja, o produtor deseja nesse modelo, encontrar o valor de $\underline{\alpha}$ (representado por $\left.\alpha^{*}\right)$ que soluciona:

\section{Max.:}

$$
E U(R L(\alpha))=E(R L)-\frac{r}{2} \cdot V(R L)
$$

Onde:

$\mathrm{E}(\mathrm{RL})=$ esperança da receita líquida

$$
\begin{aligned}
& =E\left[\alpha\left(\bar{P} Y_{A}-\bar{C}_{A}\right)+(1-\alpha)\left(\bar{P} Y_{B}-\bar{C}_{B}\right)\right] \\
& =\alpha\left[\bar{P} \bar{Y}_{A}-\bar{C}_{A}\right]+(1-\alpha)\left[\bar{P} \bar{Y}_{B}-\bar{C}_{B}\right]
\end{aligned}
$$

$\mathrm{r}=$ coeficiente de aversão ao risco

$\mathrm{V}(\mathrm{RL})=$ variância da receita líquida

$$
\begin{aligned}
& =\alpha^{2} \bar{P}^{2} \sigma_{A}+(1-\alpha)^{2} \bar{P}^{2} \sigma_{B}+2 \alpha(1-\alpha) \bar{P}^{2} \operatorname{Cov}\left(Y_{A}, Y_{B}\right) \\
& =\bar{P}^{2}\left[\alpha^{2} \sigma_{A}^{2}+(1-\alpha)^{2} \sigma_{B}^{2}+2 \alpha(1-\alpha) \rho_{A, B} \sigma_{A} \sigma_{B}\right]
\end{aligned}
$$

A partir destes pontos, podemos descobrir qual o $\alpha$ ótimo para o produtor, derivando a função EU $(\operatorname{RL}(\alpha))$ em relação a $\alpha$, e igualando o resultado a zero.

Esses desenvolvimentos são apresentados a seguir:

Definindo que $\mathrm{k}=\frac{\partial E(R L)}{\partial \alpha}=\bar{P} \bar{Y}_{A}-\bar{C}_{A}-\bar{P} \bar{Y}_{B}-\bar{C}_{B}=\bar{P}\left(\mu_{A}-\mu_{B}\right)+\left(C_{B}-C_{A}\right)$

Onde:

$\bar{P}=$ preço do produto (assumido como fixo)

$\mathrm{Y}_{\mathrm{n}}=$ produção do bem na área $\mathrm{n}$ (aleatório)

$\mathrm{C}_{\mathrm{n}}=$ custo de produção na área $\mathrm{n}$ (assumido como fixo) 
Temos que:

$\frac{\partial E U(R L(\alpha))}{\partial \alpha}=k-\frac{r}{2}\left\{2 \alpha \bar{P}^{2} \sigma_{A}^{2}-2(1-\alpha) \sigma_{B}^{2} P^{2}+2 \bar{P}^{2} \rho_{A, B} \sigma_{A} \sigma_{B}[(1-\alpha)-\alpha]\right\}$

ou

$$
\alpha=\left(\frac{k}{r \bar{P}^{2}}+\sigma_{B}^{2}-\rho_{A, b} \sigma_{A} \sigma_{B}\right) \frac{1}{\sigma_{A}^{2}-\sigma_{B}^{2}-2 \rho_{A, B} \sigma_{A} \sigma_{B}}
$$

Solucionando a última expressão para $\alpha$ chegamos a:

$$
\alpha^{*}=\left[\frac{W_{0}\left(\mu_{A}-\mu_{B}\right)}{R \bar{P}}+\sigma_{B}^{2}-\rho_{A, B} \sigma_{A} \sigma_{B}\right] \cdot \frac{1}{\sigma_{A}^{2}+\sigma_{B}^{2}-2 \rho_{A, B} \sigma_{A} \sigma_{B}},
$$

que define a quantidade ótima da área em A e B.

Nesse modelo:

$\mathrm{W}_{0}=$ riqueza do produtor por hectare

$\mathrm{r}=$ coeficiente de aversão ao risco relativo

$\mathrm{P}=$ preço médio da soja

$\alpha=$ coeficiente de produção (quanto do total de produção será produzido em A);

$\mu_{\mathrm{n}}=$ esperança matemática da produção na área $\mathrm{n}$

$\mu_{\mathrm{A}, \mathrm{B}}=$ correlação entre produtividade das áreas A e B

$\sigma_{n}^{2}=$ variância da produtividade da área n.

Este modelo conceitual apresentado justifica claramente a necessidade de se conhecer diversos parâmetros estatísticos tais como: esperanças de produtividade, desvios-padrão, variâncias, correlações entre produtividades, etc, dentro de um processo que visa definir níveis ótimos de diversificação. Este modelo que foi utilizado simplesmente para obtenção da diversificação espacial entre duas áreas pode ser 
facilmente estendido para o caso de $\mathrm{n}$ áreas distintas, através de procedimentos similares aos utilizados. Os resultados neste modelo estendido às informações necessárias para o processo de otimização são exatamente os mesmos considerados no modelo que envolve apenas dois pontos, só que neste caso seriam consideradas as informações associadas aos $\mathrm{n}$ pontos. É importante considerar também que, em situações práticas, o fato de se trabalhar com áreas distintas pode gerar custos adicionais decorrentes da dificuldade de gestão e logística. Desta forma, o ganho resultante da otimização no modelo apresentado tenderá a superestimar os ganhos efetivamente observados tendo-se em vista os custos adicionais decorrentes da diversificação. Um modelo mais sofisticado poderia considerar na equação (2) um termo associado ao custo de diversificação em função de $\alpha$. A solução ótima deste modelo também demandaria o conhecimento das mesmas informações definidas anteriormente, assim como da relação entre o custo da diversificação e os valores de $\alpha$.

O entendimento da caracterização geográfica dos parâmetros considerados no modelo pode ser facilitado pela análise do efeito da distância entre os pontos considerados e a orientação geográfica do posicionamento desses pontos. $\mathrm{O}$ entendimento deste efeito possibilita a elaboração de algumas conclusões relativamente gerais com respeito à redução da correlação espacial obtida na medida em que cresce a distância entre os dois pontos segundo uma certa direção geográfica. Isso motiva o interesse deste trabalho em conhecer com maior profundidade esse efeito da distância e orientação geográfica na correlação entre a produtividade média obtida entre dois pontos quaisquer definidos em uma dada região.

Uma aplicação importante deste instrumental desenvolvido neste trabalho é a definição de prêmios (líquidos) básicos de seguro para produtores que desenvolvam a sua produção em áreas distintas, o que pode motivar prêmios inferiores aos obtidos caso as áreas sejam seguradas independentemente, em lugar de considerá-las em conjunto. 


\subsubsection{Modelo conceitual para definição de prêmios de seguros}

Antes de começar a definir o modelo de precificação de seguro que esta sendo utilizado, vale a pena definir o que esta sendo estudado. Os procedimentos usados freqüentemente para a precificação do seguro acabam sendo refinamentos técnicos dos conceitos já observados por Adam Smith, em A Riqueza das Nações, dentro do qual o prêmio do seguro pode ser caracterizado como uma função com 3 componentes principais, ilustrada a seguir:

$$
P=f\left(P_{1}, P_{2}, P_{3}\right)
$$

onde:

$\mathrm{P}_{1}=$ parte do prêmio relacionada com a indenização de um possível sinistro

$\mathrm{P}_{2}=$ parte do prêmio relacionada com os custos administrativos da seguradora

$\mathrm{P}_{3}=$ parte do prêmio relacionada com a retenção do risco por parte do segurador

Importante destacar que o trabalho está concentrado na parte $\mathrm{P}_{1}$ do prêmio, o qual está relacionado diretamente com uma eventual indenização por parte do segurador, ou melhor dizendo, é a parte do seguro onde se realiza uma previsão das possíveis indenizações futuras. Assim, podemos definir o prêmio puro, ou prêmio líquido, como sendo o resultado da esperança da indenização, que é a esperança de quanto se vai pagar no contrato $[\mathrm{I}(\mathrm{Y})]$.

De acordo com Azevedo Filho (2001) "num contrato fundamentado em índices, a idéia é substituir informações locais do próprio estabelecimento por indicadores regionais de produtividade e preço que possam capturar uma parcela importante da informação relevante para caracterização de variações da renda local não antecipadas. 
Esses indicadores agiriam, nesse caso, como o gatilho de compensação. Com isso, o mecanismo de compensação dos contratos que utilizam índices pode ser idêntico ao dos contratos convencionais, com uma única diferença: nesse caso será utilizado como gatilho de compensação um índice que possa refletir, em alguma medida, a produtividade local ou mesmo a renda, mas que, idealmente, seja menos sujeito a problemas de risco moral, seleção adversa, e possa ser medido por algum processo de baixo custo. Um problema certamente importante nesse contexto é a definição de um índice que possa atender a esses e outros desideratos”.

Seguindo o modelo apresentado por Azevedo Filho (2001) para contratos de seguros baseados em índices, no modelo então, Y será definido como o gatilho de compensação, e está sendo representado como a produtividade média municipal computada pelo IBGE. $\mathrm{O}$ limite do gatilho $\mathrm{Y}_{0}$ pode ser fixado em contrato como uma porcentagem de uma estimativa da esperança da produtividade do município, obtida a partir de dados históricos do mesmo.

Continuando, seleciona-se um preço base $\mathrm{P}_{0}$ que será usado para cômputo da eventual indenização. Escolhe-se portanto um nível de indenização $\mathrm{N}_{0}$ que deve variar de 0 até 1,00. Desta forma, a indenização será calculada por:

$$
I\left(Y, Y_{0}, P_{0}\right)=P_{0} Y_{0} \max \left(1-\frac{Y}{Y_{0}}, 0\right) N_{0},
$$

ou simplesmente por

$$
I\left(Y, Y_{0}, P_{0}\right)=P_{0} \max \left(Y_{0}-Y\right) N_{0} .
$$

Dentro dessa última expressão, no início da safra, por ocasião do início da cobertura, é incerto apenas Y, o valor da produtividade que será obtida. Todas as outras variáveis da última expressão são conhecidas e fixas durante a vida da apólice. Esse é o 
modelo tipicamente utilizado em contratos como os realizados pela COSESP. Nos casos mais comuns, $\mathrm{Y}_{0}$ pode variar de 70 a $90 \%$ da produtividade esperada, representada aqui pela estimativa da esperança de Y no início da safra.

Serão consideradas 2 situações: (a) Y será modelado como uma variável com distribuição de $\mathrm{t}$ student (generalizada) corrigida para apresentar esperança idêntica à média aritmética das produtividades observadas em cada safra e desvio padrão definido a partir do desvio padrão das produtividades obtidas de 1990 a 2002; (b) Y será modelado como uma variável com distribuição de $t$ student (generalizada) corrigida para apresentar esperança e desvio padrão idênticos à esperança e desvio padrão da distribuição preditiva obtida por um modelo de regressão linear, considerando produtividades obtidas de 1990 a 1999 e de 1990 a 2003.

Em cada um dos casos o prêmio líquido será definido como sendo a estimativa de $\mathrm{E}\left(\mathrm{P}\left(\mathrm{Y}, \mathrm{Y}_{0}, \mathrm{~F}\right)\right)$, obtida através da média de 10000 simulações, o que possibilita razoável precisão para as estimativas realizadas.

\subsubsection{Procedimentos estatísticos utilizados}

O modelo apresentado no parágrafo anterior indica os parâmetros necessários para análises envolvendo gerenciamento de riscos associados à produtividade de um modo geral. Nesta seção são apresentados os procedimentos considerados para estimativa destes parâmetros a partir da fonte de dados utilizados (que será descrita na próxima seção). 


\subsubsection{Análise de incerteza sobre as produtividades (kg/ha)}

A análise desenvolvida utiliza como proxy da produtividade em quilos por hectare $(\mathrm{kg} / \mathrm{ha})$ obtida em uma dada região, a variável aleatória definida com uma distribuição de probabilidade condicional posterior, derivada a partir de um modelo de regressão obtido a partir de métodos Bayesianos. Essa distribuição posterior será obtida em particular a partir da distribuição preditiva posterior, calculada a partir dos dados de produtividades históricas levantadas pelo IBGE na pesquisa agrícola municipal (PAM). Assim, aproveitando-se dos dados obtidos com a séria histórica, calcula-se o valor estimado da produtividade para o ano seguinte ao último disponível. Este procedimento tem o objetivo de considerar possíveis impactos positivos de aprimoramentos na tecnologia utilizada por produtores na produtividade obtida nas várias regiões.

O fato de estar sendo realizado o estudo a partir de métodos Bayesianos está relacionado ao grande interesse desses métodos e com grande aceitação na área atuarial. Desta forma, por estarem sendo bastante estudados e desenvolvidos neste ambiente atuarial, desenvolve-se neste trabalho uma metodologia baseada na inferência bayesiana.

No modelo básico assumem-se as pressuposições de normalidade, independência linear, homocedasticia e ausência de medidas de erros. O modelo de estimação, baseado no livro “An Introduction to Bayesian Inference in Econometrics” extraído de Zellner (1987), é apresentado detalhadamente a seguir:

\section{Teorema de Bayes}

Um primordial elemento da estimativa Bayesiana é o Teorema de Bayes, também chamado na literatura como o princípio da probabilidade inversa. O teorema será apresentado aqui para variáveis aleatórias contínuas. Denota-se por $\mathrm{p}(\mathrm{y}, \theta)$, a função de 
densidade para um vetor $\mathbf{y}$ aleatório e um vetor parâmetro $\theta$, também aleatório. Assim, temos:

$$
\begin{aligned}
\mathrm{p}(\mathrm{y}, \theta) & =\mathrm{p}(\mathrm{y} \mid \theta) \mathrm{p}(\theta) \\
& =\mathrm{p}(\theta \mid \mathrm{y}) \mathrm{p}(\mathrm{y})
\end{aligned}
$$

portanto:

$$
p(\theta \mid y)=\frac{p(\theta) p(y \mid \theta)}{p(y)}
$$

$\operatorname{com} \mathrm{p}(\mathrm{y}) \neq 0$. Assim, podemos escrever a expressão seguinte:

$$
p(\theta \mid y) \propto p(\theta) p(y \mid \theta)
$$

$\mathrm{p}(\theta \mid \mathrm{y}) \propto$ função densidade a priori X função de probabilidade,

onde $\propto$ denota proporcionalidade, $\mathrm{p}(\theta \mid \mathrm{y})$ é a função de densidade posterior para o vetor parâmetro $\theta$ dada a informação primária $\mathrm{y}, \mathrm{p}(\theta)$ é a função de densidade a priori para o vetor parâmetro $\theta$ e $\mathrm{p}(\mathrm{y} \mid \theta)$, vista em função de $\theta$, é a função de probabilidade conhecida. A equação 11 é um teorema de Bayes, que é um resultado matemático simples na teoria da probabilidade. Importante notar que a função densidade posterior, $\mathrm{p}(\theta \mid \mathrm{y})$, tem todas as informações primárias incorporadas nela.A função de densidade posterior é usada na estimação Bayesiana para fazer inferências sobre parâmetros.

Com relação à informação a priori, tem-se que esta informação geralmente é obtida a partir de exemplos passados, resultados de pesquisas ou análises anteriores.

A título de exemplo, assume-se que existam n observações independentes, $\mathbf{y}^{\mathbf{\prime}}=$ $\left(\mathrm{y}_{1}, \mathrm{y}_{2}, \ldots, \mathrm{y}_{\mathrm{n}}\right)$ observadas de uma população normal com média $\mu$ desconhecida e 
variância $\sigma^{2}=\sigma_{0}^{2}$ conhecida. Espera-se obter a função densidade posterior para $\mu$. Aplicando (15) para este particular problema, temos:

$$
p\left(\mu \mid y, \sigma_{0}^{2}\right) \propto p(\mu) p\left(y \mid \mu, \sigma_{0}^{2}\right),
$$

onde $\mathrm{p}\left(\mu \mid \mathrm{y}, \sigma_{0}{ }^{2}\right)$ é a função de densidade posterior para o parâmetro $\mu$, dada a informação primária y e assumindo valores conhecidos de $\sigma_{0}^{2}, p(\mu)$ é a função de densidade a priori para $\mu$, e $\mathrm{p}\left(\mathrm{y} \mid \mu, \sigma_{0}{ }^{2}\right)$, sendo a função de probabilidade. A função de probabilidade é dada por:

$$
\begin{aligned}
p\left(y \mid \mu, \sigma_{0}^{2}\right) & =\left(2 \pi \sigma_{0}^{2}\right)^{-n / 2} \exp \left[-\frac{1}{2 \sigma_{0}^{2}} \sum_{i=1}^{n}\left(y_{i}-\mu\right)^{2}\right] \\
& =\left(2 \pi \sigma_{0}^{2}\right)^{-n / 2} \exp \left[-\frac{1}{2 \sigma_{0}^{2}}\left[v s^{2}+n(\mu-\hat{\mu})^{2}\right],\right.
\end{aligned}
$$

onde $\mathrm{v}=\mathrm{n}-1, \hat{\mu}=(1 / n) \sum_{i=1}^{n} y_{i}$ é a média da amostra, e $s^{2}=(1 / v) \sum_{i=1}^{n}\left(y_{i}-\hat{\mu}\right)^{2}$ é a variância da amostra.

Assim, considerando a função de densidade de $\mu$ a priori, assume-se que a informação a priori a respeito deste parâmetro pode ser representada da seguinte forma:

$$
p(\mu)=\frac{1}{\sqrt{2 \pi \sigma_{a}}} \exp \left[-\frac{1}{2 \sigma_{a}^{2}}\left(\mu-\mu_{a}\right)^{2}\right]
$$

onde $\mu_{\mathrm{a}}$ é a média a priori e $\sigma_{\mathrm{a}}{ }^{2}$ a variância a priori, que são obtidos a partir das informações primárias. Desta forma, usando o teorema de Bayes para combinar a função de probabilidade em (14) e a função de densidade a priori em (15), obtém-se a seguinte função densidade posterior para $\mu$ : 


$$
\begin{aligned}
p\left(\mu \mid y, \sigma_{0}^{2}\right) & \propto p(\mu) p\left(y \mid \mu, \sigma_{0}^{2}\right) \\
& \propto \exp \left\{-\frac{1}{2}\left[\frac{\left(\mu-\mu_{a}\right)^{2}}{\sigma_{a}^{2}}+\frac{n}{\sigma_{0}^{2}}(\mu-\hat{\mu})^{2}\right]\right\} \\
& \propto \exp \left[-\left(\frac{\sigma_{a}^{2}+\sigma_{0}^{2} / n}{2 \sigma_{a}^{2} \sigma_{0}^{2} / n}\right)\left(\mu-\frac{\hat{\mu} \sigma_{a}^{2}+\mu_{a} \sigma_{0}^{2} / n}{\sigma_{a}^{2}+\sigma_{0}^{2} / n}\right)^{2}\right],
\end{aligned}
$$

onde $\mu$ tem distribuição normal posterior, com média:

$$
E_{\mu}=\frac{\hat{\mu} \sigma_{a}^{2}+\mu_{a} \sigma_{0}^{2} / n}{\sigma_{a}^{2}+\sigma_{0}^{2} / n}=\frac{\hat{\mu}\left(\sigma_{0}^{2} / n\right)^{-1}+\mu_{a}\left(\sigma_{a}^{2}\right)^{-1}}{\left(\sigma_{0}^{2} / n\right)^{-1}+\left(\sigma_{a}^{2}\right)^{-1}}
$$

e variância dada por:

$$
\operatorname{Var}(\mu)=\frac{\sigma_{a}^{2} \sigma_{0}^{2} / n}{\sigma_{a}^{2}+\sigma_{0}^{2} / n}=\frac{1}{\left(\sigma_{0}^{2} / n\right)^{-1}+\left(\sigma_{a}^{2}\right)^{-1}}
$$

Para dar números ao exemplo em questão, suponha-se que existam $n=10$ observações, sendo:

Número da Observação Valor de $y_{i} \quad$ Número da Observação Valor de $y_{i}$

$\begin{array}{cccc}1 & 0,699 & 6 & -0,648 \\ 2 & 0,320 & 7 & 1,572 \\ 3 & -0,799 & 8 & -0,319 \\ 4 & 9 & 2,049 \\ 5 & -0,927 & 10 & -3,077\end{array}$


Média simples: $\hat{\mu}=\frac{1}{10} \sum_{i=1}^{10} y_{i}=-0,0757$

onde os valores de y fazem parte de uma população com média desconhecida e variância $\sigma^{2}=\sigma_{0}^{2}=1,00$. Assume-se que a partir de informações a priori que $\mu_{\mathrm{a}}=-0,0200$ e a variância a priori, $\sigma_{\mathrm{a}}{ }^{2}=2,00$. Esta função de densidade a priori que está plotada na figura 1 abaixo, representa o conhecimento inicial sobre o parâmetro $\mu$. Assim, combinando a função de densidade a priori com a função probabilidade, a função densidade posterior é dada pela expressão (15). Neste exemplo, com média $\hat{\mu}=-0,0757$ e os valores dos parâmetros a priori $\mu_{\mathrm{a}}=-0,02$ e $\sigma_{0}{ }^{2}=2,00$, a média da função densidade posterior é:

$$
E_{\mu}=\frac{-0,0757 / 0,100-0,0200 / 2,00}{1 / 0,100+1 / 2,00}=-0,0730
$$

e a variância:

$$
\operatorname{Var}(\mu)=\frac{1}{1 / 0,100+1 / 2,00}=0,0952
$$

Para facilitar a comparação, as duas funções de densidade estão plotadas na Figura 1. 


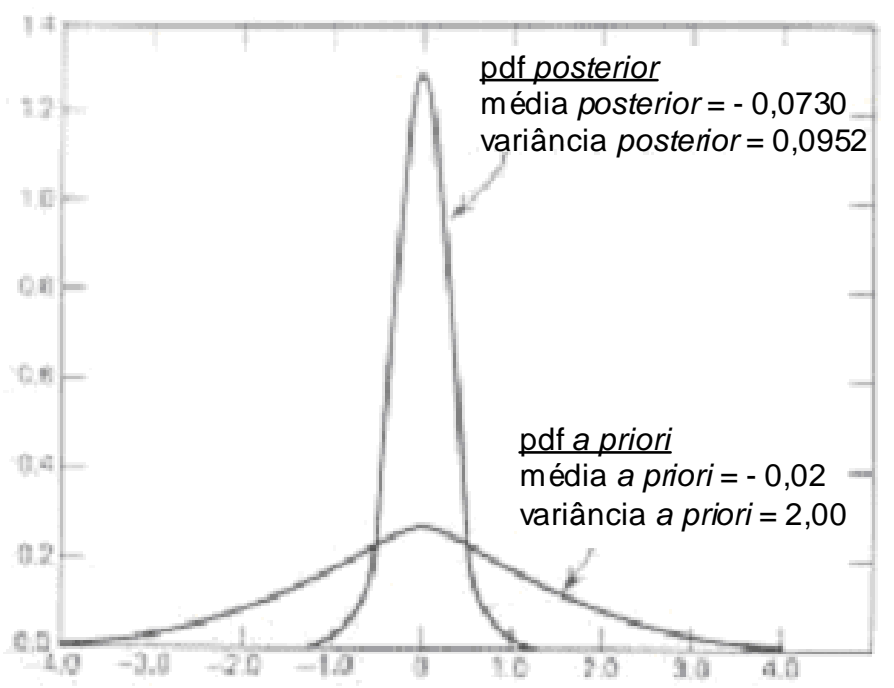

Figura 1 - Funções de densidade a priori e posterior de $\mu$

\section{Funções de Densidade Preditivas}

Em algumas oportunidades, dada a informação a priori $\mathbf{y}$, tem-se interesse em fazer inferências sobre observações que ainda não foram observadas, ou seja, sobre observações futuras. Na aproximação bayesiana, a função de densidade para as observações futuras, pode ser obtida e é conhecida como função de densidade preditiva. Por exemplo, considerando $\tilde{y}$ como sendo um vetor de observações futuras. Tem-se:

$$
p(\tilde{y}, \theta \mid y)=p(\tilde{y} \mid \theta, y) p(\theta \mid y)
$$

como sendo a função de densidade de $\tilde{y}$ tendo com parâmetro o vetor $\theta$, dada a informação y. No lado direito de (22), $p(\tilde{y} \mid \theta, y)$ é a função densidade condicional de $\tilde{y}$, dado $\boldsymbol{\theta}$ e $\mathbf{y}$, e $p(\theta \mid y)$ é a função densidade de $\theta$ dado $\mathbf{y}$, que é a função densidade posterior de $\boldsymbol{\theta}$. Para obter a função densidade preditiva, $p(\tilde{y} \mid y)$, integra-se (22) com relação a $\theta$ : 


$$
\begin{aligned}
p(\tilde{y} \mid y) & =\int_{R \theta} p(\tilde{y}, \theta \mid y) d \theta \\
& =\int_{R \theta} p(\widetilde{y} \mid \theta, y) p(\theta \mid y) d \theta .
\end{aligned}
$$

\section{O Modelo da Regressão Múltipla}

Será apresentado nesta seção, um modelo generalizado sobre a regressão múltipla que tem como base a inferência Bayesina. Generalizado, pois a partir deste, facilmente se consegue derivar e estabelecer um modelo de regressão linear simples, se for necessário, fato que será estudado mais adiante.

\section{- Modelo e Função Probabilidade}

Com o modelo de regressão normal múltipla, assume-se que um vetor $\mathrm{n}$ x 1 de observações y, a variável dependente, satisfaça:

$$
y=X \beta+u
$$

onde $\mathrm{X}$ é uma matrix $\mathrm{n} \times \mathrm{k}$, com rank $\mathrm{k}, \beta$ é um vetor $\mathrm{k} \times 1$ de coeficientes de regressão, e u é um vetor $\mathrm{n}$ x 1 de erros ou distúrbios aleatórios.

Assume-se que os elementos de $\mathbf{u}$ normalmente e independentemente distribuídos, cada qual com média zero e variância comum $\sigma^{2}$. Com respeito à matrix $X$, assume-se que, se ela tiver um intercepto diferente de zero, todos os elementos da primeira coluna de $\mathrm{X}$ será formada por valores igual a um $(1,1, \ldots ., 1)$.

De acordo com as pressuposições acima, a função de densidade para os elementos de $\mathbf{y}$, dado $X, \beta$ e $\sigma$, será: 


$$
\begin{aligned}
p(y \mid X, \beta, \sigma) & \propto \frac{1}{\sigma^{n}} \exp \left[-\frac{1}{2 \sigma^{2}}(y-X \beta)^{\prime}(y-X \beta)\right. \\
& \propto \frac{1}{\sigma^{n}} \exp \left\{-\frac{1}{2 \sigma^{2}}\left[v s^{2}+(\beta-\hat{\beta})^{\prime} X^{\prime} X(\beta-\hat{\beta})\right]\right\},
\end{aligned}
$$

onde $\mathrm{v}=\mathrm{n}-\mathrm{k}$,

$$
\hat{\beta}=\left(X^{\prime} X\right)^{-1} X^{\prime} y
$$

e

$$
s^{2}=\frac{(y-X \hat{\beta})^{\prime}(y-X \hat{\beta})}{v}
$$

\section{- Função de Densidade Posterior}

$\mathrm{Na}$ análise da regressão múltipla, assume-se que a informação da função de densidade a priori é vaga ou difusa, e é representada por elementos de $\beta$ e $\log \sigma$ uniformemente e independentemente distribuídos:

$$
p(\beta, \sigma) \propto \frac{1}{\sigma}, \quad-\infty<\beta_{i}<\infty, \quad 0<\sigma<\infty, \text { para } \mathrm{i}=1,2, \ldots . ., \mathrm{k}
$$

Combinado então (4.23) e (4.26), a função densidade posterior para os parâmetros $\beta$ e $\sigma$ será:

$$
p(\beta, \sigma \mid y, X) \propto \frac{1}{\sigma^{n+1}} \exp \left\{-\frac{1}{2 \sigma^{2}}\left[v s^{2}+(\beta-\hat{\beta})^{\prime} X^{\prime} X(\beta-\hat{\beta})\right]\right\} .
$$


Embora este fato seja interessante e tenha algum uso em certas derivações, $\sigma^{2}$ raramente é conhecido na prática, fazendo com que a matrix $\left(X^{\prime} X\right)^{-1} \sigma^{2}$ não possa ser calculada. Para evitar este problema no parâmetro $\sigma$, integra-se (29) com relação a $\sigma$ para obter a seguinte função densidade posterior marginal para os elementos de $\beta$ :

$$
\begin{aligned}
p(\beta \mid y, X) & =\int_{0}^{\infty} p(\beta, \sigma \mid y, X) d \sigma \\
& \propto\left\{v s^{2}+(\beta-\hat{\beta})^{\prime} X^{\prime} X(\beta-\hat{\beta})\right\}^{-n / 2}
\end{aligned}
$$

\section{O Modelo da Regressão Linear Simples}

Acima foi apresentado o modelo de regressão linear múltipla, que é um caso geral do processo de regressão, e foi apresentado apenas para se ter uma visão mais generalizada do processo de regressão envolvendo inferência bayesiana. A seguir, será apresentado o modelo de regressão linear simples, que é um modelo mais específico neste caso, e será o modelo utilizado no desenvolvimento do trabalho.

- Modelo e Função Probabilidade

No modelo de regressão linear simples, temos a variável dependente, cuja variação é explicada, ao menos em parte, pela variação de uma outra variável, denominada independente. A parte da variação da variável dependente não explicada pela variável independente é assumida como sendo produzida por um erra não observado ou distúrbio aleatório.

Desta forma, denotando por $\mathrm{y}$ a variável dependente e por $\mathrm{x}$ a variável independente, temos a seguinte relação:

$$
y_{i}=\beta_{i}+\beta_{2} x_{i}+u_{i} \quad \mathrm{i}=1,2, \ldots, \mathrm{n}
$$


onde:

$\mathrm{y}_{\mathrm{i}}=$ i-ésima observação da variável dependente, no caso, as produtividades médias,

$\mathrm{x}_{\mathrm{i}}$ = i-ésima observação da variável independente, no caso, os anos $(1990,1991, \ldots)$,

$\mathrm{u}_{\mathrm{i}}=\mathrm{i}$-ésimo valor não observado do distúrbio ou erro aleatório, e,

$\beta_{1}$ e $\beta_{2}=$ parâmetros da regressão, chamados de intercepto e coeficiente de inclinação, respectivamente.

Pressuposições:

Pressuposição 1: Os erros $\mathrm{u}_{\mathrm{i}}, \mathrm{i}=1,2, \ldots, \mathrm{n}$, são normalmente e independentemente distribuídos, cada um com média zero e variância comum $\sigma^{2}$.

Pressuposição 2: As variáveis independentes $\mathrm{x}_{\mathrm{i}}, \mathrm{i}=1,2, \ldots, \mathrm{n}$, são variáveis fixas não estocásticas.

Pressuposição 3: As variáveis independentes $\mathrm{x}_{\mathrm{i}}, \mathrm{i}=1,2, \ldots, \mathrm{n}$, são variáveis aleatórias, distribuídas independentemente dos erros $\left(\mathrm{u}_{\mathrm{i}}\right)$, com função de probabilidade não envolvendo os parâmetros $\beta_{1}, \beta_{2}, \sigma$.

Para formar a função de probabilidade de acordo com as pressuposições 1,2 e 3, nós escrevemos a função de densidade para $\mathrm{y}^{\prime}=\left(\mathrm{y}_{1}, \mathrm{y}_{2}, \ldots, \mathrm{y}_{\mathrm{n}}\right)$ e $\mathrm{x}^{\prime}=\left(\mathrm{x}_{1}, \mathrm{x}_{2}, \ldots \mathrm{x}_{\mathrm{n}}\right)$ :

$$
p\left(y, x, \beta_{1}, \beta_{2}, \sigma^{2}, \theta\right)=p\left(y \mid x, \beta_{1}, \beta_{2}, \sigma^{2}\right) g(x \mid \theta)
$$


onde $\theta$ denota os parâmetros da distribuição de densidade marginal de $\mathbf{x}$. Note de (1) que, para cada $\mathbf{x}, \beta_{1}, \beta_{2}$ e $\sigma^{2}$, $\mathbf{y}$ será normalmente distribuído com $\mathrm{E}\left(\mathrm{y}_{\mathrm{i}} \mid \mathrm{x}_{\mathrm{i}}, \beta_{1}, \beta_{2}, \sigma^{2}\right)$ $=\beta_{1},+\beta_{2} x_{i}$ e $\operatorname{Var}\left(y_{i} \mid x_{i}, \beta_{1}, \beta_{2}, \sigma^{2}\right)=\sigma^{2}, i=1,2, \ldots, n$.

Assim, tem-se:

$$
p\left(y \mid x, \beta_{1}, \beta_{2}, \sigma\right) \propto-\frac{1}{2 \sigma^{2}} \exp \left[-\frac{1}{2 \sigma^{2}} \sum\left(y_{i}-\beta_{1}-\beta_{2} x_{i}\right)^{2}\right]
$$

- $\quad$ Função de Densidade Posterior para Parâmetros com uma Desconhecida Função de Densidade

Para a função de densidade para $\beta_{1}, \beta_{2}$ e $\sigma$, assume-se que $\beta_{1}, \beta_{2}$ e $\log \sigma$ são uniformemente e independentemente distribuídos. Então, combinando (32) e (33), a função de densidade posterior para $\beta_{1}, \beta_{2}$ e $\sigma$ é:

$$
p\left(\beta_{1}, \beta_{2}, \sigma \mid y, x\right) \propto \frac{1}{\sigma^{n+1}} \exp \left[-\frac{1}{2 \sigma^{2}} \sum\left(y_{i}-\beta_{1}-\beta_{2} x_{i}\right)^{2}\right]
$$

Desenvolvendo tem-se:

$$
\begin{aligned}
& \sum\left(y_{i}-\beta_{1}-\beta_{2} x_{i}\right)^{2}=v s^{2}+n\left(\beta_{1}-\hat{\beta}\right)^{2}+ \\
& +\left(\beta_{2}-\hat{\beta}\right) \sum x_{i}^{2}+2\left(\beta_{1}-\hat{\beta}\right)\left(\beta_{2}-\hat{\beta}_{2}\right) \sum x_{i}
\end{aligned}
$$

onde $\mathrm{v}=\mathrm{n}-2$

$$
\begin{aligned}
& \hat{\beta}_{1}=\bar{y}-\hat{\beta}_{2} \bar{x}_{i}, \hat{\beta}_{2}=\frac{\sum\left(x_{i}-\bar{x}\right)\left(y_{i}-\bar{y}\right)}{\sum\left(x_{i}-\bar{x}\right)^{2}}, \\
& s^{2}=v^{-1} \sum\left(y_{i}-\hat{\beta}_{1}-\hat{\beta}_{2} x_{i}\right)^{2}
\end{aligned}
$$


$\operatorname{com} \bar{y}=n^{-1} \sum y_{i}$ e $\bar{x}=n^{-1} \sum x_{i}$. Para estabelecer (34), tem-se:

$$
\sum\left(y_{i}-\beta_{1}-\beta_{2} x_{i}\right)^{2}=\sum\left\{\left(y_{i}-\hat{\beta}_{1}-\hat{\beta}_{2} x_{i}\right)-\left[\left(\beta_{1}-\hat{\beta}_{1}\right)+\left(\beta_{2}-\hat{\beta}_{2}\right) x_{i}\right]\right\}^{2}
$$

Substituindo (35) em (36), tem-se:

$$
\begin{aligned}
& p\left(\beta_{1}, \beta_{2}, \sigma \mid y, x\right) \propto \frac{1}{\sigma^{n+1}} \exp \left\{-\frac{1}{2 \sigma^{2}}\left[v s^{2}+n\left(\beta_{1}-\hat{\beta}_{1}\right)^{2}\right.\right. \\
& \left.\left.+\left(\beta_{2}-\hat{\beta}_{2}\right)^{2} \sum x_{i}^{2}+2\left(\beta_{1}-\hat{\beta}_{1}\right)\left(\beta_{2}-\hat{\beta}_{2}\right) \sum x_{i}\right]\right\}
\end{aligned}
$$

Para obter a função densidade posterior marginal para $\beta_{1}$ e $\beta_{2}$, integra-se (37) com respeito a $\sigma$ para obter:

$$
\begin{aligned}
& p\left(\beta_{1}, \beta_{2} \mid y, x\right)=\int_{0}^{\infty} p\left(\beta_{1}, \beta_{2}, \sigma \mid y, x\right) d \sigma \\
& \propto\left[v s^{2}+n\left(\beta_{1}-\hat{\beta}_{1}\right)^{2}+\left(\beta_{2}-\hat{\beta}_{2}\right)^{2} \sum x_{i}^{2}\right. \\
&\left.+2\left(\beta_{1}-\hat{\beta}_{1}\right)\left(\beta_{2}-\hat{\beta}_{2}\right) \sum x_{i}\right]^{-n / 2}
\end{aligned}
$$

Independentemente, temos as seguintes funções de densidades marginais:

$$
\begin{aligned}
& p\left(\beta_{1} \mid y, x\right) \propto\left[v+\frac{\sum\left(x_{i}-\bar{x}\right)^{2}}{s^{2} \sum x_{i}^{2} / n}\left(\beta_{1}-\hat{\beta}_{1}\right)^{2}\right]^{-(v+1) / 2},-\infty<\beta_{1}<\infty \\
& p\left(\beta_{2} \mid y, x\right) \propto\left[v+\frac{\sum\left(x_{i}-\bar{x}\right)^{2}}{s^{2}}\left(\beta_{2}-\bar{\beta}_{2}\right)^{2}\right]^{-(v+1) / 2},-\infty<\beta_{2}<\infty
\end{aligned}
$$




\section{Função de Densidade Preditiva}

Nesta parte, será derivada a função de densidade preditiva (estimada) de um vetor com q futuras observações, $\tilde{y}^{\prime}=\left(y_{n+1}, y_{n+2}, \ldots, y_{n+q}\right)$. Espera-se portanto, derivar a função de densidade para $\tilde{y}$ que assume-se ser gerada por:

$$
\tilde{y}=\tilde{X} \beta+\widetilde{u}
$$

onde $\widetilde{X}$ é uma matriz q x k de valores de variáveis independentes no período futuro q e $\widetilde{u}$ é um vetor $\mathrm{q}$ x 1 de distúrbios ou erros futuros normalmente e independentemente distribuídos, cada um com média zero e variância comum $\sigma^{2}$.

Uma maneira de derivar a função de densidade preditiva é escrever a função de densidade $p(\tilde{y}, \beta, \sigma \mid X, \tilde{X}, y)$ e integrar em relação a $\beta$ e $\sigma$ para obter a função de densidade marginal para $\tilde{y}$, que é a função de densidade preditiva. Assim, tem-se:

$p(\widetilde{y}, \beta, \sigma \mid X, \widetilde{X}, y)=p(\widetilde{y} \mid \beta, \sigma, \widetilde{X}) p(\beta, \sigma \mid y, X)$

$\operatorname{com} p(\beta, \sigma \mid y, X)$ sendo a função de densidade posterior para $\beta$ e $\sigma$, e:

$p(\tilde{y} \mid \beta, \sigma, \widetilde{X}) \propto \exp \left[-\frac{1}{2 \sigma^{2}}(\tilde{y}-\tilde{X} \beta)^{\prime}(\tilde{y}-\tilde{X} \beta)\right]$

Integrando com relação a $\sigma$, obtém-se:

$p(\beta, \tilde{y} \mid y, X, \tilde{X}) \propto\left[(y-X \beta)^{\prime}(y-X \beta)+(\tilde{y}-X \beta)^{\prime}(\tilde{y}-X \beta)\right]^{-(n+q) / 2}$ 
Desenvolvendo, tem-se:

$$
\begin{aligned}
& \begin{aligned}
(y-X \beta)^{\prime}(y-X \beta)+(\tilde{y}-X \beta)(\tilde{y}-X \beta) & =y^{\prime} y+\tilde{y}^{\prime} \tilde{y}+\beta^{\prime} M \beta-2 \beta^{\prime}\left(X^{\prime} y+\tilde{X}^{\prime} \tilde{y}\right) \\
& =y^{\prime} y+\tilde{y}^{\prime} \tilde{y}-\left(y^{\prime} X+\tilde{y}^{\prime} \tilde{X}^{\prime}\right) M^{-1}\left(X^{\prime} y+\tilde{X}^{\prime} y^{\prime}\right)+
\end{aligned} \\
& {\left[\beta-M^{-1}\left(X^{\prime} y+\tilde{X}^{\prime} y^{\prime}\right)\right]^{\prime} M\left[\beta-M^{-1}\left(X^{\prime} y+\tilde{X}^{\prime} y^{\prime}\right)\right]}
\end{aligned}
$$

onde $M=X^{\prime} X+\tilde{X}^{\prime} \tilde{X}$. Substituindo em (46) e integrando com relação aos k elementos de $\beta$, obtém-se:

$$
p(\tilde{y} \mid y, X, \widetilde{X}) \propto\left[y^{\prime} y+\tilde{y}^{\prime} \tilde{y}-\left(y^{\prime} X+\tilde{y}^{\prime} \tilde{X}\right) M^{-1}\left(X^{\prime} y+\tilde{X}^{\prime} \tilde{y}\right)\right]^{-(v+q) / 2}
$$

onde $\mathrm{v}=\mathrm{n}-\mathrm{k}$. Para deixar (47) em uma forma mais fácil, tem-se:

$$
\begin{aligned}
& y^{\prime}\left(I-X M^{-1} X^{\prime}\right) y+\widetilde{y}^{\prime}\left(I-\widetilde{X} M^{-1} \widetilde{X}^{\prime}\right) \tilde{y}-2 \widetilde{y}^{\prime} \widetilde{X} M^{-1} X^{\prime} y= \\
&=y^{\prime}\left(I-X M^{-1} X^{\prime}\right) y-y^{\prime} X M^{-1} \widetilde{X}^{\prime}\left(I-\widetilde{X} M^{-1} \widetilde{X^{\prime}}\right)^{-1} X^{\prime} y \\
&+\left[\widetilde{y}-\left(I-\widetilde{X} M^{-1} \widetilde{X}^{\prime}\right)^{-1} \widetilde{X} M^{-1} X^{\prime} y\right]^{\prime}\left(I-\widetilde{X} M^{-1} \widetilde{X}^{\prime}\right) \\
& x\left[\tilde{y}-\left(I-\widetilde{X} M^{-1} \widetilde{X}^{\prime}\right)^{-1} \widetilde{X} M^{-1} X^{\prime} y\right]
\end{aligned}
$$

Agora, tem-se o seguinte resultado que pode ser obtido pela multiplicação matricial:

$$
\left(I-\widetilde{X} M^{-1} \tilde{X}^{\prime}\right)^{-1}=I+\widetilde{X}\left(X^{\prime} X\right)^{-1} \widetilde{X}^{\prime}
$$

Usando este resultado, tem-se:

$$
\begin{aligned}
\left(I-\widetilde{X} M^{-1} \widetilde{X}^{\prime}\right)^{-1} \widetilde{X} M^{-1} & =\left[I+\widetilde{X}\left(X^{\prime} X\right)^{-1} \widetilde{X}^{\prime}\right] \widetilde{X} M^{-1} \\
& =\widetilde{X}\left[I+\left(X^{\prime} X\right)^{-1} \widetilde{X}^{\prime} \widetilde{X}\right]\left(X^{\prime} X+\widetilde{X}^{\prime} \widetilde{X}\right)^{-1} \\
& =\widetilde{X}\left(X^{\prime} X\right)^{-1}
\end{aligned}
$$


Substituindo este resultado em (48), tem-se:

$$
\begin{aligned}
& y^{\prime}\left(I_{-} X M^{-1} X^{\prime}\right) y-y^{\prime} X M^{-1} \widetilde{X}^{\prime} \tilde{X}\left(X^{\prime} X\right)^{-1} X^{\prime} y+(\tilde{y}-\tilde{X} \hat{\beta})^{\prime}\left(I-\tilde{X} M^{-1} \tilde{X}^{\prime}\right)(\tilde{y}-\tilde{X} \hat{\beta}) \\
& =y^{\prime}\left\{I-X\left[M^{-1}+M^{-1} \widetilde{X^{\prime}} \widetilde{X}\left(X^{\prime} X\right)^{-1}\right] X^{\prime}\right\} y+(\widetilde{y}-\widetilde{X} \hat{\beta})^{\prime}\left(I-\widetilde{X} M^{-1} \widetilde{X}^{\prime}\right)(\widetilde{y}-\tilde{X} \hat{\beta}) \\
& =y^{\prime}\left[I-X M^{-1}\left(X^{\prime} X+\tilde{X}^{\prime} \tilde{X}\right)\left(X^{\prime} X\right)^{-1} X^{\prime}\right] y+(\tilde{y}-\tilde{X} \hat{\beta})^{\prime}\left(I-\widetilde{X} M^{-1} \widetilde{X}^{\prime}\right)(\tilde{y}-\tilde{X} \hat{\beta}) \\
& =y^{\prime}\left[I-X\left(X^{\prime} X\right)^{-1} X^{\prime}\right] y+(\tilde{y}-\tilde{X} \hat{\beta})^{\prime}\left(I-\tilde{X} M^{-1} \tilde{X}^{\prime}\right)(\tilde{y}-\tilde{X} \hat{\beta})
\end{aligned}
$$

onde $\hat{\beta}=\left(X^{\prime} X\right)^{-1} X^{\prime} y$. Desenvolvendo, chega-se à função de densidade preditiva:

$$
p(\widetilde{y} \mid y, X, \widetilde{X}) \propto\left[v+(\widetilde{y}-\tilde{X} \hat{\beta})^{\prime} H(\widetilde{y}-\tilde{X} \hat{\beta})\right]^{-(v+q) / 2}
$$

onde $H=\left(1 / s^{2}\right)\left(I-\widetilde{X} M^{-1} \widetilde{X}^{\prime}\right)$. Em (51), nota-se que $\widetilde{y}$ tem distribuição $\mathrm{t}$ Student.

\subsubsection{Medidas de risco consideradas (desvio-padrão e coeficiente de variação)}

O desvio-padrão e o coeficiente de variação serão as proxys utilizadas para mensuração do risco associado à variação da produtividade e da renda. Essas medidas estatísticas serão obtidas a partir do desvio-padrão dos desvios calculados entre as produtividades efetivamente obtidas a cada ano considerado na análise e as produtividades estimadas pela regressão linear já descrita no parágrafo anterior. Os coeficientes de variação em cada um desses casos serão obtidos a partir da razão entre o desvio-padrão e a produtividade esperada definida no parágrafo anterior. $\mathrm{O}$ cálculo direto do desvio-padrão e do coeficiente de variação não seria um procedimento adequado em função de que não seriam considerados os impactos da tecnologia, o que 
tenderia a superestimar a magnitude desses parâmetros. Uma outra proxy que poderia ser utilizada como medida de risco em futuros trabalhos é o próprio desvio-padrão associado ao erro de previsão, estimado através de procedimentos associados à análise de regressão (Johnston, 1984, p.43).

\subsubsection{Coeficiente de correlação}

Os coeficientes de correlação entre a produtividade média ou a renda, em dois pontos A e B, serão obtidos a partir dos desvios-padrão computados em regressões lineares considerando como variável "independente" o tempo medido em anos e como variável "dependente" a produtividade média ou a renda, para cada um dos pontos A e B considerados. Esse procedimento visará reduzir os impactos positivos da tecnologia na produtividade e renda, tal como já descrito anteriormente no item associado à estimativa da produtividade esperada.

\subsubsection{Correlação de produtividade $\mathrm{X}$ distância}

Nesta parte procurar-se-á realizar uma análise mais aprofundada da relação entre a correlação da produtividade média por hectare, em pontos A e B definidos em uma dada região, e a distância linear entre esses dois pontos.

Para o cálculo da distância linear (em linha reta) entre dois pontos, parte-se da existência das coordenadas geográficas (latitude e longitude) desses pontos, que foram obtidas para todos os municípios do Brasil considerados na pesquisa. Para o cálculo dessas distâncias, a partir de um banco de dados com as latitudes e longitudes foi necessário o desenvolvimento de procedimentos específicos e de um programa implementando esses procedimentos (ver Anexo). 
A análise envolvendo o efeito da orientação geográfica no posicionamento dos pontos será desenvolvida a partir da medida da orientação através do módulo do ângulo (representado por $\theta$ ) da intersecção da reta que liga certos pontos A e B de interesse, com uma reta orientada na direção leste-oeste. A título de exemplo, se os dois pontos situados numa mesma latitude como os pontos A e B na figura 1, o ângulo $\theta$ assume um valor de $0^{\circ}$. Por outro lado, se os dois pontos $\mathrm{A}$ e $\mathrm{B}$ estão situados numa mesma longitude, como na figura 2, o ângulo $\theta$ assume valor igual a $90^{\circ}$. As figuras $3 \mathrm{a}$ e $3 \mathrm{~b}$ ilustram pontos com orientação definida entre os ângulos $0^{\circ}$ e $90^{\circ}$.

A



(direção leste-oeste)

$$
\theta=0^{\circ}
$$

Figura 2 - Ângulo $\theta=0^{\circ}$

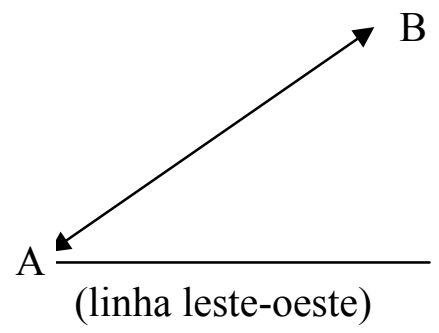

$\theta=45^{\circ}$

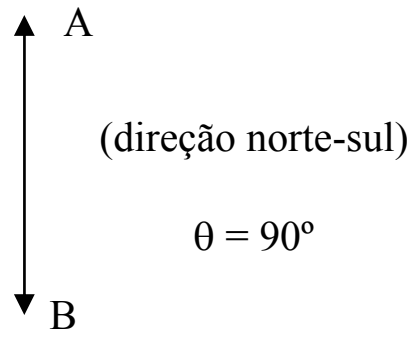

Figura - 3 Ângulo $\theta=90^{\circ}$

A



$\theta=20^{\circ}$

Figura 4 - Ângulo $\theta=45^{\circ}$

Figura 5 - Ângulo $\theta=20^{\circ}$

A razão pela qual se está considerando a orientação geográfica na análise decorre da possível influência da orientação do posicionamento de pontos na correlação da produtividade entre dois pontos para uma mesma distância. Ou seja, a intenção é analisar o que ocorre com a correlação da produtividade entre as cidades, com um aumento ou 
diminuição da distância, dentro de uma certa faixa de orientação geográfica previamente definida.

$\mathrm{Na}$ apresentação dos resultados, procurar-se-á analisar os impactos da distância na correlação segundo quatro categorias de orientação geográfica. Primariamente, a primeira categoria considerará pontos (representados pelos municípios) cuja orientação geográfica estiver compreendida no intervalo de $0^{\circ}$ à $20^{\circ}(0 \leq \theta \leq 20)$. A segunda categoria considerará pontos com orientação definida de forma que $35^{\circ} \leq \theta \leq 55^{\circ}$. A terceira categoria considerará pontos com orientação definida de forma que $70^{\circ} \leq \theta \leq$ $90^{\circ}$. Finalmente, a quarta categoria considerará pares de pontos sem consideração de restrições quanto à orientação geográfica.

\subsection{Fonte de dados}

A fonte de dados utilizada para o desenvolvimento do trabalho será composta de informações sobre a atividade agrícola no Brasil que são disponibilizados pelo Instituto Brasileiro de Geografia e Estatística (IBGE). Estas incluem áreas plantadas, áreas colhidas, quantidade produzida e rendimento médio (produtividade), este último tendo

participação direta nas análises realizadas, para a cultura da soja, considerando a disponibilidade temporal desses dados dentro do intervalo compreendido entre 1990 e 2002.

Outro conjunto de dados que também será utilizado para as análises e desenvolvimento do trabalho contém as coordenadas geográficas de cidades que serão estudadas, ou seja, referentes às suas respectivas latitudes e longitudes. A fonte de dados utilizada neste caso será a existente na base de informações municipais do IBGE complementada com informações externas nos casos da inexistência das informações necessárias para certos municípios. 


\subsection{Preparação dos dados}

O principal passo realizado na preparação dos dados foi a realização de uma filtragem visando a eliminação daqueles municípios que não apresentavam informações completas de produtividade média entre os anos de 1990 e 1999 e entre 1990 e 2003. Com isso, o número de observações (municípios) consideradas dentro da análise foi reduzido de um total de 1815 , para um total de 652 municípios no primeiro caso e 843 municípios no segundo.

\subsection{Ferramental computacional utilizado}

A implementação dos procedimentos descritos nas seções anteriores considerou a utilização exaustiva de algumas ferramentas estatísticas e econométricas, disponíveis em programas como Excel e, assim como programas específicos desenvolvidos na pesquisa para tratamento dos dados, cálculo de distâncias a partir de coordenadas geográficas, cálculo dos ângulos de orientação geográfica, análises gráficas, e outros procedimentos necessários.

Para os cálculos estatísticos, foi utilizado o programa $\mathrm{R}$, que apesar de ser mais trabalhoso por requerer diversos conhecimentos de programação computacional e estatística, apresenta resultados menos propícios a erros $^{3}$.

Além disso, uma ferramenta computacional bastante utilizada no trabalho foi o programa de geo-referenciamento MapInfo, no qual se pode realizar uma aplicação prática e melhor visível das análises realizadas. Com a ajuda deste programa, foi possível apresentar em mapas muitos dos resultados derivados no decorrer deste estudo. A utilização do MapInfo, contudo, exigiu um significativo esforço computacional no

\footnotetext{
${ }^{3}$ Notável participação do professor Adriano Azevedo Filho para a conclusão desta tarefa de programação.
} 
desenvolvimento dos programas necessários à preparação dos dados para que esses pudessem ser apresentados nos formatos apropriados. 


\section{RESULTADOS E DISCUSSÃO}

\subsection{Caracterização geral da produtividade e medida de risco}

Esta primeira parte da apresentação dos resultados do trabalho tem a intenção de oferecer uma caracterização geral dos parâmetros estatísticos relevantes associados a produtividade média esperada e medidas de risco. Todas as figuras apresentadas a seguir estão representadas em nível nacional, considerando apenas aquelas cidades com as quais foi mais conveniente trabalhar (os procedimentos da filtragem utilizados estão especificados na seção de metodologia). Para cada análise, é realizado o estudo comparativo entre dois mapas sendo que o primeiro representa o estudo com os dados disponíveis até o ano de 1999 e o segundo com os dados disponíveis até o ano de 2003. O objetivo desta parte é o de realizar uma análise comparativa e verificar a evolução dos indicadores durante os anos.

As figuras 6 e 7 apresentam as produtividades esperadas para cada município, sendo que a figura 6 representa a produtividade esperada para o ano de 2000 e a figura 7 a produtividade esperada para o ano de 2004. Estas produtividades foram encontradas através dos valores da regressão das produtividades médias de cada observação, a partir de procedimentos já descritos. Percebe-se nas duas figuras, que nos estados do Mato Grosso e do Paraná tem-se uma concentração da produtividade esperada mais alta do que nos demais estados apresentados, sendo esta produtividade (próxima a 3000 quilos/hectare) considerada alta em comparação aos outros estados. Ponto crítico perceptível nas figuras é o estado do Rio Grande do Sul, que possui uma produtividade 
esperada baixa, quando comparada com outras cidades produtoras de soja no Brasil. Neste estado, as produtividades esperadas se situam, nos dois casos, abaixo dos 2000 quilos por hectare. Já nos estados de Goiás, do Mato Grosso do Sul e do Maranhão, a produtividade esperada de soja está concentrada em um valor comparativamente mediano aos demais estados, estando estas produtividades situadas entre os valores de 2500 e 3000 quilos de soja por hectare. No oeste da Bahia, oeste de Minas Gerais, e norte de São Paulo, as produtividades esperadas apresentam-se em valores médio-baixos e se situam na faixa de 2000 a 2500 quilos de soja por hectare. Comparativamente entre os dois mapas, podemos notar uma ligeira diminuição da produtividade estimada quando se considera um maior intervalo de dados. Tal fato pode ser bastante importante na precificação do seguro, uma vez que com um maior conjunto de dados, pode-se obter uma aproximação mais exata do está sendo estimado, pois um dado bastante diferente dos demais apresenta pouco impacto quanto maior for a amostra.

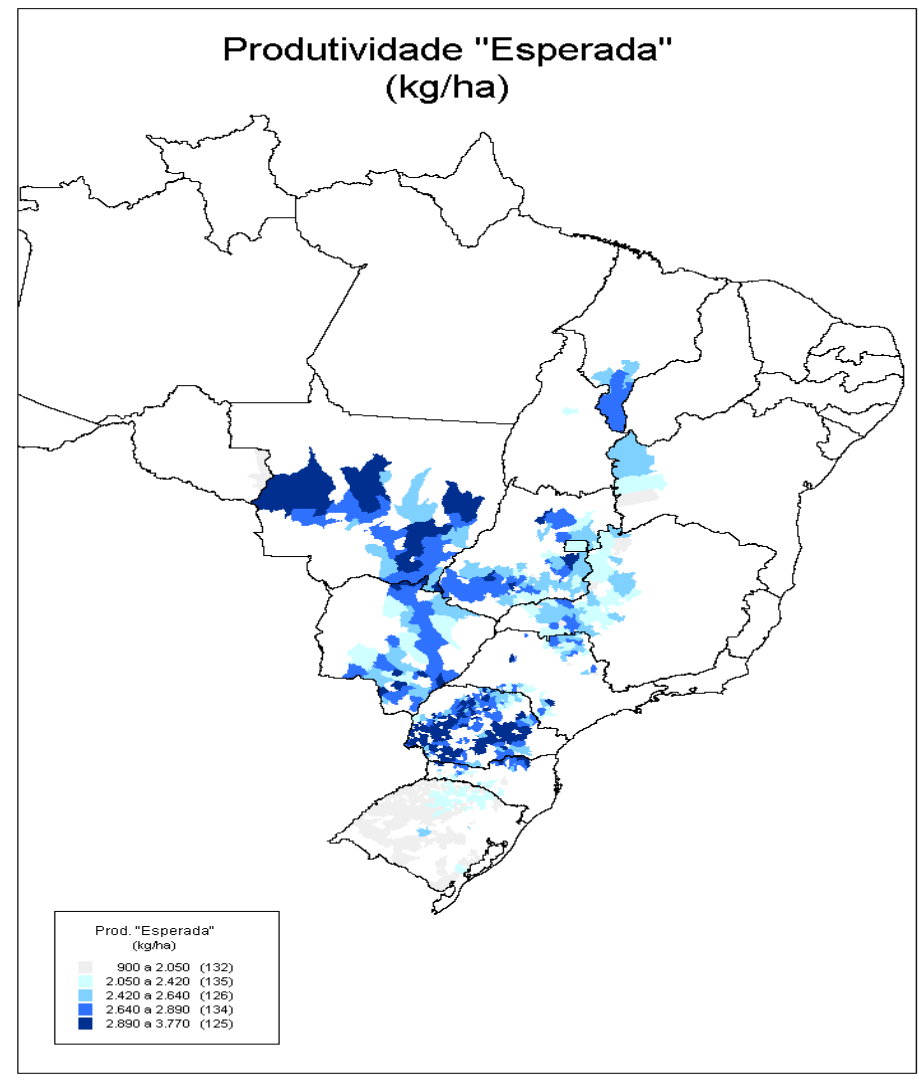

Figura 6 - Produtividade esperada de soja em quilos por hectare até 1999 


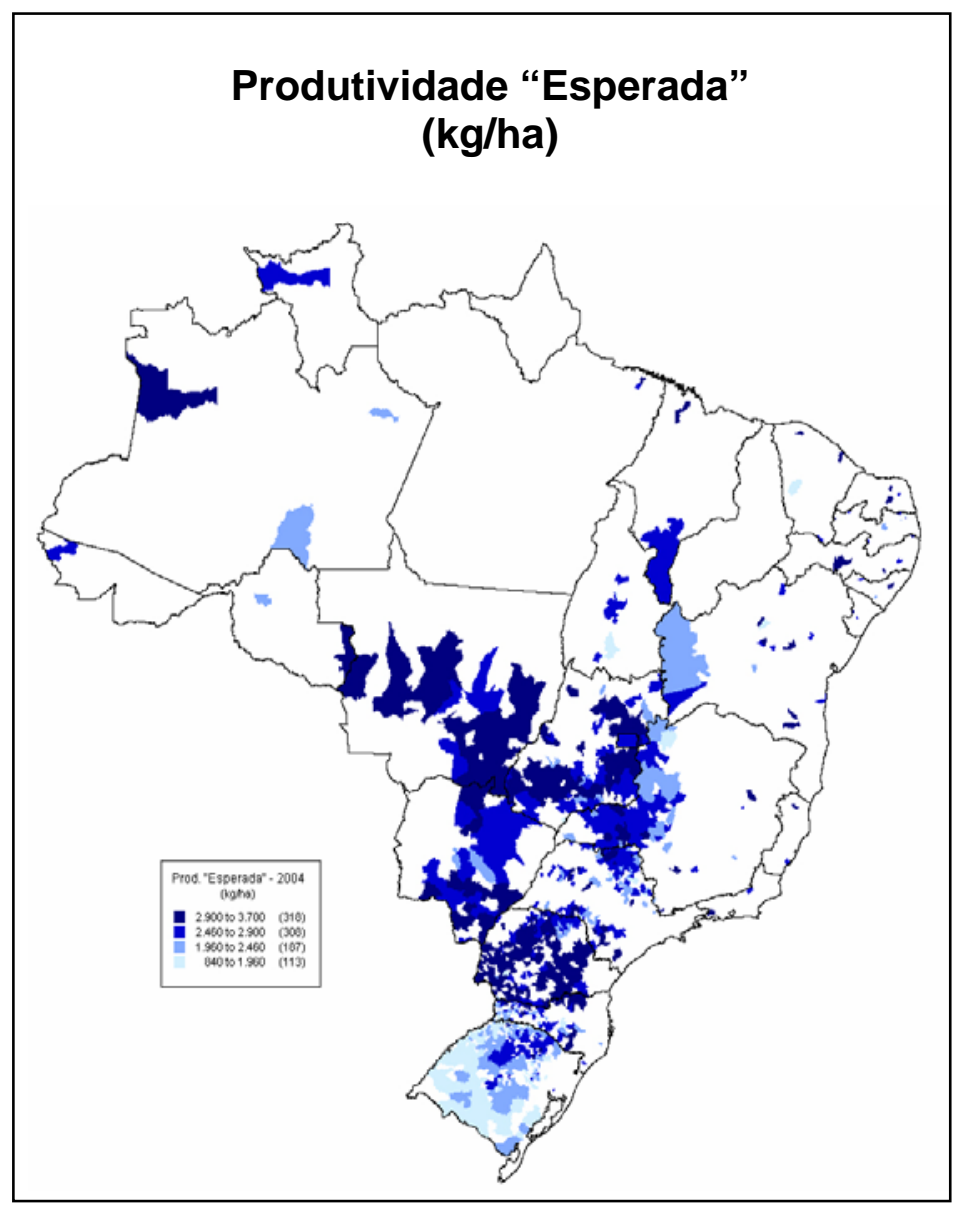

Figura 7 - Produtividade esperada de soja em quilos por hectare até 2003

As figuras 8 e 9 apresentadas em seqüência mostram a distribuição espacial dos desvios-padrão das produtividades médias obtidos através do procedimento descrito na metodologia.

Nas figuras, pode-se verificar a mesma tendência nos dois casos considerados confirmando que os "riscos" de produtividade não apresentam grande variação em intervalos curtos de tempo. Assim, fica claro destacar que nos municípios dos estados de Mato Grosso e Paraná, o desvio-padrão é relativamente mais baixo que os municípios situados em outras regiões. Na outra ponta, com resultados contrastantes, estão os municípios do estado do Rio Grande do Sul, do oeste baiano, do sul maranhense, do sul paulista, do oeste goiano e do noroeste mineiro. Algumas regiões ainda apresentam 
valores intermediários de desvio-padrão, quando comparado aos demais, como são os casos dos municípios do Mato Grosso do Sul, sul goiano, sudoeste mineiro e norte paulista. Em comum, estas duas figuras apresentam uma concentração de municípios situados entre os valores intermediários, mas elas se diferenciam no intervalo das amostras. A partir do conjunto de dados maior (até 2003) obtém-se um intervalo de desvios-padrão menores, o que pode ser entendido como uma maior precisão dos resultados obtidos, podendo-se chegar a análises e resultados finais mais próximos da realidade.

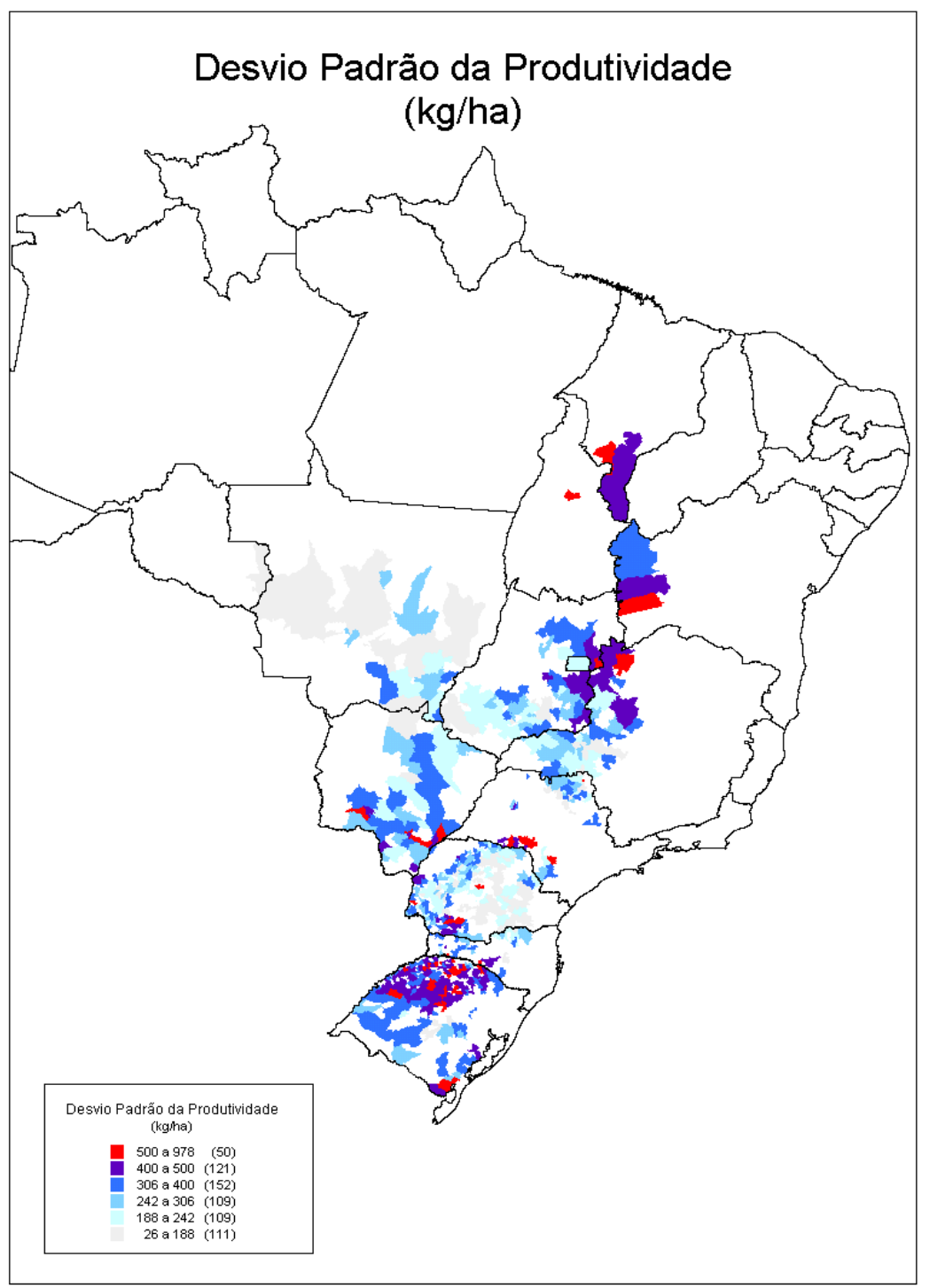

Figura 8 - Desvio padrão da produtividade até 1999 


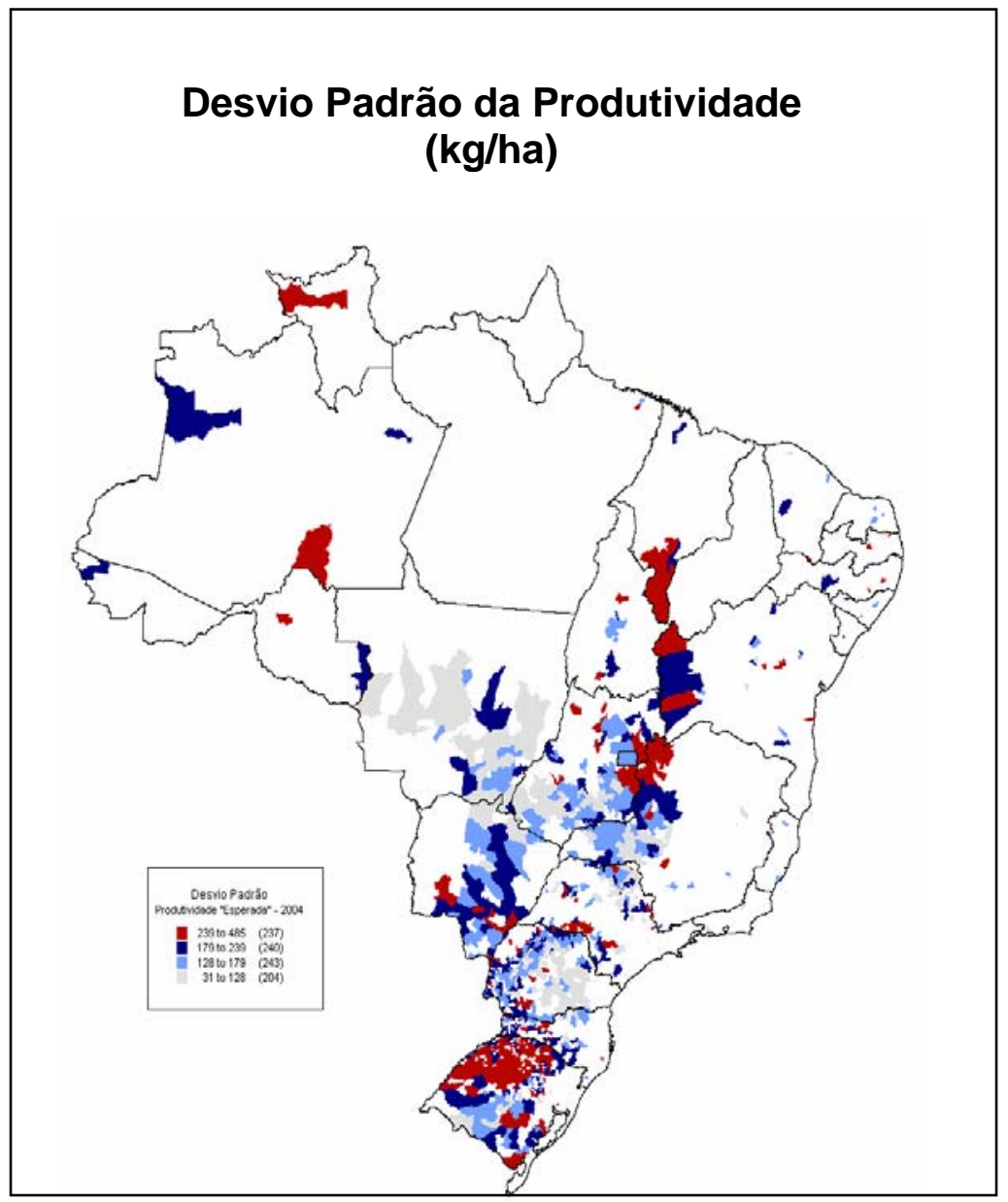

Figura 9 - Desvio Padrão da produtividade até 2003

As figuras 10 e 11, apresentadas a seguir, mostram a distribuição espacial do coeficiente de variação da produtividade. As figuras anteriores já possibilitam antecipar os resultados aqui apresentados, dado que o coeficiente de variação é definido como a razão entre o desvio-padrão e a produtividade esperada. De uma certa forma, a conjunção de produtividades mais altas e desvios-padrão mais baixos (caso de MT e PR) ou produtividades mais baixas e desvios-padrão mais altos (caso do RS) promovem uma melhor visualização da amplitude dos riscos existentes no território nacional. Nos municípios dos estados de Mato Grosso e Paraná, os valores do coeficiente de variação calculados apresentados são muito próximos, sempre abaixo de 0,1 . O oposto novamente ocorre com os municípios do estado do Rio Grande do Sul, noroeste de Minas, leste de 
Goiás, oeste da Bahia e Sul do Maranhão, que apresentam coeficientes de variação com valores entre 0,15 e 0,30. E novamente os municípios do norte de São Paulo, Mato Grosso do Sul, sul de Goiás e sudoeste de Minas ficam nos valores intermediários. Caso crítico novamente é o estado do Rio Grande do Sul, que além de possuir uma produtividade esperada mais baixa, apresenta também um desvio-padrão alto, o que acaba explicando o porque das dificuldades enfrentadas pelos produtores de soja desta região, e mesmo o grande interesse desses produtores por instrumentos de seguro agrícola.

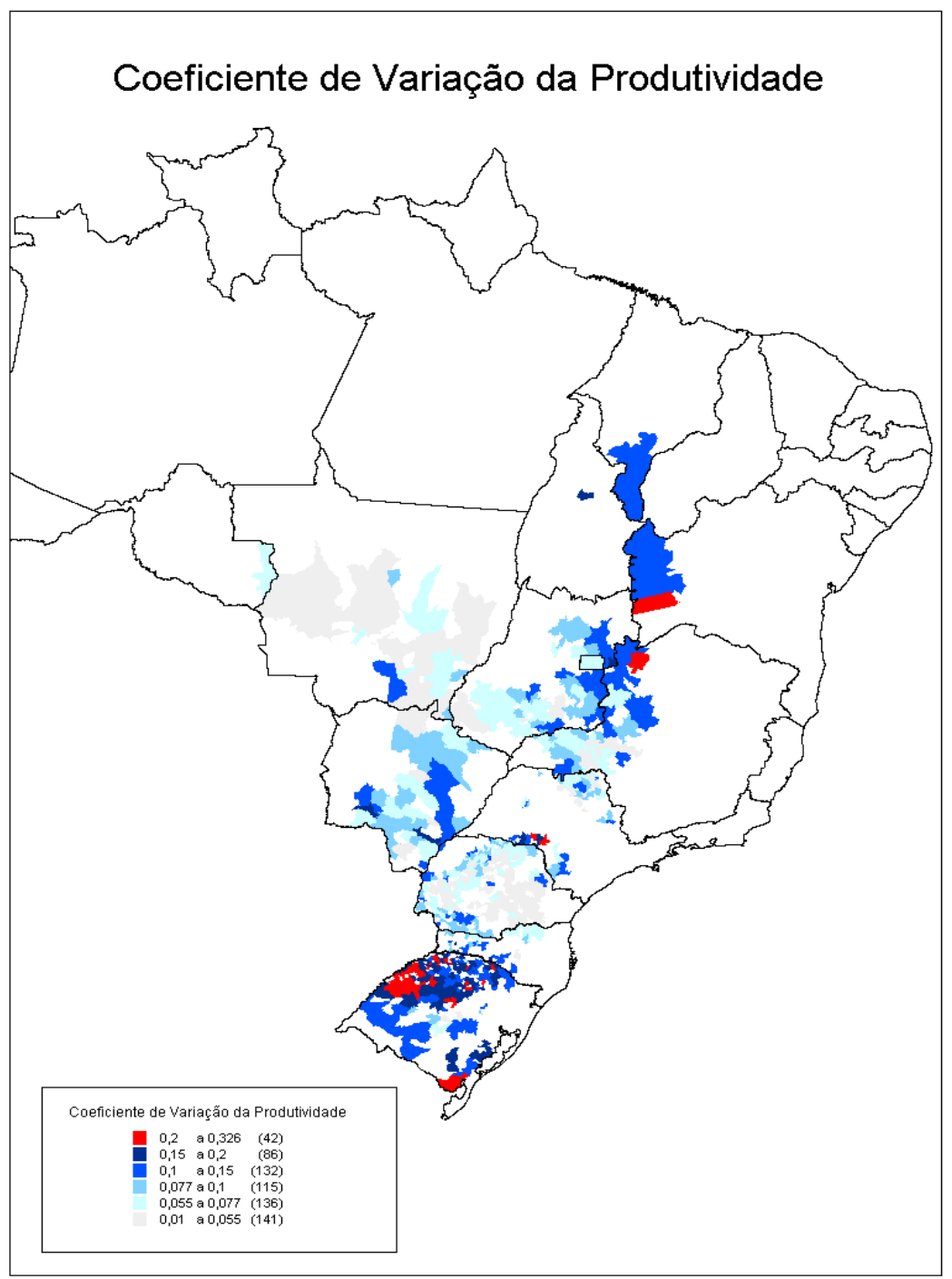

Figura 10 - Coeficiente de variação da produtividade média de soja até 1999 
E as mesmas análises realizadas anteriormente são válidas para este caso. Quando está sendo considerado um número maior de informações os resultados tornamse mais abrangentes e conseqüentemente mais precisos, o que pode ser verificado pelo fato de o coeficiente de variação ser um pouco maior quando é considerado um número mais restrito de dados. Difícil seria prever qual o número suficiente de informações que levaria a um resultado mais correto, mas importante saber que quanto maior o número de informações disponíveis para se realizar as análises menor é a probabilidade de erro.

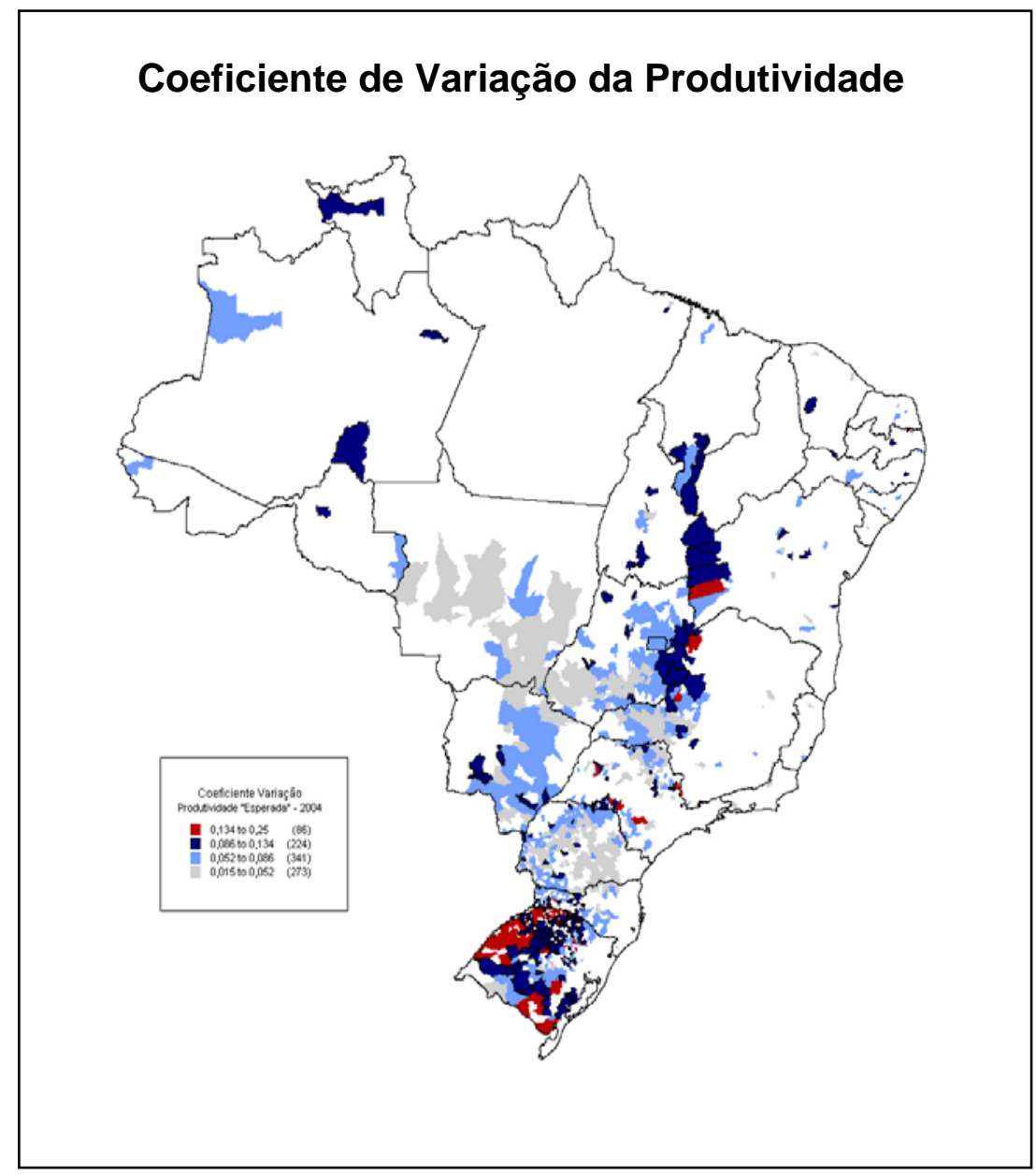

Figura 11 - Coeficiente de variação da produtividade média de soja até 2003 


\subsection{Impactos da Distância na Correlação Espacial}

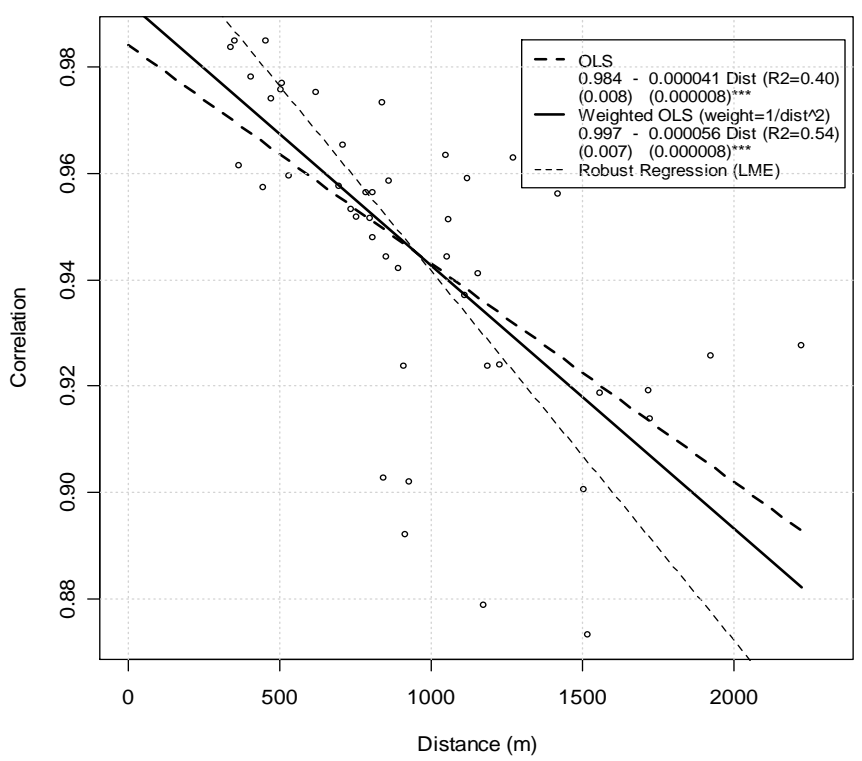

Figura 12 - Correlação entre a precipitação pluviométrica e distância

O impacto da distância na redução da correlação de parâmetros climáticos em uma escala local (1000 ha) é evidenciado em Azevedo Filho e Rolim (2001). Neste estudo os autores mostram que mesmo em distâncias relativamente curtas (entre 0 e 2000 metros) há uma significativa redução na correlação entre a precipitação medida em dois pontos distintos, separados por esta distância. Adicionalmente, esses mesmo autores mostram, utilizando modelos que simulam a produtividade de milho, que a distância tende também a reduzir a correlação entre produtividades simuladas nessa escala de análise.

Os resultados da seção anterior motivam uma análise mais detalhada dos impactos da distância na redução da correlação da produtividade segundo diferentes orientações geográficas. Para o desenvolvimento desta análise, foi necessária a estimativa da distância e correlação entre todos os municípios que pudessem satisfazer restrições definidas com relação à orientação geográfica. Foram selecionadas quatro categorias de orientação: $0^{\circ}$ a $20^{\circ}, 35^{\circ}$ a $55^{\circ}, 70^{\circ}$ a $90^{\circ}$ e $0^{\circ}$ a $90^{\circ}$ (todos). As análises foram desenvolvidas para restrições nessas quatro categorias para dois estados MT e RS. 
Esses dois estados foram escolhidos por apresentarem características bastante adversas, uma vez que mato Grosso possui uma alta produtividade com desvio-padrão baixo e o Rio Grande do Sul possui uma produtividade mais baixa e com desvio-padrão bem mais alto.

As figuras 13 e 14 apresentam estes resultados. Dentro de cada gráfico estão visíveis também os coeficientes da regressão, como a estimativa do coeficiente linear (a), do coeficiente angular (b), o desvio-padrão da regressão “dp(b)", e o valor p correspondente ao nível de significância (bilateral) associado à rejeição da hipótese da nulidade (valor do coeficiente angular $=0$ ). A critério de exemplo, no caso do Mato Grosso (0 a 20 graus), na figura 5.13, o valor p é igual a 0,32 diferente de zero, sendo desta forma não significativo para rejeitar a hipótese da nulidade.

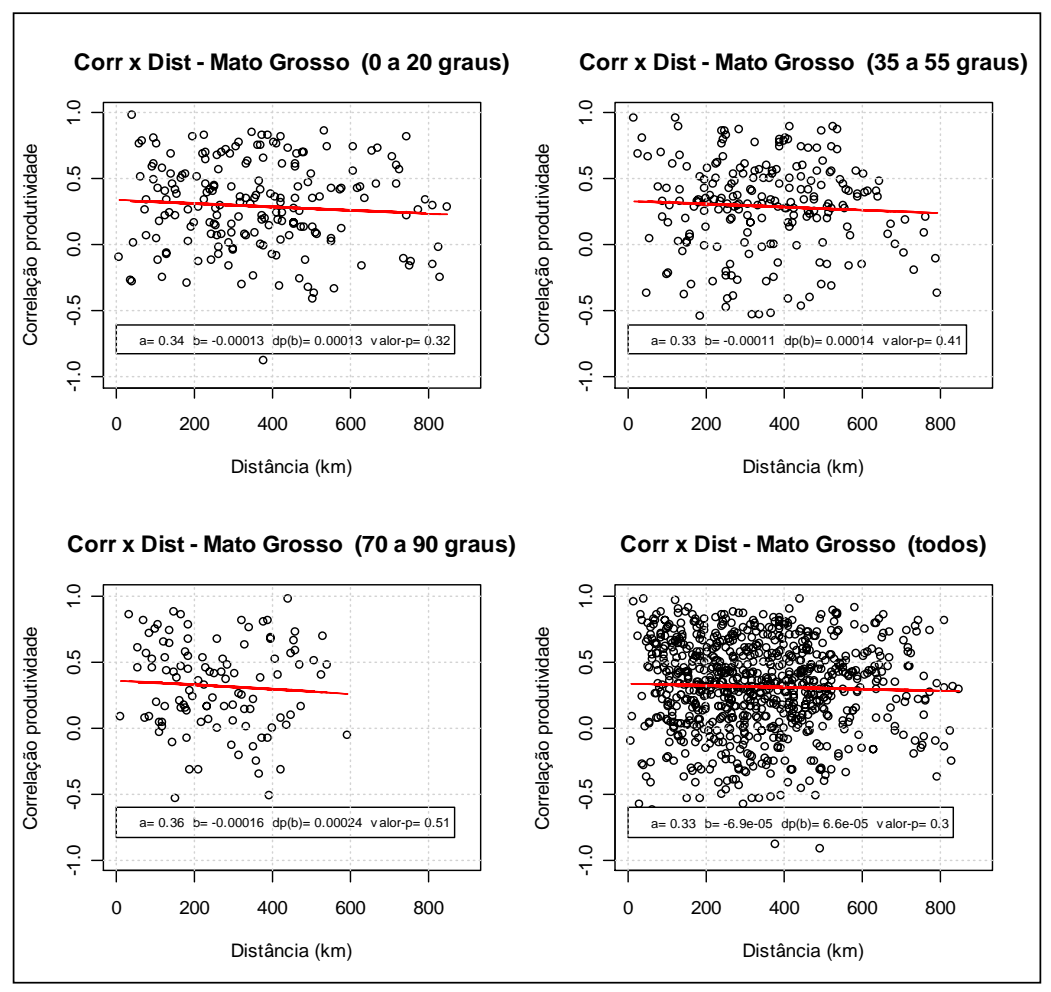

Figura 13 - MT: Relação espacial da produtividade segundo direções diferentes 


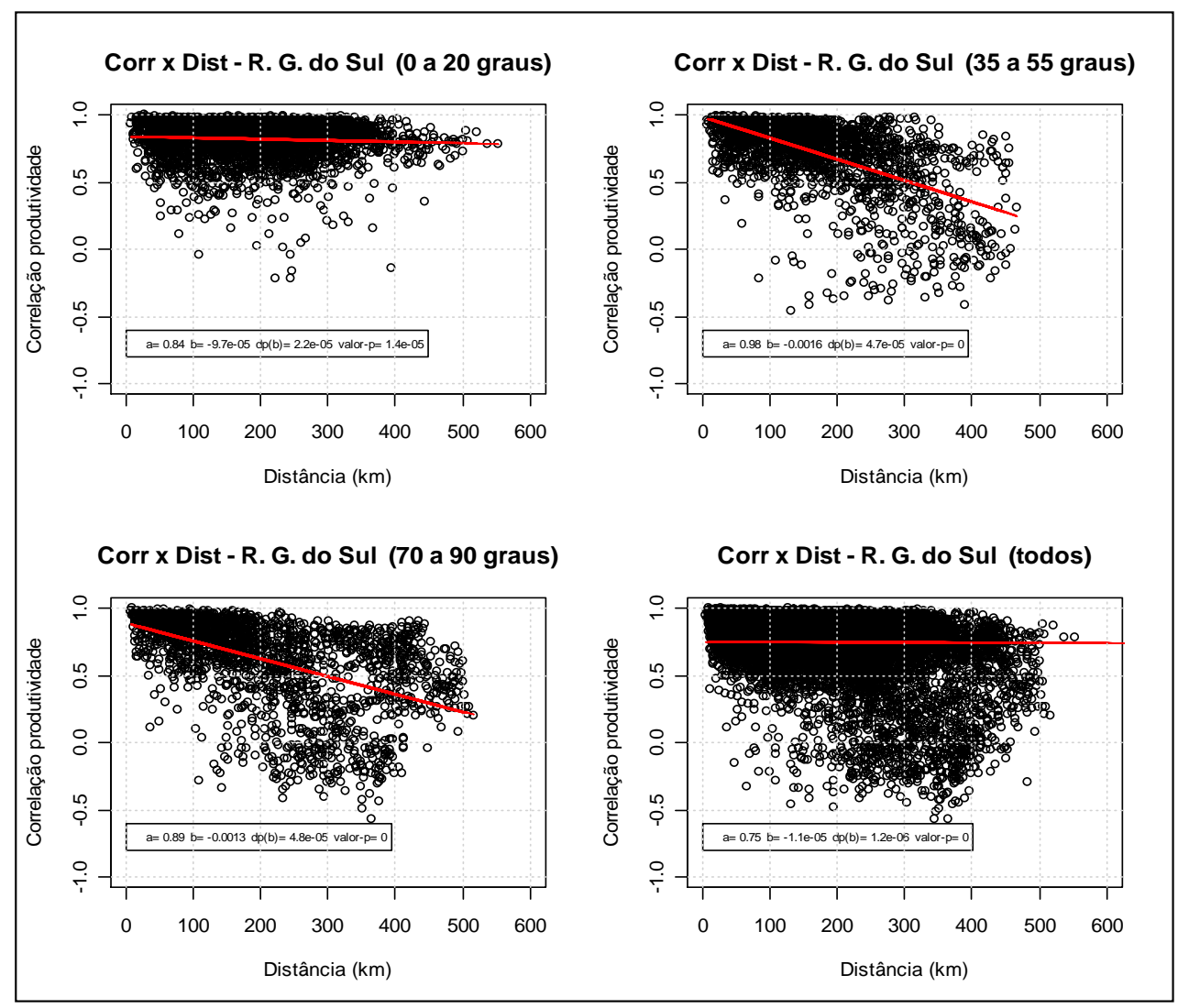

Figura 14 - RS: Relação espacial da produtividade segundo direções diferentes

\subsection{Estimativa dos prêmios de seguro baseado em índices de produtividade}

A partir dos dados disponíveis pode-se estimar, utilizando métodos estatísticos Bayesianos, os prêmios líquidos de um seguro para a soja baseado em índices de produtividade para o nível municipal. Utilizou-se para a análise e cálculo das taxas de prêmios de seguros dois métodos: no primeiro método (método A), a produtividade esperada (estimada) para o ano seguinte ao das observações foi calculada a partir da média da produtividade dos anos anteriores; no segundo método (método B), a produtividade esperada (estimada) foi calculada a partir da regressão linear das amostras anteriores. Vale destacar que este último método pode ser entendido como a forma mais correta de se prever a produtividade do ano posterior, pois considera que possam ocorrer avanços tecnológicos e tendência de crescimento na medida em que passam os anos, o 
que não é considerado quando a produtividade esperada é calculada simplesmente pela média dos anos anteriores.

Porém, importante destacar também que o modelo de previsão baseado na produtividade média dos anos anteriores ainda é o mais utilizado. Por não considerar que possa existir uma tendência de crescimento da produtividade com o passar dos anos, o modelo pode acabar superestimando os riscos existentes, não apresentando um resultado correto. Algumas evidências e exemplos de tal fato puderam ser percebidos nas análises e figuras anteriores.

Nas duas figuras, apresentam-se a distribuição espacial destes prêmios calculados a partir destes dois modelos. A figura 15 representa as taxas de prêmios líquidos de seguros calculados a partir do modelo A. Pode-se notar que para os municípios localizados no Estado do Rio Grande do Sul, do Mato Grosso do Sul e da região CentroOeste, a taxa de prêmio é mais alta do que para as outras regiões, confirmando que essas regiões estão mais propícias a volatilidade em suas produtividades do que nas demais regiões que apresentam taxas de prêmios mais baixas. Esta volatilidade da produtividade está atribuída ao maior risco climático ao qual estas áreas estão sujeitas.

A figura 16 seguinte representa o prêmio líquido de seguro calculado a partir do modelo B definido acima. Pode-se notar a partir da figura, que a concentração dos municípios continua localizada no Estado do Rio Grande do Sul, por ainda estar sujeito às maiores variabilidades climáticas, mas diferente da análise anterior, a taxa de prêmio do modelo $\mathrm{B}$ está localizada em patamares inferiores às taxas calculadas a partir do modelo A. Como colocado anteriormente, o cálculo das taxas de prêmios a partir do modelo A superestima os riscos existentes, resultando assim em prêmios maiores do que quando calculados a partir do modelo B que calcula a produtividade estimada a partir de uma regressão. 




Figura 15 - Taxas de prêmios líquido de seguros a partir do modelo A 


\section{Taxa de Prêmio de Seguro Regressão}

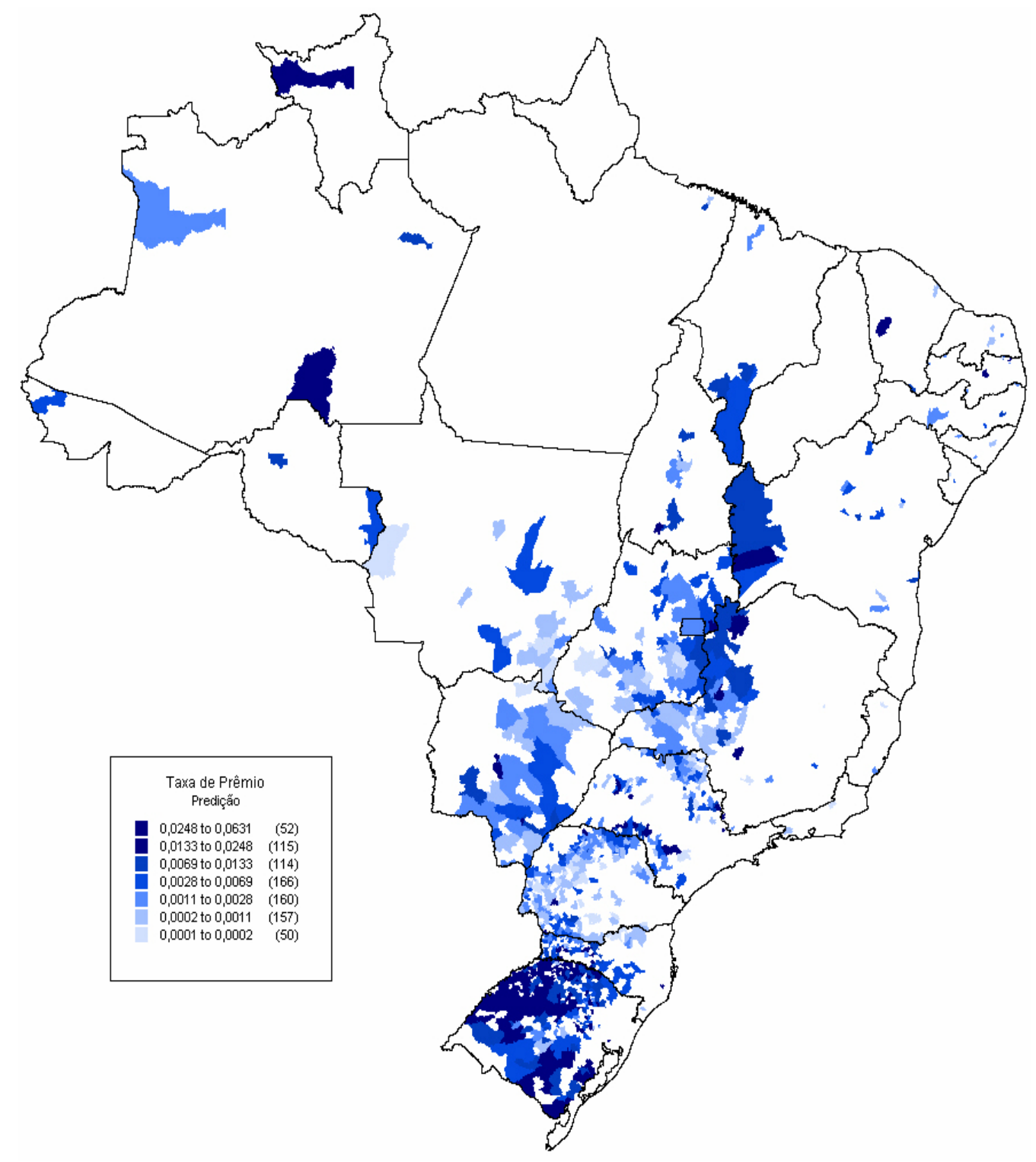

Figura 16 - Taxas de prêmios líquido de seguros a partir do modelo B 
Apenas para poder realizar uma comparação entre os dados e também para corroborar a análise realizada acima, o mesmo exercício para a precificação do prêmio do seguro foi realizado para a cultura do milho. Foram novamente utilizados dois modelos, considerando a produtividade estimada para o ano posterior a partir da média e da predição (regressão) das produtividades anteriores. A cultura do milho foi utilizada para realizar tal comparação, simplesmente porque é uma cultura que atinge todo o território nacional, e por isso mesmo apresenta uma grande diferenciação de produtividade nas diversas regiões do Brasil. Dos municípios analisados considerando apenas aqueles que apresentaram dados completos de 1990 a 2003 obteve-se um total de 2358 cidades, bem superior aos 841 municípios analisados considerando-se a cultura do milho. Destaque para o fato de as taxas de prêmio de seguro serem maiores nos estados do Norte, do Nordeste e no Rio Grande do Sul e mais baixas na região Centro-Sul do Brasil.

Justamente por englobar um maior número de municípios com maior volatilidade entre suas produtividades, as taxas de prêmios de seguro também apresentam uma maior diferenciação entre elas, mas apresentam uma característica em comum com a cultura da soja. Quando o cálculo das taxas de prêmios de seguro ocorre a partir da produtividade esperada obtida pela média histórica entre as produtividades, o resultado obtido é superior a quando as taxas são calculadas a partir da produtividade esperada obtida a partir da predição.

Novamente, podemos entender que o cálculo do seguro a partir da produtividade estimada obtida através da regressão gera um resultado mais eficaz por apresentar uma menor volatilidade entre as taxas, diminuindo assim as hipóteses de prováveis erros.

Deve ficar claro também, que o objetivo desta análise é de apenas comparar os resultados primários do prêmio líquido de seguro do milho com a soja, não sendo importante aqui realizar um estudo detalhado da cultura do milho. 


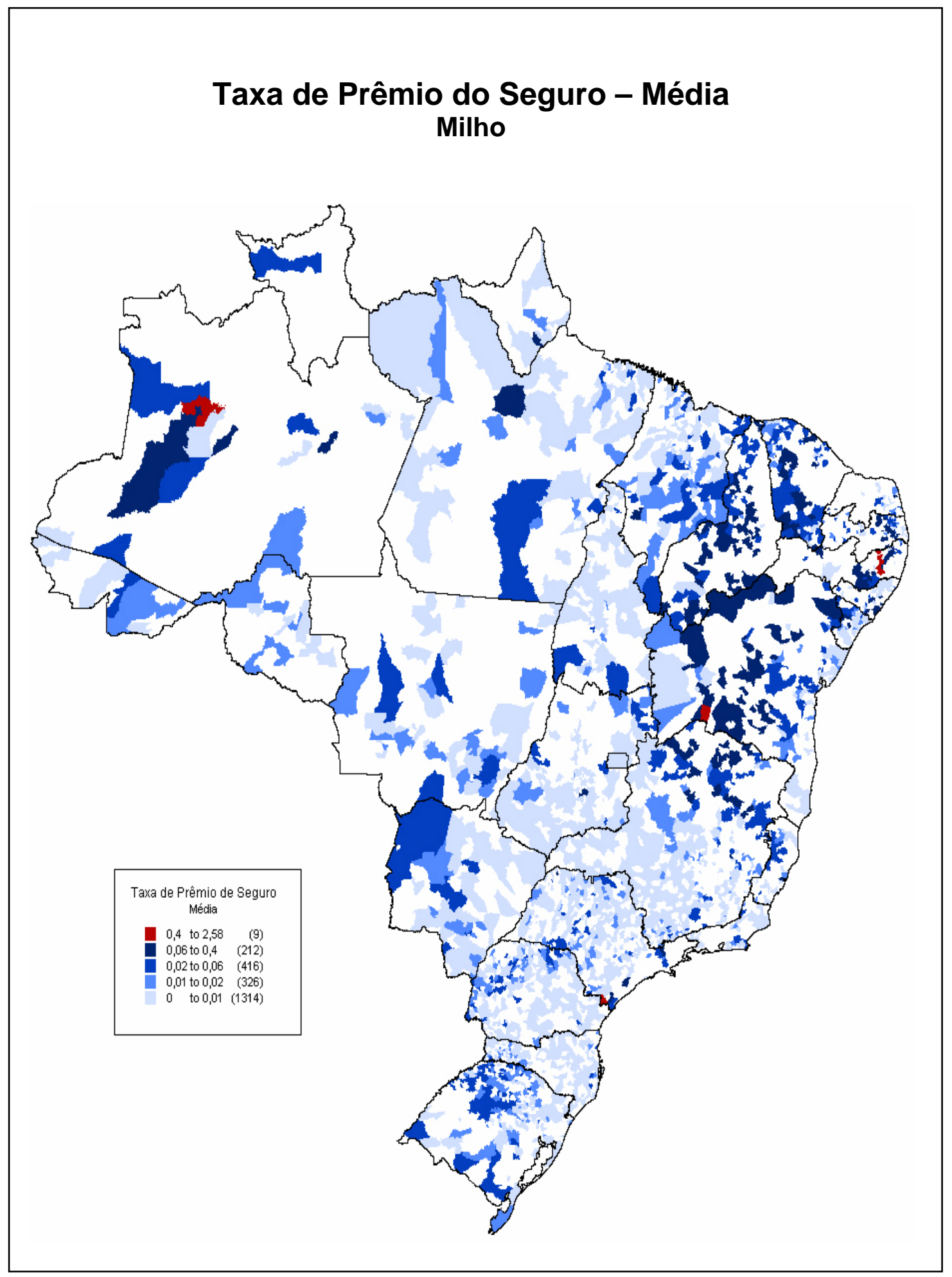

Figura 17 - Taxas de prêmios líquido de seguros a partir do modelo A para o milho 


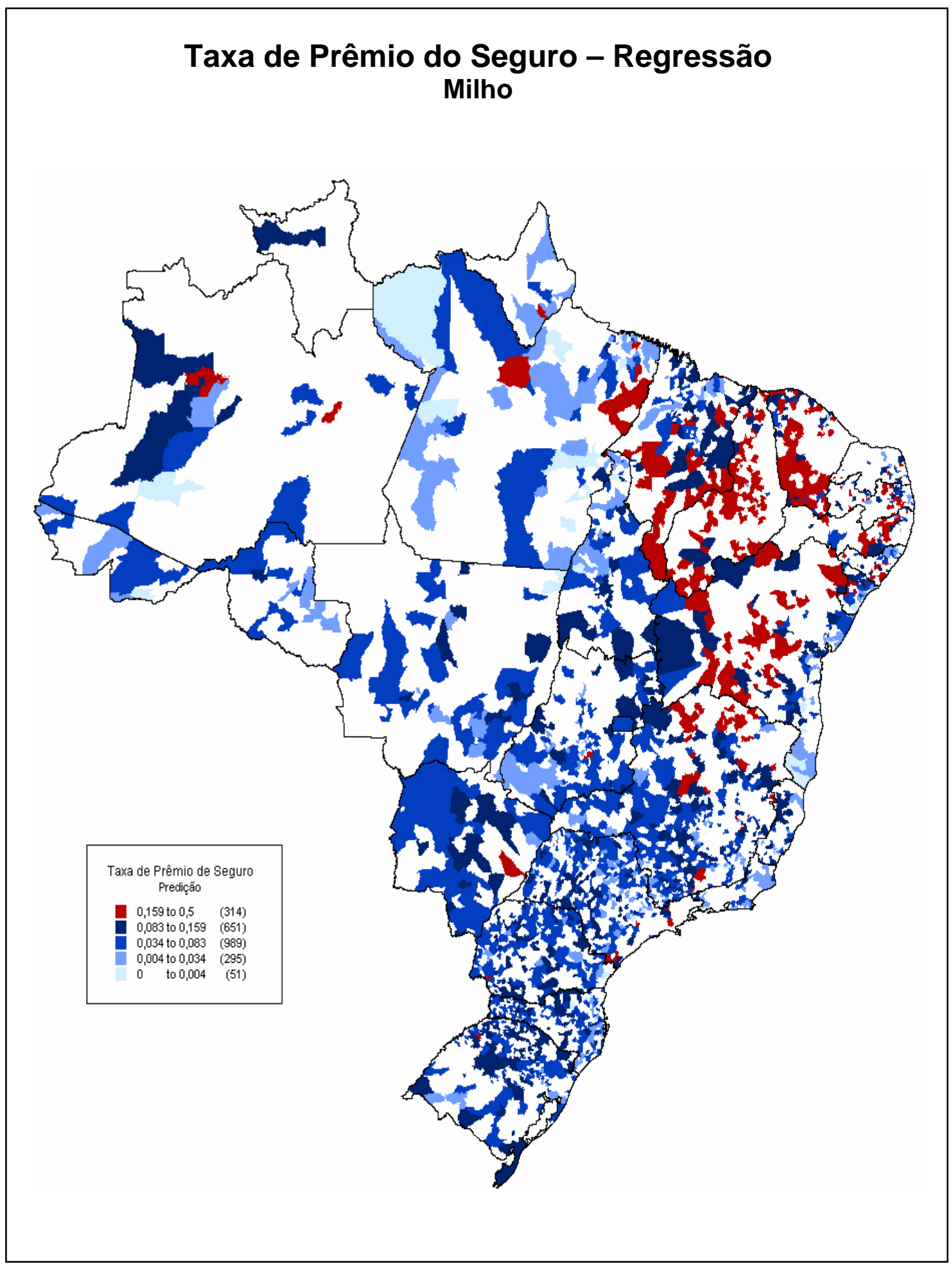

Figura 18 - Taxas de prêmios líquido de seguros a partir do modelo B para o milho 
As análises a seguir estão detalhadas para cada estado considerado na pesquisa, a fim de ter conhecimento da distribuição das taxas dos prêmios de seguro numa mesma região, e com isso saber para áreas mais próximas, a volatilidade entre as taxas. $\mathrm{Na}$ figura 19 abaixo, no entanto, podemos verificar a distribuição dos prêmios para todos os municípios analisados na pesquisa, ou melhor dizendo, considerando todo o Brasil. Verifica-se uma grande concentração de municípios que apresentam um prêmio de seguro baixo, ou seja, que se situam abaixo de $2 \%$ e apresentam riscos de produtividades menores, em conjunto com uma menor quantidade de municípios que se situam no outro extremo apresentando taxas mais altas.

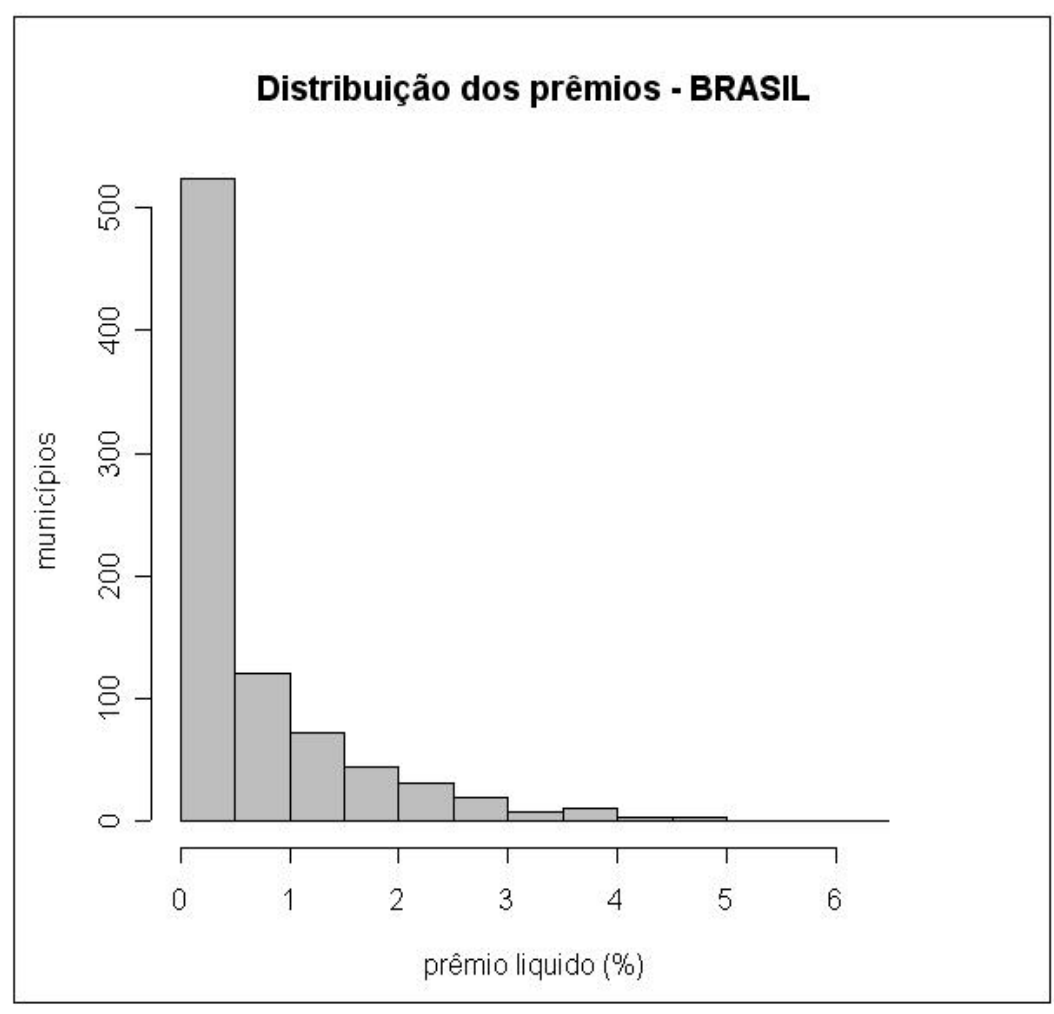

Figura 19 - Histograma da distribuição dos prêmios do seguro para os municípios analisados

Considerando cada estado individualmente, pode-se notar através das figuras abaixo que para estados que apresentam índices altos de produtividade (em relação aos demais municípios brasileiros) como é o caso de Mato Grosso do Sul, Mato Grosso, 
Goiás e Paraná, o prêmio do seguro está concentrado em valores mais baixos, praticamente abaixo de $1,5 \%$ do valor total assegurado, devido principalmente aos menores riscos climáticos e de queda na produtividade aos quais estão sujeitos. Destaque nestes resultados para o Estado do Mato Grosso que apresenta taxas de seguros bem baixas, ficando a totalidade dos municípios analisados com taxas de prêmios abaixo de 0,5\%. Desta forma, para essas regiões, é mais viável ou mais "barato" para os produtores realizar o seguro de sua propriedade, apesar deste preço pago pelo seguro ainda ser considerado alto em comparação a outras ferramentas de administração de riscos.

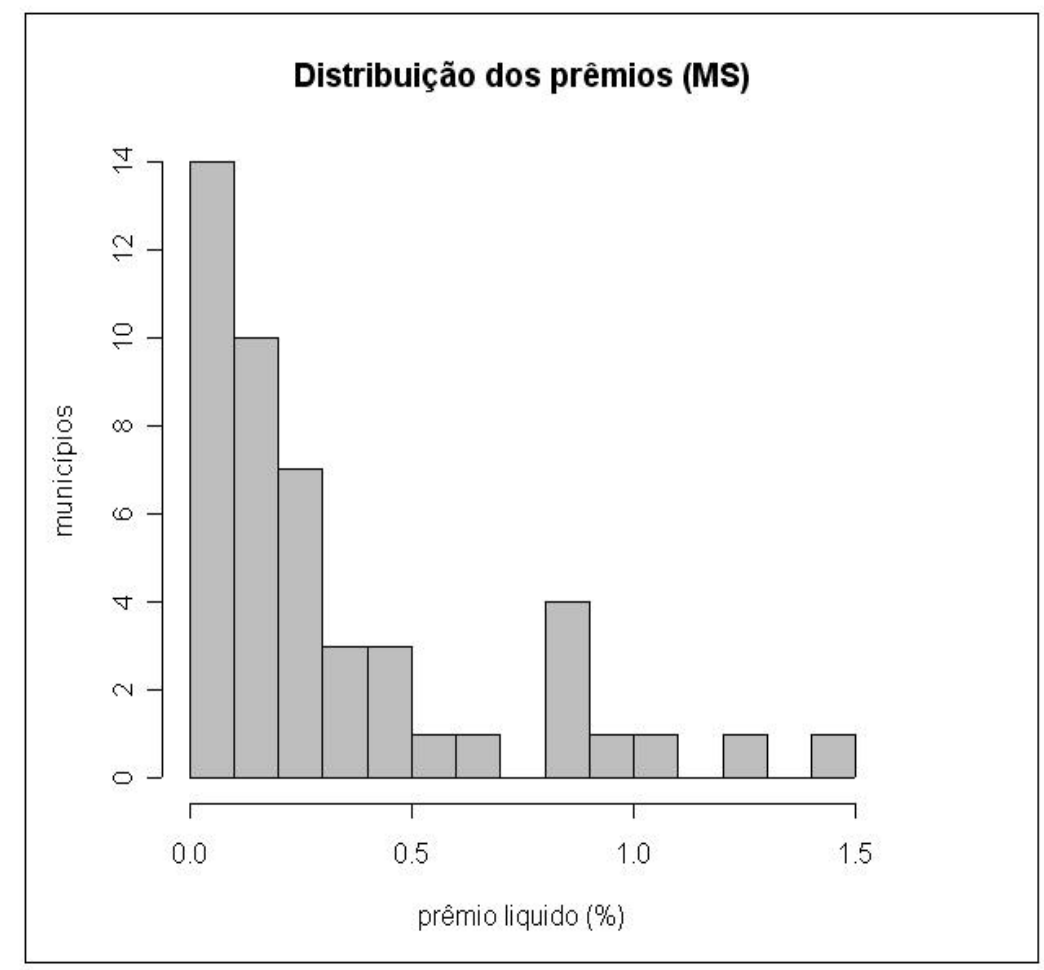

Figura 20 - Histograma da distribuição dos prêmios do seguro para Mato Grosso Do Sul 


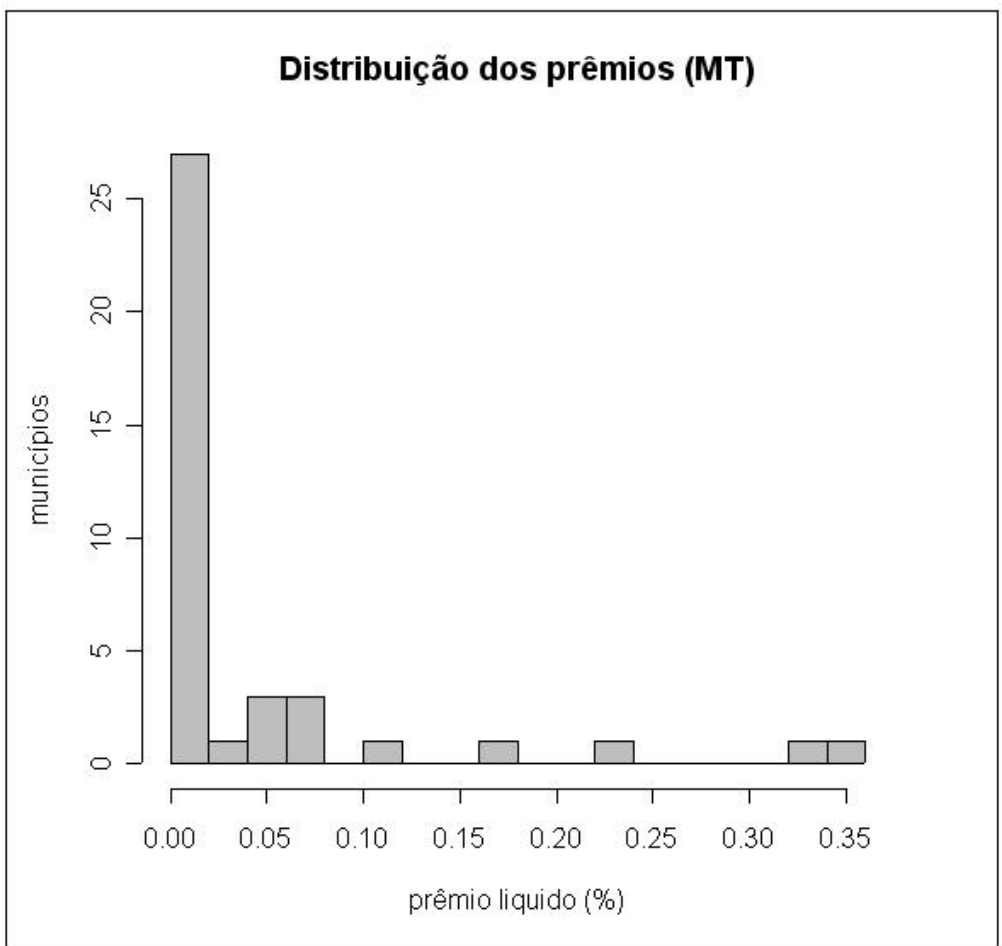

Figura 21 - Histograma da distribuição dos prêmios do seguro para Mato Grosso

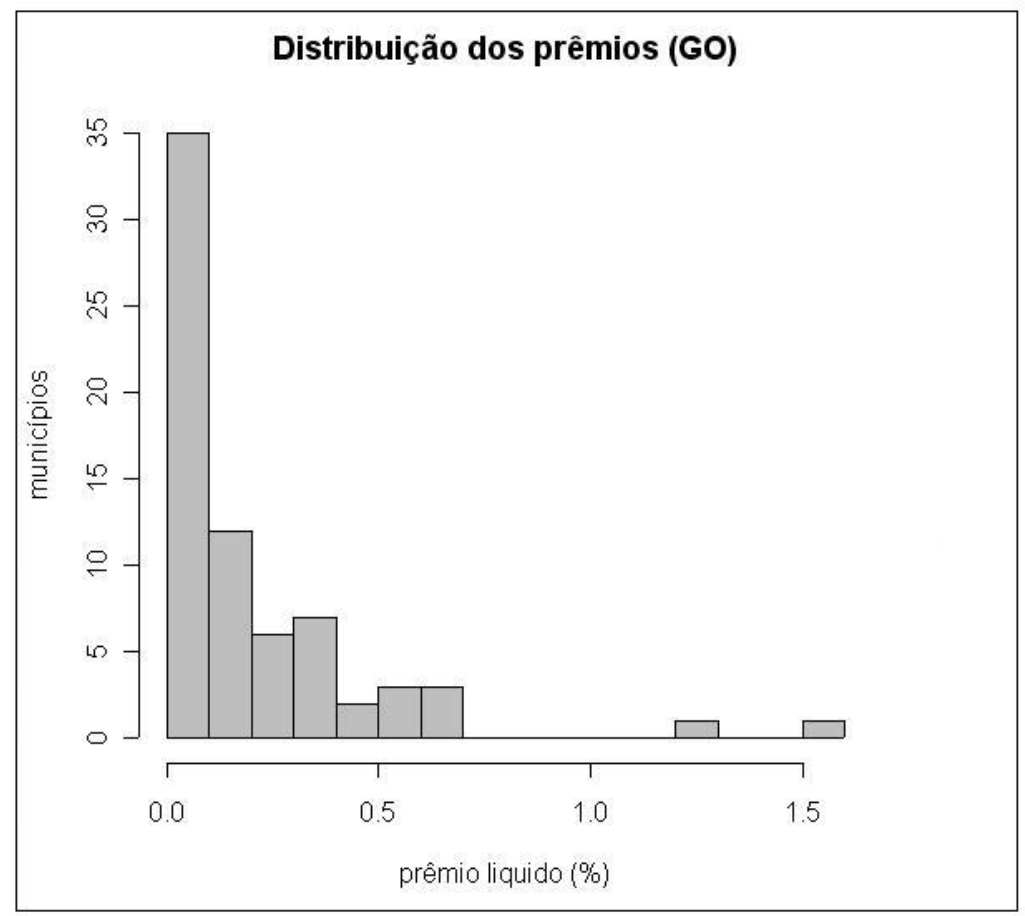

Figura 22 - Histograma da distribuição dos prêmios do seguro para Goiás 


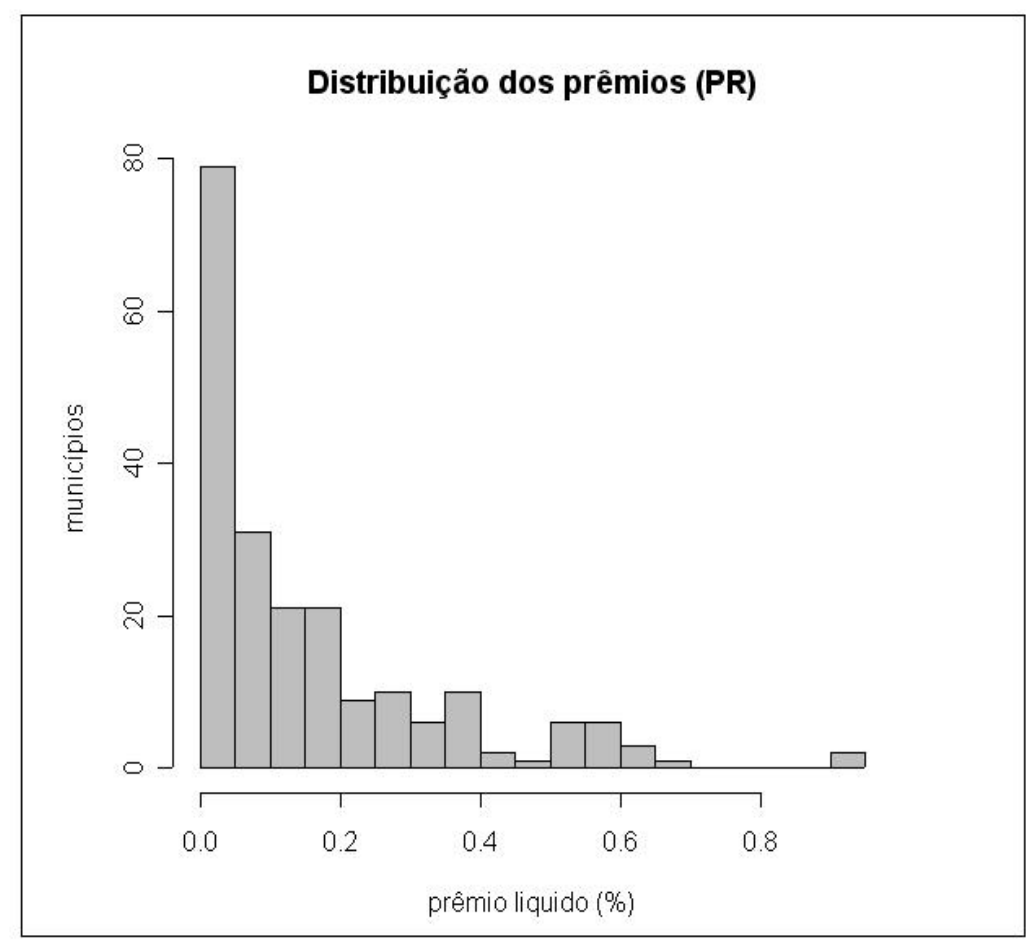

Figura 23 - Histograma da distribuição dos prêmios do seguro para Paraná

Para o Estado de São Paulo, verificam-se taxas de prêmios bastante dispersas, variando de municípios que apresentam taxas próximas a $0 \%$ (bastante baixas) para municípios que apresentam taxas mais altas chegando a valores próximos de $3 \%$. Apesar desta dispersão, é importante destacar que a maioria dos municípios está concentrada em valores inferiores, principalmente abaixo de $1 \%$, pelo fato de o estado estar situado em uma "zona climática" de baixa variação, o que sugere uma produtividade razoavelmente constante ao longo dos anos, diferente de outras regiões como o caso do Rio Grande do Sul que apresenta uma volatilidade climática maior.

O mesmo estudo realizado para o caso do Estado de São Paulo pode ser aplicado para o Estado de Minas Gerais, que também apresenta taxas bastante dispersas e que, apesar de possuir um município com taxa de prêmio acima de $3 \%$, a grande maioria concentra-se no patamar abaixo de 1\% ficando apenas dois municípios analisados na pesquisa com taxas acima de $2 \%$. 


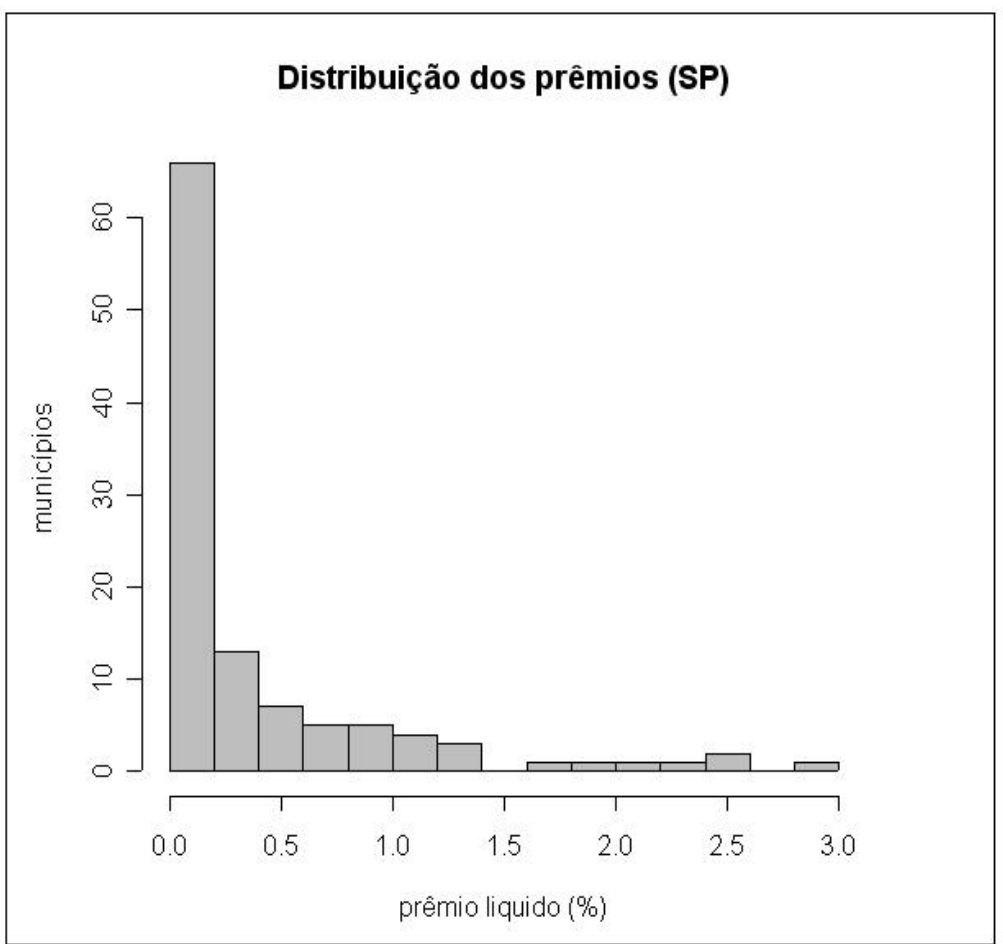

Figura 24 - Histograma da distribuição dos prêmios do seguro para São Paulo



Figura 25 - Histograma da distribuição dos prêmios do seguro para Minas Gerais 
Dois outros estados que apresentam características de prêmios bastante semelhantes, são Santa Catarina e Rio Grande do Sul. Devido à grande quantidade de municípios estudados para esses dois estados já era esperado inicialmente que ocorresse uma grande dispersão entre as taxas, constatando a diferença entre as produtividades na região. Apesar de apresentarem para alguns municípios as taxas de prêmios mais altas de todos os estudados, chegando a mais de $6 \%$ do total assegurado, verifica-se uma grande concentração em patamares inferiores, no caso do Rio Grande do Sul abaixo de 4\% e de Santa Catarina abaixo de 2\%. Porém, comparativamente aos demais estados, estas taxas são consideradas altas o que confirma as análises acima de que estas regiões apresentam maior variabilidade climática, representando assim maiores riscos. Importante destacar para os casos onde a dispersão dentro de um estado é alta que a diversificação entre os municípios pertencentes a esse ajudaria a reduzir o prêmio do seguro como um todo, o que será exemplificado mais a frente.



Figura 26 - Histograma da distribuição dos prêmios do seguro para Rio Grande Do Sul 


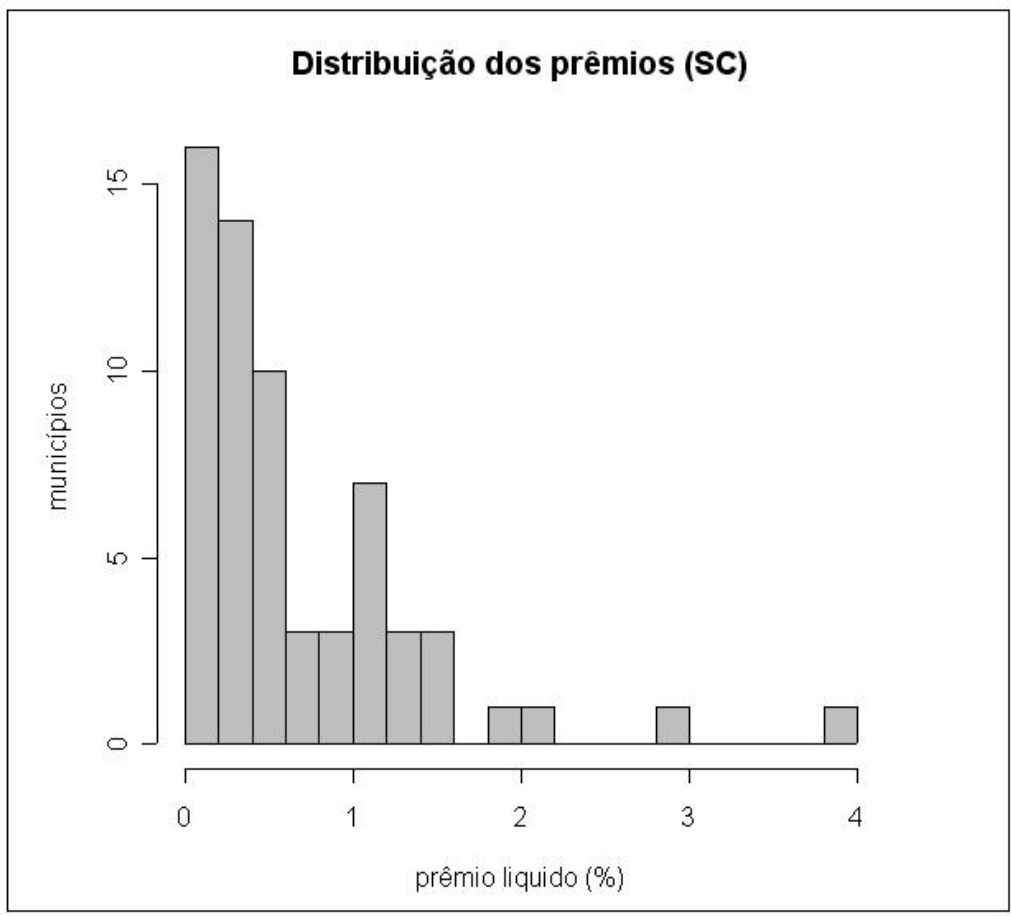

Figura 27 - Histograma da distribuição dos prêmios do seguro para Santa Catarina

Os dois últimos estados estudados apresentam suas particularidades e semelhanças também. Pelo fato de possuírem poucos municípios considerados, a análise do prêmio do seguro ficou um pouco prejudicada pois não é possível assegurar em que níveis estão concentrados todos municípios, mas aqueles que foram considerados no estudo possuem taxas de prêmios nos patamares inferiores a $2 \%$, o que representa taxas altas em comparação a alguns estados considerados na pesquisa por se situarem em regiões com "variações climáticas" mais intensas do que os anteriormente citados. 


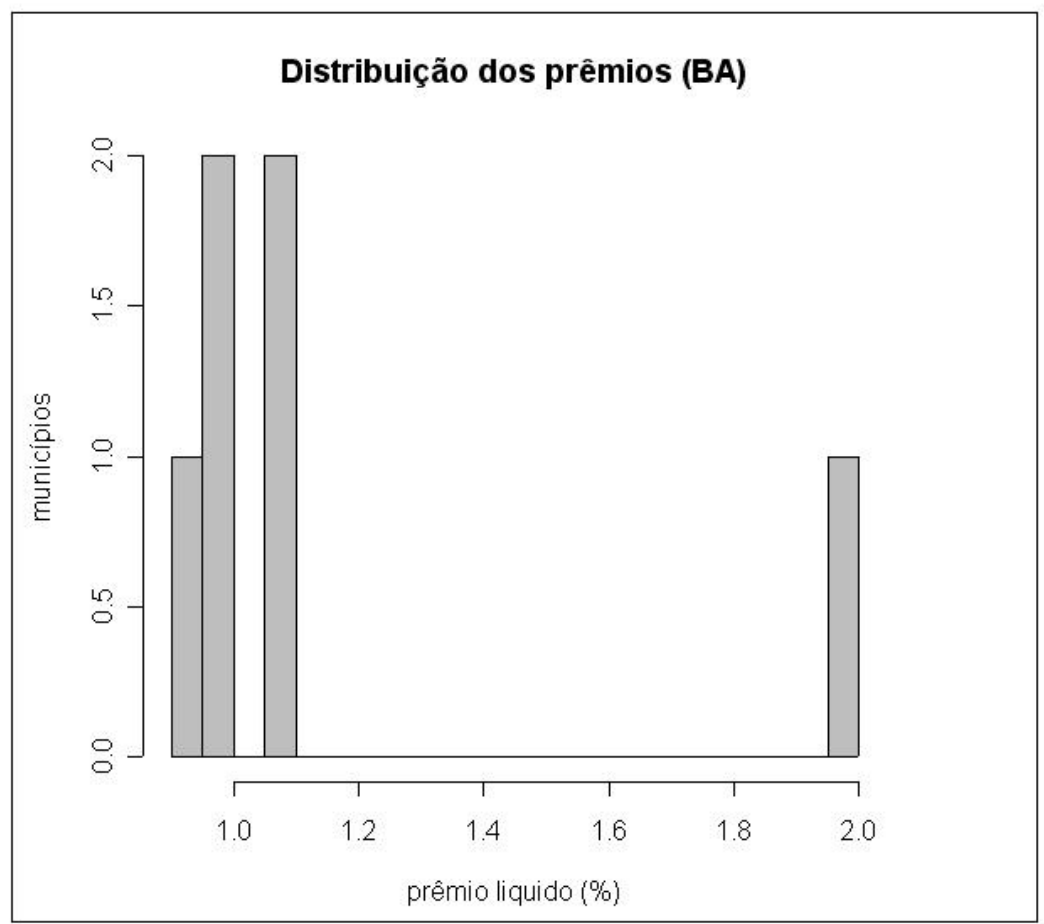

Figura 28 - Histograma da distribuição dos prêmios do seguro para Bahia

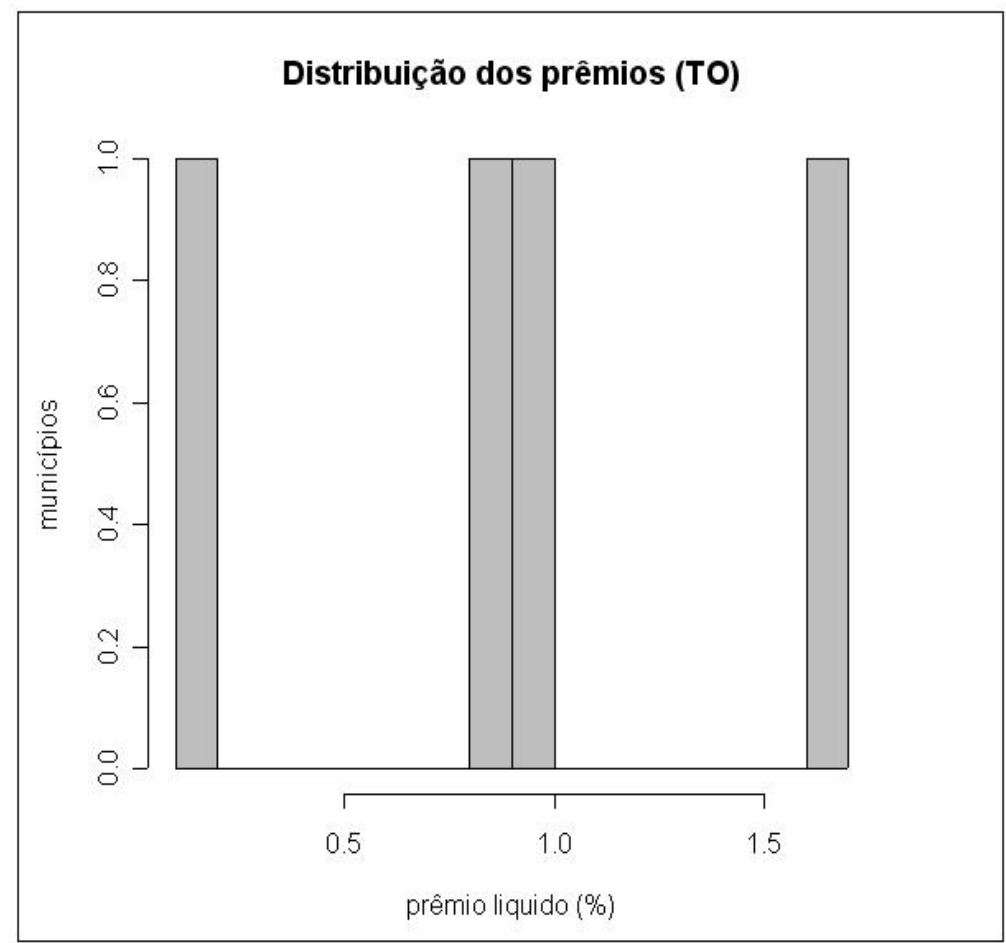

Figura 29 - Histograma da distribuição dos prêmios do seguro para Tocantins 


\subsection{Estimativa dos prêmios de seguro utilizando diversificação espacial}

Nesta próxima seção serão realizadas algumas aplicações práticas para o cálculo do prêmio líquido de seguros para contratos que envolvem áreas isoladas e áreas diversificadas espacialmente mas que estão incluídas em um mesmo contrato. No caso, apenas um exemplo será apresentado com maiores detalhes, mas ao final da análise deste será apresentado uma tabela apresentando algumas simulações de diversificação entre áreas distintas.

Nesta exemplificação, consideramos os dados de produtividade de três municípios: Rondonópolis (MT), Itambé (PR) e Barreiras (BA). A partir dos dados obtidos nas análises anteriores, temos que a taxa de prêmio líquido de seguro para cada município considerado individualmente é: 0,88 \% para Rondonópolis, 3,78 \% para Itambé e 5,78 \% em Barreiras. Se um mesmo produtor quisesse realizar o seguro nestas três áreas individualmente, pagaria uma taxa média de prêmio de seguro de 3,48 \%.

Considera-se agora que estes três municípios seriam considerados em conjunto, ou seja, o produtor estaria optando pela diversificação de sua produção nestas três áreas, sendo esses considerados em um único contrato. Através da correlação das produtividades entre eles, e considerando que a produção estaria igualmente distribuída (1/3 em cada propriedade) representando o conjunto como sendo uma única área foi possível chegar em uma taxa de prêmio de seguro de 2,26\%. Portanto, com a produção diversificada, o produtor estaria pagando uma taxa média de prêmio de seguro de $2,26 \%$, que está abaixo do valor médio da taxa considerando os municípios individualmente que é de 3,48\%. Para este caso específico, há uma redução de aproximadamente $35 \%$ no prêmio do seguro utilizando-se a diversificação. Desta forma, a redução de riscos propiciada pela diversificação espacial pode ser utilizada para justificar taxas mais baixas de prêmios líquidos de seguros conforme apresentado acima. 
A tabela 1 abaixo apresenta alguns resultados obtidos em algumas simulações de diversificação entre áreas, considerando a mesma modelagem do exemplo descrito acima. As simulações foram realizadas a fim de demonstrar potenciais ganhos da diversificação espacial, considerando municípios de diferentes estados (caso da Simulação 1 e 2) e municípios pertencentes a um mesmo estado (caso da Simulação 3 e 4) demonstrando que esse gerenciamento de risco pode apresentar ganhos realizando a diversificação entre áreas que não apresentam uma distância física muito grande como já apresentado em sessão anterior. Na coluna intermediária da tabela estão representadas as taxas de prêmios de seguro individuais e as médias entre elas, e na coluna da direita representadas as taxas de prêmios de seguro considerando as áreas diversificadas entre si, mas fazendo parte de um mesmo contrato de seguro.

Tabela 1. Taxas de Prêmios de Seguro com e sem diversificação espacial da propriedade.

\begin{tabular}{lcc}
\hline & \multicolumn{2}{c}{ Taxas de Prêmios de Seguro } \\
\hline Simulação 1 & Individual & Diversificado \\
Rondonópolis (MT) & $0,89 \%$ & \\
Itambé (PR) & $3,78 \%$ & $2,26 \%$ \\
Barreiras (BA) & $5,79 \%$ & \\
MÉDIA & $3,49 \%$ & $2,26 \%$ \\
& & \\
Simulação 2 & Individual & Diversificado \\
Campos Novos Paulista (SP) & $1,73 \%$ & \\
Cuz Alta (RS) & $2,63 \%$ & $1,21 \%$ \\
Sorriso (MT) & $1,31 \%$ & \\
MÉDIA & $2,22 \%$ & $1,21 \%$ \\
& & \\
Simulação 3 & Individual & Diversificado \\
Erechim (RS) & $4,67 \%$ & $3,46 \%$ \\
Santo Augusto (RS) & $4,23 \%$ & \\
Redentora (RS) & $3,18 \%$ & $3,46 \%$ \\
MÉDIA & $4,03 \%$ & \multirow{2}{*}{ Diversificado } \\
Simulação 4 & Individual & \\
Torixoréu (MT) & $2,95 \%$ & $1,54 \%$ \\
Paranatinga (MT) & $1,58 \%$ & $1,54 \%$ \\
Alto Taquari (MT) & $2,55 \%$ & \\
MÉDIA & $2,36 \%$ &
\end{tabular}




\section{CONCLUSÕES}

O trabalho introduziu inicialmente uma visão geral sobre os riscos na agricultura e suas potenciais ferramentas de administração destes que afetam diretamente a renda do proprietário, que por sua vez não tem muito controle sobre as oscilações de preço mas possui maneiras de controlar a produtividade de sua produção.

Apresentados as ferramentas existentes para o gerenciamento dos riscos, partiuse para o desenvolvimento do foco principal do trabalho que foi o de desenvolver os potenciais ganhos que a diversificação espacial da propriedade agrícola apresenta para diminuir os riscos de perdas na produtividade agrícola e de que forma esta contribui para a redução do prêmio do seguro agrícola. Como anteriormente demonstrado no desenvolver no trabalho, as ferramentas de administração dos riscos agrícolas podem ser desenvolvidas de maneira conjunta sempre beneficiando um maior controle, tanto de produção como de renda, por parte do produtor.

Deve ficar claro que não foi objetivo do presente trabalho calcular o valor monetário do preço do seguro, tampouco o da renda do produtor, não se preocupando assim com os valores da soja nas diversas regiões do Brasil. O objetivo foi o de

simplesmente apresentar como as taxas dos prêmios do seguro agrícola podem se diferenciar entre as regiões produtoras e quais os reais ganhos da diversificação espacial como medida de administração de riscos.

Com todo o material que seria utilizado para as análises em mãos, realizou-se a caracterização geral da produtividade e das medidas de risco, apresentando as análises 
realizadas em programas estatísticos (no caso MapInfo) em forma de mapas que melhor visualizam e ajudam interpretar os resultados. Seguindo, a distribuição espacial da correlação para municípios selecionados, forneceu dados suficientes para verificarmos que o fator clima tem muito mais efeito nas produtividades médias dos municípios situados em um nível horizontal, que definimos como sendo a orientação leste-oeste, do que nos municípios que estão localizados no eixo norte-sul (vertical). Tal conclusão pode ser obtida de uma forma clara e precisa, considerando que o clima, em qualquer parte do globo terrestre, varia mais intensamente longitudinalmente do que latitudinalmente, ou seja, possui uma maior variância em linhas geográficas horizontais (a partir da linha do Equador) do que verticais. Um exemplo que podemos colocar é o fato de que, quanto mais ao norte do Brasil, mais as temperaturas vão se tornando elevadas, o que pode explicar por si só parte significativa das grandes variações de produtividades médias observadas.

Pode-se concluir também, que os impactos da distância na correlação espacial em diferentes orientações diferem para cada região considerada, ou ainda dizendo, para cada estado analisado. Como colocado na seção de resultados, no Mato Grosso por exemplo, a distância pouco influi na correlação entre produtividades médias nos municípios deste estado, fato que não é observado no Rio Grande do Sul, onde a distância entre municípios tem uma grande influência nas correlações de produtividades entre estes. Melhor dizendo, no caso do RS, quanto maior a distância entre os municípios menor é a correlação entre produtividades, já no MT, uma variação na distância entre municípios pouco varia a correlação de produtividade entre as regiões.

Os resultados apresentados ajudaram ainda a entender melhor a situação da soja em cada região do país e estes resultados também contribuíram para um melhor entendimento entre a correlação das produtividades no espaço e nos impactos que a orientação geográfica podem resultar na análise da produtividade entre regiões. 
Aspectos fundamentais também foram considerados para $\mathrm{o}$ desenho $\mathrm{e}$ entendimento de instrumentos de gerenciamento de risco, tais como diversificação espacial e o próprio seguro agrícola como foi evidenciado nas observações apresentadas.

No caso do seguro agrícola pode-se evidenciar os ganhos da diversificação espacial no que se refere a diminuição das taxas dos prêmios dos contratos. Isso ocorreu porque a diversificação espacial reduz o risco de quedas de produtividades para as regiões consideradas num mesmo contrato, e uma menor probabilidade de queda implica em menores indenizações do seguro reduzindo assim as taxas cobradas pelas seguradoras. Para se ter uma perfeita visualização de que a soja não é apenas um caso isolado para essas conclusões, uma breve análise foi realizada para a cultura do milho que corroborou as conclusões obtidas para os prêmios do seguro agrícola. E como apresentado, os ganhos da diversificação espacial não ocorrem apenas quando se diversifica entre diferentes estados e regiões distantes. Pode ser verificado que a diversificação espacial gera ganhos até mesmo quando se diversifica entre um mesmo estado ou uma mesma região.

Importante destacar que o trabalho procurou apresentar duas formas possíveis de estimar a produção esperada para o ano seguinte aos dados disponíveis que é necessário para a definição do seguro agrícola. Muito utilizado ainda é a estimativa da produtividade baseado nas médias das produtividades anteriores que é uma maneira errônea de se precificar o seguro, pois não considera os possíveis ganhos tecnológicos que ocorrem no decorrer dos anos. Também por isso, a produtividade média apresenta uma maior volatilidade o que se traduz em taxas de prêmios de seguros maiores do que quando a produtividade esperada é calculada a partir de regressões das amostras anteriores, que considera que possam ocorrer avanços nas produtividades ao longo dos anos. Assim, quando o seguro é calculado a partir das médias as taxas não estão sendo calculadas de maneira correta, o que acaba por gerar um seguro não otimizado. Por isso, o trabalho sugere a utilização do modelo baseado em regressão que acaba por gerar resultados mais corretos, otimizando assim o seguro agrícola como um todo. 
Essa questão envolve também um dos motivos pelo qual o seguro agrícola é pouco desenvolvido no Brasil. Pode-se perceber que quando as taxas dos prêmios são calculadas a partir da regressão das produtividades anteriores, as taxas dos prêmios de seguro retornam valores mais baixos do que quando calculados da outra maneira, que ainda é a mais utilizada para se precificar os seguros no país. Desta forma o seguro agrícola, que é considerado caro em comparação a outras formas de gerenciamento de riscos, acaba ficando ainda mais "proibitivo" por estar sendo calculado de uma forma incorreta. Caso fosse calculado da maneira correta, o seguro agrícola seria mais barato e poderia ser mais desenvolvido e utilizado pelos produtores agrícolas que visam garantir uma segurança para a sua produção. Não se pode deixar de colocar também, que uma parte do preço do seguro agrícola ainda envolve os riscos que as seguradoras estão sujeitas, como a seleção adversa e o risco moral, mas esses podem ser reduzidos inclusive com o conceito desenvolvido e apresentado no trabalho, que é o seguro baseado em indicadores de produtividade regional.

Com relação à metodologia utilizada no trabalho uma importante consideração deve ser feita. Para se obter a produtividade estimada e com isso a precificação do prêmio do seguro foram utilizados métodos estatísticos bayesianos devido ao crescente interesse por esses métodos observado na ciência atuarial. O paradigma Bayesianos oferece um tratamento compreensivo das incertezas associadas ao problema, possibilitando uma estimativa de distribuições de probabilidade que caracterizam o fenômeno de interesse, a partir dos dados observados "a priori" existentes, algo que os métodos estatísticos tradicionais não podem fazer.

Deve ficar claro que a intenção no caso não é o de obter um valor concreto para a produtividade estimada, mas sim uma maneira que encontre um prêmio de seguro mais próximo da realidade. Isso porque com as simulações de produtividades futuras realizadas, estima-se possíveis indenizações que possam vir a ocorrer, e com a Lei dos Grandes Números espera-se que a esperança desses valores se aproxime da média. 
Como a produtividade real do ano seguinte só poderá ser conhecida posteriormente, a atividade do seguro no momento de precificar este, é a de antecipar e prever eventuais problemas que possam ocorrer para que com isso possa obter uma taxa de prêmio correta.

Um fato importante também já apresentado mas que deve ser destacado é sobre o número de amostras de dados obtidos para as análises. Como pode ser verificado nas comparações quando se possui uma amostra com um histórico de dez anos de dados e outra que possui uma amostra de quatorze anos, quanto maior o número de informações disponíveis mais precisa tende a ficar a análise e por sua vez o seguro agrícola. Isso ocorre porque quanto maior o número de amostras, um dado aleatório que possua uma variância muito grande em comparação aos demais, tem uma pequena participação nos resultados finais, ou seja, tem uma menor influência no cálculo das medidas de risco consideradas. O mesmo não ocorre quando a amostra é menor, pois um dado com uma variância muito diferente dos outros afeta com mais intensidade as análises o que pode acabar gerando interpretações incorretas ou menos precisas no resultado final.

Ainda com relação aos dados não se pode deixar de destacar que estes foram obtidos junto ao IBGE ficando os resultados sujeitos á confiabilidade do instituto. Algumas empresas que necessitam das mesmas informações apresentam banco de dados próprios e que pode ser, pelo menos regionalmente, mais precisos que os anteriores citados mas que não são divulgados e são de difíceis acesso. Portanto, o mesmo estudo realizado no trabalho pode diferir em seus resultados de outros que apresentem uma fonte de dados que não se identifique com a que foi neste utilizada.

Finalizando, é importante colocar, que este trabalho não possui um limite muito próximo, pode-se facilmente haver uma continuação da pesquisa realizada, prevendo desta forma, uma análise similar à realizada para soja, porém utilizando-se de diversas outras culturas como o milho (brevemente apresentada), o arroz, o algodão, o feijão, e outros. Assim, a exploração desses resultados ajudariam a desenhar de uma forma mais 
eficiente as estratégias para o gerenciamento de riscos, tanto para produtores, seguradoras, bancos e para o próprio governo. 
ANEXO 


\section{ANEXO - Cálculo da distância entre dois pontos na superfície da terra a partir do conhecimento das latitudes e longitudes}

\section{INTRODUÇÃO}

O trabalho que será apresentado a seguir procurará detalhar o procedimento para o cálculo da distância entre dois pontos na superfície da Terra, partindo-se do conhecimento de suas respectivas coordenadas de latitude e de longitude.

Serão importantes para a evolução do trabalho, conhecimentos trigonométricos que serão apresentados na medida em que forem sendo usados.

O trabalho está estruturado em mais três seções. Inicialmente é apresentada uma síntese, sobre os procedimentos que serão utilizados no trabalho. Posteriormente, será apresentado o detalhamento teórico do trabalho, e neste, se explicará todos os passos inicialmente apresentados na síntese. Por fim, será realizada uma validação dos procedimentos utilizados, onde será realizado um exemplo de estudo, utilizando todos os procedimentos anteriormente citados e explicados.

\section{SÍNTESE DOS PROCEDIMENTOS UTILIZADOS}

Os procedimentos a serem seguidos serão apresentados na seguinte seqüência:

- Troca das coordenadas polares para cartesianas 
- Cálculo da distância e valores dos vetores definidos na figura 1 abaixo. Assim, temos três vetores a calcular, o da distância $Z_{A}$, o da distância $d_{x}$, e o da distância relativa aos pontos $\mathrm{Y}_{\mathrm{A}}$ e $\mathrm{X}_{\mathrm{A}}$

- Cálculo da distância linear $\left(\mathrm{C}_{\mathrm{L}}\right)$ entre dois pontos definidos por coordenadas cartesianas

- Cálculo do ângulo entre os vetores que caracterizam dois pontos na superfície da terra.

- Cálculo da distância curvilínea $\left(\mathrm{C}_{\mathrm{C}}\right)$ entre dois pontos.

\section{DETALHAMENTO TEÓRICO}

\subsection{Troca das coordenadas polares para cartesianas}

O primeiro passo para se realizar o objetivo do trabalho, é a troca das coordenadas polares de cada ponto da superfície terrestre, de coordenadas polares para coordenadas cartesianas, definidas num espaço tridimensional. Nesse novo sistema, cada ponto é representado por um vetor tridimensional. A visualização e também o cálculo das medidas desejadas serão obtidos assim de uma maneira mais facilitada, através dessa transformação de coordenadas.

O processo de conversão será descrito com o apoio da figura 30, que ilustra os principais conceitos utilizados. 


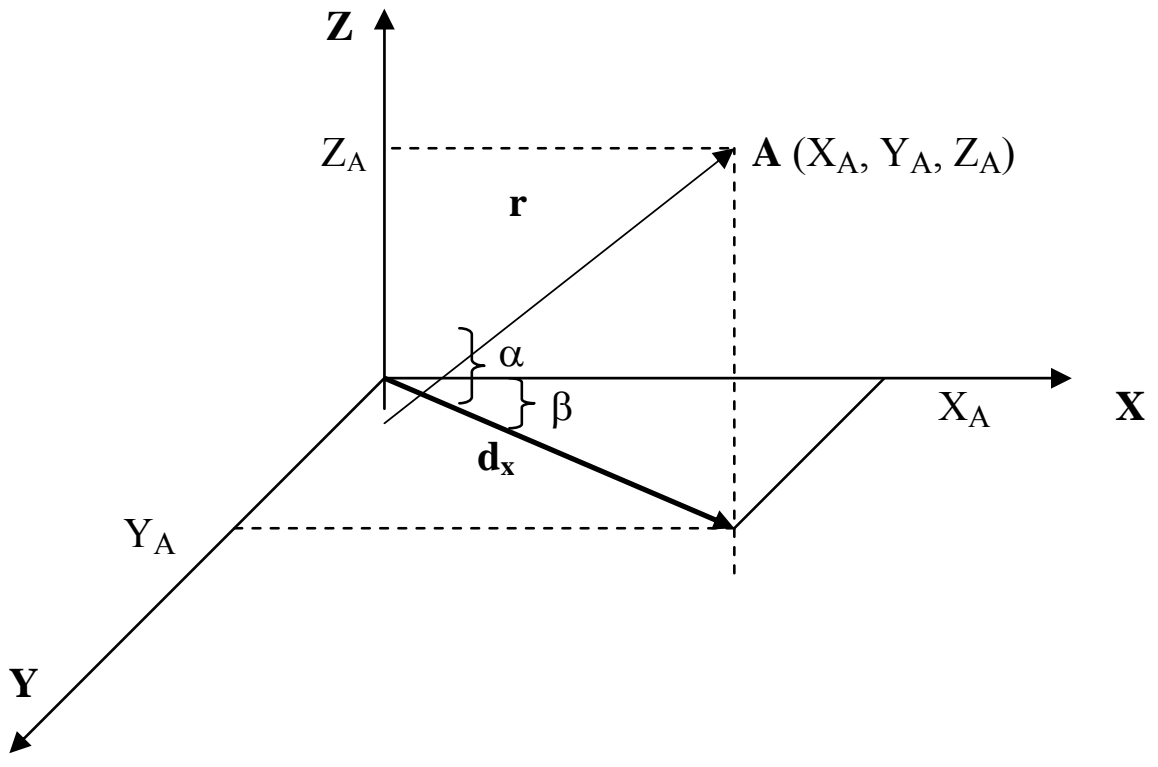

Figura 30 - Espaço tridimensional de um ponto na superfície da Terra

A figura 30 define o espaço tridimensional que representa um ponto A situado na superfície da Terra. O eixo X, assim como o eixo Y, estão situados no plano equatorial, é a distância $d_{x}$ é a distância do centro da Terra ao ponto A, refletida neste plano equatorial.

O ponto A na superfície da Terra pode, alternativamente, ser representado por coordenadas cartesianas $\mathrm{X}_{\mathrm{A}}, \mathrm{Y}_{\mathrm{A}}$ e $\mathrm{Z}_{\mathrm{A}}$, definidos com relação ao sistema de eixos $\mathrm{X}$, $\mathrm{Y}, \mathrm{Z}$ ou por coordenadas polares que consideram: raio da Terra $(\mathrm{r})$, latitude $(\alpha)$ e longitude $(\beta)$.

O processo de conversão considera resultados básicos da trigonometria, tais como as Leis e definições de seno, cosseno, tangente, entre outros.

Considerando a figura 31 abaixo, que é definida como sendo um triangulo retângulo, tem-se que esta é formada pelos catetos $b$ e $c$, pela hipotenusa $a$ e por um 
ângulo retângulo (de $90^{\circ}$ ) e por um ângulo que chamaremos de $\phi$. De acordo com os conceitos da trigonometria, sabe-se que o seno do ângulo $\phi$ é definido pelo quociente de seu cateto oposto com a hipotenusa do triângulo (seno $=b / a)$. Assim sabe-se também, que o cosseno do ângulo $\phi$ é definido pelo quociente do cateto adjacente pela hipotenusa do triângulo (cosseno $=c / a$ ). Finalmente, cabe colocar, que a hipotenusa pode ser obtida também pelo conhecimento do valor dos catetos. É conhecido que o quadrado da hipotenusa, é igual a soma dos quadrados dos catetos, assim temos que $a^{2}=c^{2}+b^{2}$.

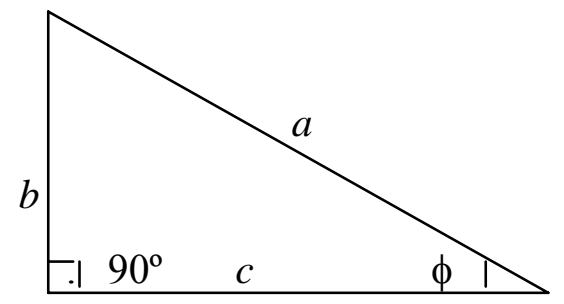

Figura 31 - Triângulo retângulo (a)

Com isso, pode-se estabelecer algumas conotações para o nosso caso de estudo, como o representado na figura 1. Desta forma, temos que:

$\mathrm{Y}_{\mathrm{A}}=\mathrm{d}_{\mathrm{x}} \cdot \operatorname{seno} \beta$

$X_{A}=d_{x} \cdot \operatorname{cosseno} \beta$

$\mathrm{Z}_{\mathrm{A}}=\mathrm{r} \cdot \operatorname{seno} \alpha$

$\mathrm{d}_{\mathrm{x}}=\sqrt{\left(r^{2}-Z a^{2}\right)}$

\subsection{Cálculo da distância $\mathrm{Z}_{\mathrm{A}}$}

Já é conhecida a fórmula (54) para o cálculo da variável $\mathrm{Z}$ do espaço tridimensional definido na figura 30, agora falta estabelecer e definir os valores de $\alpha$ (latitude) e $\beta$ (longitude), para os pontos que serão estudados. É importante destacar também, que tais valores de latitude e longitude, estão primariamente expressos em ângulos, como por exemplo $22^{\circ} 32^{\prime} 45^{\prime}$, mas por ser mais conveniente, é necessário 
transformá-los em medidas de radianos ${ }^{4}$. No exemplo acima, encontra-se que tal valor representa 0,3934 radianos.

Considerando que o raio da terra seja igual a $6378 \mathrm{~km}^{5}$, pode-se então encontrar o valor da distância $Z$ que desejamos, utilizando a fórmula (54) apresentada da seção anterior deste trabalho. Com isso, está preenchido mais um passo do processo.

\subsection{Cálculo da distância $\mathbf{d}_{x}$}

O próximo procedimento a ser executado será o de se definir a distância $d_{x}$ (apresentada na figura 30), que assim como foi dito anteriormente, é o reflexo da distância entre o ponto e o centro da Terra no plano equatorial. Porém, assim como foi colocado, já é possível calcular esta distância, apoiando-se nos conhecimentos trigonométricos. Tem-se assim, pela fórmula (55), que $d^{2}=r^{2}-Z_{A}{ }^{2}$. Desta forma, é possível obter para cada um dos pontos os valores procurados, podendo assim passar ao procedimento seguinte.

\subsection{Cálculo dos pontos $\mathrm{Y}_{\mathrm{A}}$ e $\mathrm{X}_{\mathrm{A}}$}

Para este procedimento a ser executado, será importante o conhecimento da distância $d_{x}$ calculada acima, pois será definido agora os valores das distâncias $X_{A} e Y_{A}$ como demonstrado na figura 30, até o ponto de origem. Utilizando as fórmulas (52 e 53), tem-se que $Y_{A}=d_{x} \cdot \cos \beta(52)$ e $X_{A}=d_{x} \cdot$ sen $\alpha$ (53). Com isso, já se tem preparada a base para o cálculo final da distância. Porém, cabe destacar que até aqui, realiza-se o cálculo para cada ponto em especial. No próximo procedimento será

\footnotetext{
${ }^{4}$ Para encontrar a medida em radianos, basta multiplicar o ângulo original por $\pi(3,1416)$, e em seguida dividir o valor encontrado por 180, que corresponde ao valor do ângulo da metade de uma circunferência $\left(180^{\circ}\right)$.

${ }^{5}$ Em quilômetros, pois facilitará para o cálculo da distância entre os pontos também em quilômetros. 6378 é o raio medido equatorialmente, pois tem-se também o raio de 6357 que é medido pelos pólos, mas que não é de importância para o estudo. É conhecido que a Terra não é totalmente esférica.
} 
apresentado como os pontos estão relacionados, e como pode-se estabelecer alguma condição entre eles.

\subsection{Cálculo da distância linear $\left(C_{L}\right)$ entre dois pontos definidos por coordenadas cartesianas}

Agora que já se tem definidos os valores de cada ponto, cabe agora fazer a comparação de valores entre dois pontos em particular, para se obter a distância entre elas. Considerando que já se tem definidos os valores $Z_{A}, Y_{A}$ e $X_{A}$ para cada ponto, resta agora descobrir qual a distância em módulo entre estas. A figura 32 abaixo representa estes dois pontos $\mathrm{A}$ e $\mathrm{B}$, que estão situados na superfície da Terra, e o ponto $\mathrm{C}_{\mathrm{L}}$, é a distância linear que pretendemos de início saber.

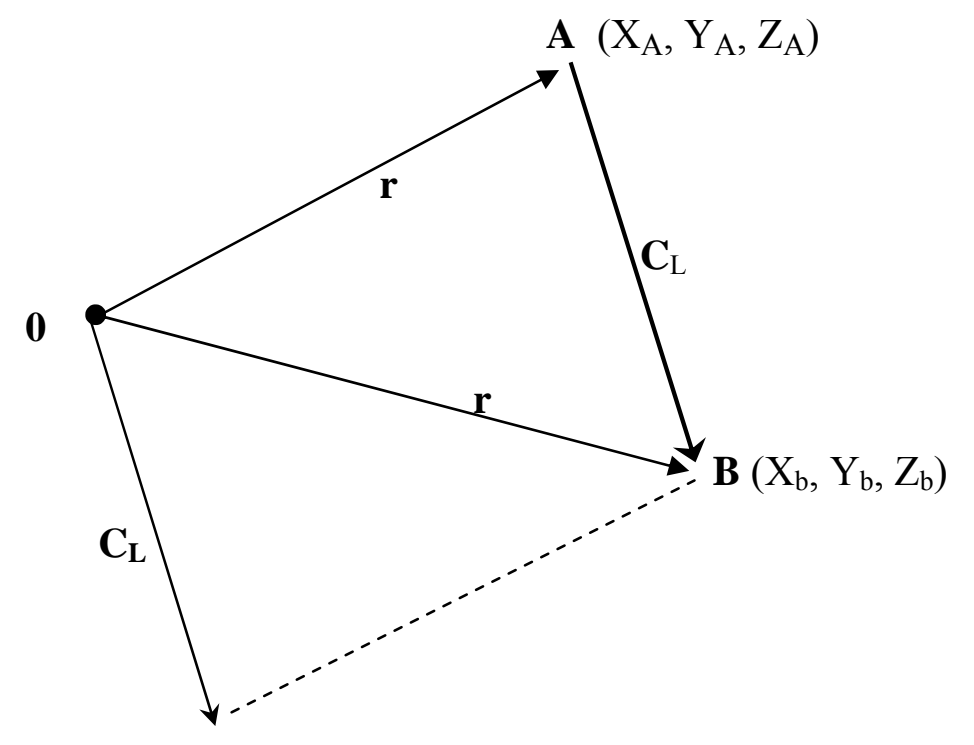

Figura 32 - Dois pontos (A e B) situados na superfície da Terra e a distância linear $C_{L}$ entre eles

Desta forma, a distância que se pretende achar entre duas cidades é a distância $\mathrm{C}_{\mathrm{L}}$, expressa na figura, e que é calculada a partir da soma dos vetores que definem os pontos $\mathrm{A}$ e B. Porém, vale lembrar, que esta distância $\mathrm{C}_{\mathrm{L}}$ ainda é a distância linear, ou seja, em linha reta. Num passo seguinte, será apresentado como se obter a distância considerando-se a curvatura da Terra. 
É importante também conhecer as coordenadas de C, para então se poder achar o valor do módulo de $\mathrm{C}(|\mathrm{C}|)$. Vetorialmente é verificável que $\mathrm{C}=\mathrm{B}-\mathrm{A}$, assim, por associação podemos dizer que as coordenadas $\mathrm{X}_{\mathrm{C}}, \mathrm{Y}_{\mathrm{C}}$, e $\mathrm{Z}_{\mathrm{C}}$ são calculadas da seguinte maneira: $\mathrm{X}_{\mathrm{C}}=\mathrm{X}_{\mathrm{b}}-\mathrm{X}_{\mathrm{A}} ; \mathrm{Y}_{\mathrm{C}}=\mathrm{Y}_{\mathrm{b}}-\mathrm{Y}_{\mathrm{A}}$ e $\mathrm{Z}_{\mathrm{C}}=\mathrm{Z}_{\mathrm{b}}-\mathrm{Z}_{\mathrm{A}}$. Portanto, tem-se em módulo as variáveis para cada um dos pontos estudados, ou seja, os pontos $\mathrm{X}_{\mathrm{C}}, \mathrm{Y}_{\mathrm{C}}$ e $\mathrm{Z}_{\mathrm{C}}$ para cada ponto que será conhecido após este passo.

Depois de realizado esta passagem para o cálculo das variáveis, falta calcular a distância linear entre os pontos, uma vez que já se têm todos os pontos necessários para o seu cálculo. Assim, utilizando ainda os conhecimentos a respeito de vetores, tem-se que a distância de um vetor ao quadrado, é definido a partir da soma entre o quadrado dos três vetores que o constituem, portanto:

$$
\mathrm{C}^{2}=\mathrm{X}_{\mathrm{C}}^{2}+\mathrm{Y}_{\mathrm{C}}^{2}+\mathrm{Z}_{\mathrm{C}}^{2}
$$

Como já se têm todos estes pontos, torna-se possível achar a distância linear entre os pontos aos quais estamos fazendo referência. Terminado este procedimento, só fica faltando o passo onde será encontrada a distância curvilínia entre os pontos, que serão apresentados nos dois passos a seguir.

\subsection{Cálculo do ângulo da distância entre dois pontos}

O próximo procedimento a ser seguido, será o do cálculo do ângulo $(\theta)$ que compõe a distância entre os pontos. Isto será bastante importante, para se poder considerar finalmente que a Terra é esférica e que a distância entre dois pontos possuem esta esfericidade que precisam ser calculadas com precisão.

Considerando o triângulo retângulo definido pela figura 33 abaixo, pode-se encontrar a partir do conhecimento do valor de $\mathrm{C}_{\mathrm{L}}$, o ângulo $\theta$ que é oposto a este lado. 
Este ângulo será de suma importância, para calcular a distância curvilínia final desejada, mas este passo será detalhado em um procedimento seguinte.

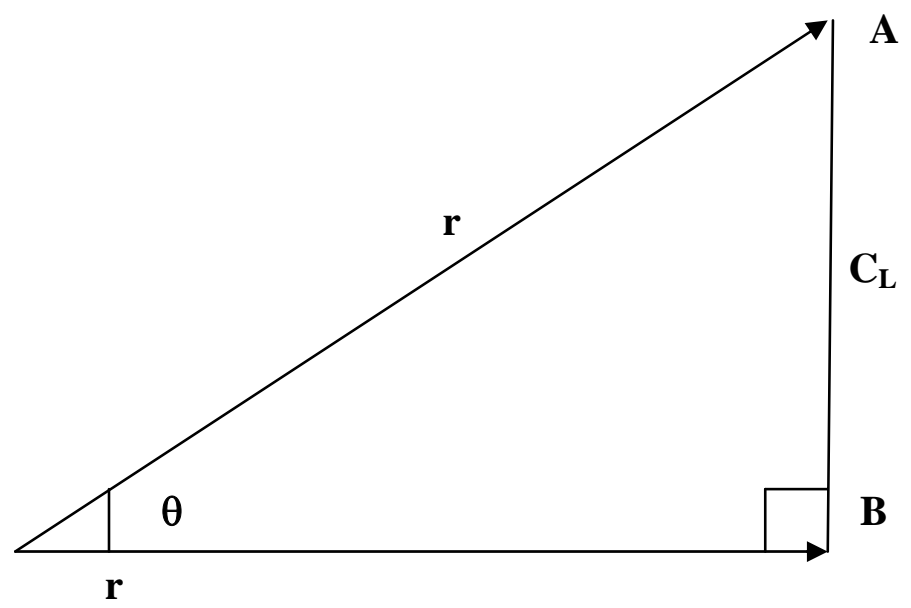

Figura 33 - Triângulo retângulo (b)

A partir da Lei dos Cossenos, sabe-se que para qualquer triângulo, como o representado na figura 1 , que a distância $C_{L}$ é calculado da seguinte forma: $\left|C_{L}\right|^{2}=r^{2}+$ $r^{2}-2 \cdot r \cdot r \cdot \cos \theta$

Desta expressão, pode-se achar o valor do ângulo $\theta$ :

$|C|^{2}=2 r^{2}-2 r^{2} \cdot \cos \theta$

Daí:

$\operatorname{Cos} \theta=\frac{2 r^{2}-|C|^{2}}{2 r^{2}}$

Isolando-se o ângulo $\theta$, chega-se a seguinte expressão para o seu cálculo:

$\theta=\arccos \left(1-\frac{|C|^{2}}{2 r^{2}}\right)$ 
Desta forma, utilizando a fórmula (57), pode-se calcular os respectivos ângulos, para a distância entre os pontos que estudados, e assim partir para o último procedimento para o cálculo desejado.

\subsection{Cálculo da distância curvilínea (CC) entre dois pontos}

O último procedimento então que falta realizar, é o do cálculo da distância entre as cidades admitindo-se que a Terra possui uma superfície esférica, e para isso, tem-se que calcular a distância final das cidades. Considerando agora a Terra uma circunferência, sabe-se que ela possui um ângulo total de 360 graus e um perímetro definido por $2 \pi \mathrm{R}$, onde $\mathrm{R}$ é o raio da terra. Como já é conhecido o valor do ângulo da distância entre as duas cidades, o último procedimento será o de fazer uma regra de três simples, para se chegar à distância desejada, já considerando a curvatura da Terra.

\section{IMPLEMENTAÇÃO EM SOFTWARE}

O software utilizado para a elaboração e conclusão deste trabalho foi o Excel, onde as suas planilhas ajudaram e facilitaram os diversos cálculos realizados neste.

Portanto, apenas será colocada as latitudes e longitudes das cidades nas planilha, e imediatamente teremos a distância entre elas.

A planilha será apresentada da seguinte forma:

\begin{tabular}{|c|c|c|c|c|c|c|c|c|c|c|}
\hline & \multicolumn{2}{|l|}{\begin{tabular}{|l|} 
latitude \\
\end{tabular}} & \multicolumn{2}{|l|}{ longitude } & & \multicolumn{2}{|l|}{ latitude } & \multicolumn{3}{|c|}{ longitude } \\
\hline & graus min.se & seg. & graus min. & seg. & & graus min & seg. & graus & $\min$. & seg. \\
\hline idade 1 & & & & & cidade 2 & & & & & \\
\hline
\end{tabular}

\begin{tabular}{|c|}
\hline $\begin{array}{c}\text { distância } \\
\text { km }\end{array}$ \\
\hline
\end{tabular}

Figura 34 - Apresentação da planilha para cálculo da distância linear entre municípios 


\section{EXEMPLIFICAÇÃO E VALIDAÇÃO DO PROCEDIMENTO UTILIZADO}

Considerando os seguintes valores de coordenadas cartesianas para os pontos que serão exemplificados (no caso, os pontos são representados por cidades).

Tabela 2. Latitude e longitude das cidades.

\begin{tabular}{lcl}
\hline \multicolumn{1}{c}{ CIDADE } & latitude & longitude \\
\hline Piracicaba & $-22^{\circ} 43^{\prime} 31^{\prime \prime}$ & $-47^{\circ} 38^{\prime} 57^{\prime \prime}$ \\
Campinas & $-22^{\circ} 54^{\prime} 20^{\prime \prime}$ & $-47^{\circ} 03^{\prime} 39^{\prime \prime}$ \\
Porto Alegre & $-30^{\circ} 01^{\prime} 59^{\prime \prime}$ & $-51^{\circ} 13^{\prime} 48^{\prime \prime}$ \\
Ribeirão Preto & $-21^{\circ} 10^{\prime} 39^{\prime \prime}$ & $-47^{\circ} 48^{\prime} 37^{\prime \prime}$ \\
\hline
\end{tabular}

Pode-se agora dar início aos procedimentos.

\subsection{Troca das coordenadas polares para cartesianas}

Assim como apresentada na figura 30, para este procedimento ilustrativo basta substituir o ponto A da figura por cada município que será estudado.

\subsection{Cálculo da distância $\mathrm{Z}_{\mathrm{A}}$}

Transformando as coordenadas cartesianas de cada município em coordenadas polares, temos que para cada cidade, tem-se a representação de sua latitude e longitude em radianos como se pode verificar na tabela abaixo. 
Tabela 3. Latitude e longitude das cidades em radianos.

\begin{tabular}{lcc}
\hline & $\alpha$ (latitude) & $\beta$ (longitude) \\
\hline Piracicaba & $-0,3966$ & $-0,8316$ \\
Campinas & $-0,3997$ & $-0,8213$ \\
Porto ALegre & $-0,5241$ & $-0,8941$ \\
Ribeirão Preto & $-0,3696$ & $-0,8344$ \\
\hline
\end{tabular}

Utilizando-se então da fórmula (54), têm-se então os valores da distância $\mathrm{Z}_{\mathrm{A}}$ para cada município.

Tabela 4. Distância $\mathrm{Z}_{\mathrm{A}}$ de cada uma das cidades.

\begin{tabular}{lc}
\hline & $Z_{A}$ \\
\hline Piracicaba & $-2463,9$ \\
Campinas & $-2482,4$ \\
Porto Alegre & $-3192,15$ \\
Ribeirão Preto & $-2304,11$ \\
\hline
\end{tabular}

\subsection{Cálculo da distância $d_{x}$ :}

Neste terceiro procedimento, necessita-se do auxílio da fórmula (55) para poder obter cada um dos pontos desejados em cada cidade.

Tabela 5. Distância $d_{x}$ das cidades.

\begin{tabular}{lc}
\hline & $\mathrm{d}_{\mathrm{x}}$ \\
\hline Piracicaba & 5882,86 \\
Campinas & 5875,08 \\
Porto Alegre & 5521,68 \\
Ribeirão Preto & 5947,26 \\
\hline
\end{tabular}




\subsection{Cálculo dos pontos $Y_{\mathrm{A}}$ e $X_{\mathrm{A}}$}

Utilizando-se as fórmulas (52 e 53) apresentadas acima, pode-se chegar aos valores da tabela abaixo.

Tabela 6. Valores de $\mathrm{Y}_{\mathrm{A}}$ e $\mathrm{X}_{\mathrm{A}}$ para cada um das cidades.

\begin{tabular}{lcc}
\hline & $\mathrm{Y}_{\mathrm{A}}$ & $\mathrm{X}_{\mathrm{A}}$ \\
\hline Piracicaba & $-4347,63$ & 3963,09 \\
Campinas & $-4300,99$ & 4002,25 \\
Porto Alegre & $-4305,06$ & 3457,66 \\
Ribeirão Preto & $-4406,45$ & 3994,14 \\
\hline
\end{tabular}

\subsection{Cálculo da distância linear $\left(C_{L}\right)$ entre dois pontos por coordenadas cartesianas}

Primeiramente calculam-se os valores para $\mathrm{X}_{\mathrm{C}}, \mathrm{Y}_{\mathrm{C}}$ e $\mathrm{Z}_{\mathrm{C}}$, para posteriormente calcular a distância linear.

Tabela 7. Distâncias $X_{C}, Y_{C}$ e $Z_{C}$ das cidades.

\begin{tabular}{lccc}
\hline & $\mathrm{X}_{C}$ & $\mathrm{Y}_{\mathrm{C}}$ & $\mathrm{Z}_{\mathrm{C}}$ \\
\hline Piracicaba / Campinas & $-39,16$ & $-46,64$ & 18,49 \\
Piracicaba / P.Alegre & 505,43 & $-42,56$ & 728,25 \\
Piracicaba / Rib.Preto & $-31,04$ & 58,81 & $-159,79$ \\
Campinas / P.Alegre & 544,59 & 4,07 & 709,75 \\
Campinas / Rib.Preto & 8,11 & 105,46 & $-178,29$ \\
P.Alegre / Rib.Preto & $-536,47$ & 101,38 & $-888,04$ \\
\hline
\end{tabular}

Utilizando a fórmula (56) então, tem-se a distância linear final $\left(\mathrm{C}_{\mathrm{L}}\right)$ entre cada uma as cidades. 
Tabela 8. Distância linear entre as cidades.

\begin{tabular}{lc}
\hline & Distância ( $\left.\mathrm{C}_{\mathrm{L}}\right)$ \\
\hline Piracicaba / Campinas & 63,65 \\
Piracicaba / P.Alegre & 887,48 \\
Piracicaba / Rib.Preto & 173,08 \\
Campinas / P.Alegre & 894,62 \\
Campinas / Rib.Preto & 207,31 \\
P.Alegre / Rib.Preto & 1042,45 \\
\hline
\end{tabular}

\subsection{Cálculo do ângulo da distância entre dois pontos}

Com o auxílio da fórmula (57), calcula-se o ângulo entre cada uma das cidades consideradas no estudo.

Tabela 9. Ângulo entre os vetores que representam a distância entre cada cidade.

\begin{tabular}{lc}
\hline & $\theta$ \\
\hline Piracicaba / Campinas & 0,5718 \\
Piracicaba / P.Alegre & 7,9789 \\
Piracicaba / Rib.Preto & 1,5549 \\
Campinas / P.Alegre & 8,0432 \\
Campinas / Rib.Preto & 1,8624 \\
P.Alegre / Rib.Preto & 9,3751 \\
\hline
\end{tabular}

\subsection{Cálculo da distância curvilínea $\left(C_{L}\right)$ entre dois pontos}

O último passo agora é calcular a distância curvilínea $\left(\mathrm{C}_{\mathrm{C}}\right)$ entre as cidades. Junto com a tabela desta distância abaixo, será colocado em conjunto a distância medida com a ajuda de uma ferramenta computacional, mais precisamente dizendo, com o apoio de um site da Internet (www.nau.edu/ cvm/latlongdisthtml) que, a partir também das coordenadas de latitude e longitude de duas cidades, calcula automaticamente e 
precisamente o valor da distância entre estas desejado, usando uma outra metodologia de cálculo.

Tabela 10. Distâncias curvilínea, linear e calculada com ferramenta especializada.

\begin{tabular}{lccc}
\hline & $\begin{array}{c}\text { Distância } \\
\text { Linear }\left(\mathrm{C}_{\mathrm{L}}\right)\end{array}$ & $\begin{array}{c}\text { Distância } \\
\text { Curvilínea }\left(\mathrm{C}_{\mathrm{C}}\right)\end{array}$ & $\begin{array}{c}\text { Distância com ajuda de } \\
(\mathrm{km})\end{array}$ \\
& $(\mathrm{km})$ & & 63,61 \\
\hline Piracicaba / Campinas & 63,65 & 63,65 & 888,23 \\
Piracicaba / Porto Alegre & 887,48 & 888,19 & 173,09 \\
Piracicaba / Ribeirão Preto & 173,08 & 173,09 & 895,37 \\
Campinas / Porto Alegre & 894,62 & 895,35 & 207,32 \\
Campinas / Ribeirão Preto & 207,31 & 207,32 & 1043,64 \\
Porto Alegre / Ribeirão Preto & 1042,45 & 1043,61 & \\
\hline
\end{tabular}

\section{Validação:}

Portanto, assim como colocado na seção 4, utiliza-se da facilidade da ferramenta computacional EXCEL para o cálculo dos procedimentos para a conclusão do trabalho.

Com esta mesma ferramenta também, foi elaborada uma planilha onde se precisa apenas colocar as coordenadas geográficas (latitude e longitude) de cada cidade, para se calcular e obter a distância entre essas cidades. Porém, vale ressaltar que, quando as coordenadas geográficas são negativas (como no exemplo abaixo), temos de colocar todos os valores, sejam eles segundos, minutos ou graus, em valores negativos, para se poder chegar a uma resposta exata e precisa.

Um fato que vale a pena destacar, é que por este procedimento, consegue-se calcular a distância de um ponto que possui latitude ou longitude igual a $0^{\circ}$ (zero graus), o que não é possível obter no caso do software especializado que encontramos na Internet. Isto mostra, que o nosso procedimento e sua implementação em um software 
próprio é bastante confiável e também bastante preciso, uma vez que é possível calcular a distância entre qualquer ponto situado na superfície da Terra.

A planilha que representa a implementação em software das quatro cidades exemplificadas está apresentada a seguir.

\begin{tabular}{|c|c|c|c|c|c|c|c|c|c|c|c|c|c|}
\hline & \multicolumn{3}{|c|}{ latitude } & \multicolumn{3}{|c|}{ longitude } & & \multicolumn{3}{|c|}{ Iatitude } & \multicolumn{2}{|c|}{ longitude } & \multirow{2}{*}{$\begin{array}{c}\text { distância } \\
\text { km }\end{array}$} \\
\hline & graus & $\min$. & seg. & graus & $\min$. & seg. & & graus & $\min$. & seg. & graus & \begin{tabular}{l|l}
$\min$. & seg.
\end{tabular} & \\
\hline & -22 & -43 & -31 & -47 & -38 & -57 & & -22 & -54 & -20 & -47 & -3 & 63.6155 \\
\hline Pir & -22 & -43 & -31 & -47 & -38 & -57 & $\widehat{P . A l \epsilon}$ & -30 & -1 & -59 & -51 & \begin{tabular}{l|l}
-13 & $-4 \varepsilon$ \\
\end{tabular} & 888.2 \\
\hline Pirac & -22 & -43 & -31 & -47 & -38 & -57 & Rib.Preto & -21 & -10 & -39 & -47 & \begin{tabular}{l|l}
-48 & -37 \\
\end{tabular} & 173.09 \\
\hline Camp & -22 & -54 & -20 & -47 & \begin{tabular}{l|}
-3 \\
\end{tabular} & -39 & P.Alegre & -30 & -1 & -59 & -51 & \begin{tabular}{l|l}
-13 & -48 \\
\end{tabular} & 895.375 \\
\hline Camp & -22 & -54 & -20 & -47 & -3 & -39 & Rib.Preto & -21 & -10 & -39 & -47 & \begin{tabular}{l|l}
-48 & -37 \\
\end{tabular} & 207.3213 \\
\hline D.Alegre & -30 & -1 & -59 & -51 & -13 & -48 & $\mid \begin{array}{l}\text { Rib.Preto } \\
\end{array}$ & -21 & -10 & -39 & -47 & \begin{tabular}{l|l}
-48 & -37 \\
\end{tabular} & 1043.64 \\
\hline
\end{tabular}

Figura 35 - Formato da planilha na implementação do cálculo em software

Observamos, que obtemos os mesmos resultados do que o site especializado nesta conversão, o que mostra a validação dos procedimentos utilizados. 


\section{REFERÊNCIAS BIBLIOGRÁFICAS}

AZEVEDO FILHO, A. Perspectivas para o seguro agrícola e indicadores regionais de produtividade. Preços Agrícolas, v.14, n.152, p.19-22, jun. 1999.

AZEVEDO FILHO, A. Seguros fundamentados em índices de produtividade e renda agrícola regional como instrumentos para administração de riscos no Brasil. Piracicaba, out. 2001. 141p. (Projeto FAPESP/CNPq)

AZEVEDO FILHO, A.; ROLIM, G. Simulated maize yield due to daily rainfal spatial variability at a local scale conditions (1000 ha). /Apresentado à 3 . Reunião Latino Americana de Agrometeorologia, Fortaleza, 2001/

AZEVEDO FILHO, A.; MARTINES FILHO, J.G.; ARAÚJO, P.F.C. Futuros e opções agrícolas: alternativas de mercados para programas governamentais. Agroanalysis, v.16, n.7, p.10-13, jul. 1996.

BARROS, G.S.C. Novas estratégias de gerenciamento de riscos e financiamento do agronegócio. Preços Agrícolas, v.14, n.152, p.9-10, jun. 1999.

BERNSTEIN, P.L. Desafio aos deuses: a fascinante história do risco. 6.ed. Rio de Janeiro: Editora Campus, 1997. 408p. 
BLAREL, B.; HAZELL, P.; PLACE, F.; QUIGGIN, J. The economics of farm fragmentation: evidence from Ghana and Rwanda. The World Bank Economic Review, v.6, n.2, p.233-254, 1992.

CAFFAGNI, L.C.; MARQUES, P.V. Seguro agropecuário no Brasil: instituições e problemas. Preços Agrícolas, v.14, n.152, p.16-18, jun. 1999.

COHEN, R.L. The economics of agriculture. Cambridge: James Nisbertand Company Limited, Cambridge University Press, 1996. 362p.

GOODWIN, B.K. Instability ans risk in U.S. agriculture. Journal of Agribusiness, v.18, n.1, p.17, 2000.

HARWOOD, J.; HEIFNER, R.; COBLE, K.; PERRY, J.; SOMWARU, A. Managing risk in farming: concepts, research and analysis. Washington: USDA, Economic Research Service, Mar. 1999. 125p. (Agricultural Economics Report, 774)

HOFFMAN, R. Estatística para economistas. São Paulo: Livraria Pioneira Editora, 1991. 426p.

JOHNSTON, J. Econometric methods. 3.ed. Los Angeles: McDrawHill Book Company, 1984. 531p.

NARTEA, G.V.; BARRY, P.J. Risk efficiency and cost effects of geographic diversification. Review of Agricultural Economics, v.16, n.3, p.341-351, 1994.

NGUYEN, T.; CHENG, E.; FINDLAY, C. Land fragmentation and farm productivity in China en the 1990s. China Economic Review, v.7, n.2, p.69-180, 1996. 
NORTHERN ARIZONA UNIVERSITY. Latitude/longitude distance calculation. http://www.nau.edu/ cvm/latlongdist.html (25 Sept. 2000)

SILVA, L.C. Riscos e incertezas. http://www.unioeste.br/agais/risco.html (21 jun. 2001)

SCANDIZZO, P.L. Securitizing insurance: risk aversion, diversification and market equilibrium. Roma: Via di Tor Vergata, 2002. 21p.

SCHURLE, B.W. Business risk economies of size: evidence an implications. /Apresentado ao Seminário realizado na University of Nevaska, Department of Economics, Nevaska, 1995/

SCHURLE, B.W. The impact od size on yield variability and crop insurance premiuns. Review of Agricultural Economics, v.18, n.2, p.425-422, 1996.

YURI, H.M. Gestão do risco de granizo pelo seguro e outras alternativas: estudo de caso em pomares de maçã de Santa Catarina. Piracicaba, 2003. 145p. Dissertação (Mestrado) - Escola Superior de Agricultura "Luiz de Queiroz", Universidade de São Paulo. 